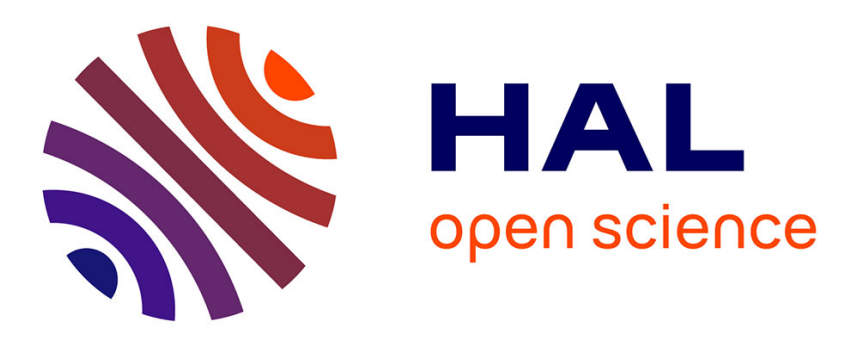

\title{
Contributions of experimental data obtained in concentrated mixtures to kinetic studies: application to MonoMethylHydrazine pyrolysis \\ Pascal Diévart, Laurent Catoire
}

\section{- To cite this version:}

Pascal Diévart, Laurent Catoire. Contributions of experimental data obtained in concentrated mixtures to kinetic studies: application to MonoMethylHydrazine pyrolysis. Journal of Physical Chemistry A, 2020, 124 (30), pp.6214-6236. 10.1021/acs.jpca.0c03144 . hal-03201924

\author{
HAL Id: hal-03201924 \\ https://hal.science/hal-03201924
}

Submitted on 19 Apr 2021

HAL is a multi-disciplinary open access archive for the deposit and dissemination of scientific research documents, whether they are published or not. The documents may come from teaching and research institutions in France or abroad, or from public or private research centers.
L'archive ouverte pluridisciplinaire HAL, est destinée au dépôt et à la diffusion de documents scientifiques de niveau recherche, publiés ou non, émanant des établissements d'enseignement et de recherche français ou étrangers, des laboratoires publics ou privés. 


\title{
Contributions of experimental data obtained in concentrated mixtures to kinetic studies: application to MonoMethylHydrazine pyrolysis
}

\author{
Pascal Diévart $^{1 *}$ and Laurent Catoire ${ }^{1,2}$
}

1: UCP, ENSTA Paris, Institut Polytechnique de Paris, 828 boulevard des Maréchaux, 91762 Palaiseau cedex, France

2: ICARE-CNRS, 1C, Avenue de la Recherche Scientifique, 45071 Orléans Cedex 2, France

E-mail : pascal.dievart@ensta-paris.fr

Tel :+33(0)181871991

Corresponding author: Pascal DIÉVART (for complete contact information, see affiliation 1)

Subjects: monomethylhydrazine, pyrolysis, ab initio, kinetic model, shock tube

Citation: J. Phys. Chem. A 2020, 124, 30, 6214-6236 


\begin{abstract}
Experimental, numerical and theoretical studies are performed to understand the explosive thermal decomposition of monomethylhydrazine/argon mixtures. Ignition delays of concentrated MMH/Ar mixtures (20-30\%) have been measured behind a reflected shock wave around $1000 \mathrm{~K}$ and $1 \mathrm{~atm}$. Although several detailed chemical kinetic models have predictive abilities for diluted and highly diluted mixtures, none of them showed predictive for concentrated mixtures. A new kinetic model is proposed, in which numerous rate constants and thermochemical data are reassessed based on theoretical calculations, with the purpose to determine whether,or to what extent, trends derived from diluted or highly diluted MMH/Ar mixtures can explain observations in concentrated MMH mixtures. The present kinetic model is found to predict speciation experimental profiles in diluted MMH/Ar mixtures and is a significant improvement in predicting theinduction delays of concentrated MMH/Ar mixtures.
\end{abstract}




\section{Introduction}

Monomethylhydrazine (MMH), has widely been used for years as a space fuel for the propulsion of satellites and interplanetary missions. $\mathrm{MMH}$, as well as hydrazine which is used as a monopropellant,are endothermic compounds, i.e. their standard enthalpies of formation $\Delta_{\mathrm{f}} \mathrm{H}^{\circ}$ in both gas and liquid phase are positive and therefore are able to sustain a decomposition flame. However, all these interesting features are poorly characterized in terms of chemical kinetics. MMH thermal decomposition has been studied in flow reactor ${ }^{1}$ and shock tubes ${ }^{2-6}$. Detailed chemical kinetic models (DCKM) for thermal decomposition have been developed by Catoire et al. ${ }^{2}$, Sun et al. ${ }^{7,8}$, Cook et al. ${ }^{4}$ and more recently by $\mathrm{Li}$ et al. ${ }^{5}$.Those models were validated against time speciation profiles obtained in highly diluted (less than hundreds ppmv MMH) and diluted (1 up to $3 \mathrm{~mol} \% \mathrm{MMH}$ ) mixtures in shock tubes. Theoretical calculations were applied to improve both the thermochemistry ${ }^{9}$ and the kinetics $7,8,10,11$. The model proposed by Cook et al. ${ }^{4}$ could be considered as predictive and since then theoretical calculations led to a better treatment of the pressure dependence of some postulated important reactions ${ }^{10}$. Later Li et al. ${ }^{5}$ updated the mechanism developed by Cook et al. and validated it with data obtained with highly diluted mixtures (<380 ppm MMH in Ar).

These last studies are relevant to elementary kinetic studies, i.e. devoted to the direct and indirect measurements of elementary reaction rate constants. Questions concerning the ability of this last model to be predictive for concentrated MMH-based mixtures remain an open issue. Fundamentally, the ability for existing validated kinetic models to predict both qualitatively and quantitatively the behavior of more concentrated mixtures is of great interest for any fuel/oxidant mixtures as it is relevant to real applications. Such attempts are rather scarce mostly because the chemical kinetics community may be more interested in kinetics issues rather than applied ones. However, nowadays detailed chemical kinetics models are more and more used for predictive purposes in the frame of industrial applications and they are often extrapolated well outside of their validity ranges, only because for industrial purposes mixtures of interest are much more concentrated than for elementary kinetic studies. Therefore, one can expect in most cases "extrapolated" DCKM to fail to predict the reactive behavior in practical applications, and for several reasons: 
- only about $10 \%$ of the reactions present in the DCKM are relevant in diluted mixtures and still less in highly diluted mixtures, while a larger set of reactions is expected to be pertinent in concentrated mixtures,

- in line with the first point, lots of reactions in DCKM have never been studied neither experimentally nor theoretically. Therefore, many of them are estimated by analogy, for instance, or by using various empirical rules, including rules of thumb. If this approach makes sense since rough estimate are generally believed to be sufficient for minor reaction paths, because their rate constant values do not matter, all rate coefficients matter for concentrated mixtures;

- if one can expect that a DCKM written for highly diluted mixtures is comprehensive, it still may happen that some "secondary" reactions have been neglected because their likelihood to occur was considered negligible. This may not be the case for concentrated mixtures and the original DCKM may need the addition of "new" reactions.

- the diluent is usually chosen to be argon for a variety of reasons: it is an atomic species with a high molecular weight producing easily high temperature for reasonable shock tube operating conditions (the pressure of the driver gas to produce a given strength of the shock waves). However, in real conditions, no argon is present in the mixture. The detailed model is optimized for conditions where argon plays solely the role of bath gas (collision efficiency in the reaction rates), while for non-diluted mixtures or with air based mixtures, three different features will play a role and determine the overall induction time:

a. $\mathrm{N}_{2}$ or the fuel are the major collision partners with efficiencies that differ from that of argon (poly-atomic molecules versus mono-atomic species);

b. $\mathrm{N}_{2}$ cannot be considered as an inert anymore and the chemistry of $\mathrm{NO}_{\mathrm{x}}$ for example has to be taken into account,

c. during the induction time, the exothermicity of the reaction induces a strong increase in the temperature whereas for highly diluted mixtures the pressure and the temperature 
remain essentially constant since no heat release is associated with the evolution of the reaction.

- As previously explained, $\mathrm{MMH}$ is able to sustain a decomposition flame, i.e. it is possible to get ignition and flame without any oxidizer. Therefore, because of its unique characteristics, MMH is certainly a fuel of interest to discuss the ability of a detailed chemical kinetic model validated with highly diluted mixtures whether to be or not predictive, not only for "simple" thermal decomposition but also for "ignition" in concentrated fuel/Ar mixtures, a much more difficult case.

The aim of this work is to report experimental data about MMH/Ar induction delays in concentrated MMH/Ar mixtures. These data are to be confronted to the most recent detailed kinetic model validated with diluted mixtures (typically 1 mol\% MMHin Ar) and highly diluted mixtures (typically a few hundreds of ppm MMH in Ar). If necessary, a new DCKM model suitable for both $\mathrm{MMH} / \mathrm{Ar}$ diluted and concentrated mixtures will then be proposed, in which thermochemistry of key species and rate constants of important reactions will have been obtained from theoretical calculations. The strategy, if successful, can later be extended to any fuel to propose a predictive a priori detailed chemical kinetic model valid for a large range of fuel loading.

\section{Materials and methods}

\section{Experimental study}

A shock tube was employed to measure the induction delays of MMH/Ar mixtures. It consists of a 50-mm-i.d. tube, with a 2.1-m-long stainless-steel driver section, filled with helium, and a 7.2-m long test section. The test section was made of Pyrex glass in order to avoid surface reactions with MMH. The MMH/Ar mixtures were introduced at room temperature at a precisely known pressure. Several piezoelectric pressure transducers are located in the second half of the driven section, mounted flush with the inside wall, for shock wave velocity measurement. Figure 1 display a typical pressure profiles from which the induction delays are inferred. The conditions behind the reflected shock wave were determined from the incident-shock velocity using the one-dimensional shock relations and 
thermodynamic data of MMH and Ar. The relative uncertainties on the temperature and pressure behind the reflected shock wave are estimated to be about 1.5 and $2 \%$, respectively.

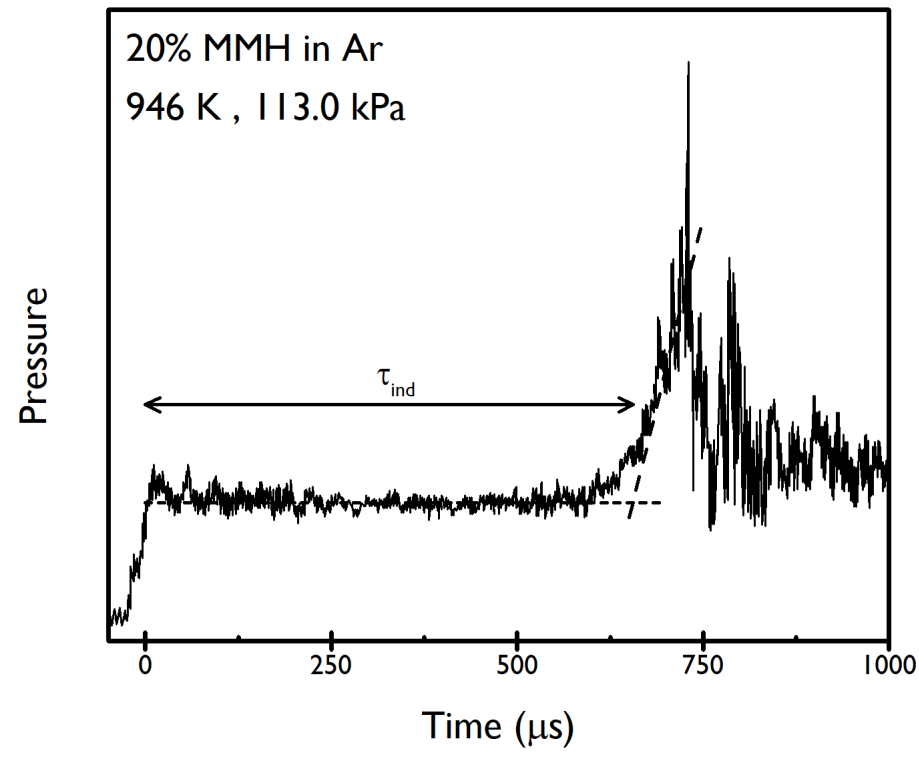

Figure 1: Typical pressure signal observed during ignition of a concentrated MMH/argon mixture in a shock tube

MMH is an endothermic compound $\left(\Delta \mathrm{H}_{\mathrm{f}, \mathrm{g}}=+22.8 \mathrm{kcal} \mathrm{mol}^{-1}\right)$ and is therefore expected to react "explosively" pure or in concentrated MMH/Ar mixtures once submitted to a shock wave. Because of this propensity to react easily, care was taken to avoid any local hot and/or catalytic spots. The shock tube was cleaned after each single measurement to remove any fragments of the separating membrane (made of terphane) and potential traces of pyrolysis products. The recorded pressure signals along the tube did not indicate any ignition between the incident and reflected shock wave at any location of the tube. This is consistent with the low $\mathrm{T}_{2}$ and $\mathrm{P}_{2}$ computed values and therefore it supports that the ignition monitored near the end tube wall (5 mm away from the wall) is solely due to self-reaction behind the reflected shock wave.

Reactive mixtures of known composition (based on partial pressures, measured with an uncertainty of $50 \mathrm{~Pa}$ ) have been prepared in Pyrex vessels by mixing argon (purity $>99.999 \%$ ) with the vapor pressure of liquid MMH (purity $>98.5 \%$ ) at room temperature. For safety reasons, the total pressure in the storage vessel was kept below atmospheric pressure. To avoid fuel condensation during storage and the filling of the tube, the prepared mixtures were such that the partial pressure of MMH 
was lower than the vapor pressure of MMH ( 6570 Pa at $298 \mathrm{~K})$. Although more concentrated mixtures (above $30 \mathrm{~mol} \% \mathrm{MMH}$ ) could have been practically achieved, safety considerations (detonation behind reflected shock, able to destroy the glass-made driven section, for instance) prevented their use.

Since $\mathrm{MMH}$ is known to react on many surfaces, analyses by infrared spectroscopy (see Supplementary Materials)of the prepared mixtures were carried out inside the Pyrex vessel to ensure that the mixture composition did not evolve during the storage period. The absorption lines specific to methane and methyl diazene, which are expected to be the main decomposition products, were not observed even after a 43-hour storage, supporting the confidence in the final mixture composition.

\section{Theoretical calculations}

The theoretical predictions thereafter employed molecular structures optimized at the M06-2xD3/aug-cc-pVTZ level of theory. The M06 functional family of Truhlar and co-workers ${ }^{12}$ is known to be well-suited for thermochemistry and kinetic calculations, and can be combined with a triple-zeta basis set at a reasonable computational cost. Rovibrational properties of the stationary points were calculated at the same level of theory, and scaled by 0.9760 and 0.9877 for zero-point vibrational energy corrections and partition function calculations, respectively ${ }^{13}$. Potential energy surface of hindered vibrational modes were computed by scanning the corresponding rotational modes by $10^{\circ}$ steps. All these calculations were performed with the Gaussian $09^{14}$.

Final energies of the stationary points were then obtained by carrying out single point energy on the M06-2x-D3/aug-cc-pVTZ optimized structures. RCCSD(T) calculations have been performed with Orca ${ }^{15,16}$ and the Dunning augmented basis sets (D, T, and Q $)^{17}$. Extrapolation to the infinite limit was achieved using a mixed Gaussian/exponential scheme for both the Hartree-Fock and the correlation energies (Equations 1-2). Due to the high cost of $\operatorname{CCSD}(T) /$ aug-cc-pVQZ calculations, the $\beta$ coefficient in the extrapolation scheme was obtained from $\operatorname{DLPNO}-\operatorname{CCSD}(\mathrm{T})^{18}$ calculations after checking for reactions of reference that this hybrid approach does not affect the final extrapolated relative energy. Final energies reported throughout this paper were thus obtained by summing the extrapolated HF and correlation energy and the scaled ZPVE. 


$$
\begin{aligned}
& E_{H F / C B S}=\frac{\left(1+e^{2}\right) E_{H F / D Z}-\left(e+e^{3}+e^{6}\right) E_{H F / T Z}+e^{6} E_{H F / Q Z}}{(1-e)\left(e^{5}-e^{2}-1\right)}
\end{aligned}
$$

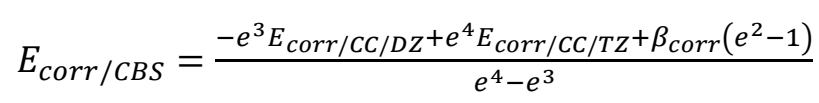

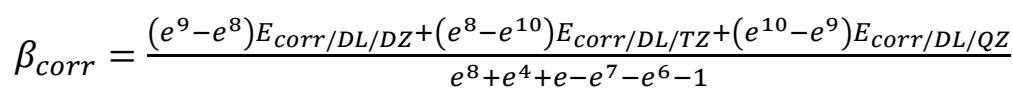

The rate coefficients of simple bimolecular reactions were obtained from classical transition state theory employing the rigid-rotor-harmonic-oscillator approximation as implemented in the Multiwell program package ${ }^{19}$. Potential energy surfaces of the hindered rotors were supplied and tunneling corrections based on the asymmetric Eckart potential were included.

For complex reactions involving barrierless entrance channels and competing decomposition channels, master equation simulations were carried out with the MESMER code ${ }^{20}$ to access the pressure dependence of the various reaction paths. An exponential-down energy transfer model $\left(\left\langle\Delta E_{d}\right\rangle=\right.$ $200\left(\frac{T}{300}\right)^{0.85} \mathrm{~cm}^{-1}$ ) coupled to Lennard-Jones collision rates was employed in these simulations.

\section{$\underline{\text { Numerical study }}$}

Kinetic numerical simulations of the different shock tube experiments displayed herein were achieved with the CHEMKIN PRO ${ }^{21}$.

\section{Results and discussion}

\subsection{Experimental results and literature model performances}

A typical pressure signal recorded during an experiment with concentrated MMH/Ar mixtures behind a reflected shock wave is given in Figure 1. As expected, the pressure is constant for a certain amount of time, then a sudden pressure jump is observed, indicating that ignition has occurred. The time lapse between the reflected shock wave arrival and the pressure signal increase is herein defined as the mixture induction delay, $\tau_{\text {ind }}$. Induction delays measured for $\mathrm{MMH} / \mathrm{Ar}$ mixtures at different initial temperature, around the atmospheric pressure, are reported in Table 1. Uncertainties associated to these measurements mainly arise from the determination methodology (highest slope) and the experiment 
repeatability, leading to an estimated overall uncertainty of $50 \%$. The existence of these induction delays is typical of concentrated mixtures. Indeed, Catoire et al. ${ }^{2}$, Cook et al. ${ }^{4}$ and $\mathrm{Li}$ et al. ${ }^{5}$ did not observe any significant pressure jump with mixtures containing 3\%, $1 \%$ and $0.35 \%$ of $\mathrm{MMH}$ in $\mathrm{Ar}$.

Table 1: Induction delays measured and computed for concentrated Mono Methyl Hydrazine (MMH) in argon

\begin{tabular}{|c|c|c|c|c|c|c|}
\hline \multirow{2}{*}{$\begin{array}{l}\text { MMH } \\
(\text { mol \%) }\end{array}$} & \multirow{2}{*}{$\begin{array}{c}\mathbf{A r} \\
(\mathbf{m o l} \%)\end{array}$} & \multirow{2}{*}{$\begin{array}{c}\mathbf{P} \\
(\mathbf{k P a})\end{array}$} & \multirow{2}{*}{$\begin{array}{c}\mathbf{T} \\
(\mathbf{K})\end{array}$} & \multicolumn{3}{|c|}{ Induction Delays $(\mu \mathrm{s})$} \\
\hline & & & & Expt. & Li model & $\begin{array}{c}\text { "Li }+ \text { Sun" } \\
\text { model }\end{array}$ \\
\hline 19.93 & 80.07 & $121.7 \pm 2.5$ & $980 \pm 15$ & $160 \pm 80$ & 1621 & 1104 \\
\hline 19.93 & 80.07 & $116.5 \pm 2.4$ & $905 \pm 14$ & $1412 \pm 706$ & 12171 & 6762 \\
\hline 19.93 & 80.08 & $125.5 \pm 2.6$ & $1016 \pm 16$ & $108 \pm 54$ & 720 & 521 \\
\hline 19.08 & 80.92 & $112.8 \pm 2.3$ & $938 \pm 15$ & $748 \pm 374$ & 4773 & 2992 \\
\hline 19.92 & 80.08 & $113.0 \pm 2.3$ & $946 \pm 15$ & $680 \pm 340$ & 3846 & 2454 \\
\hline 19.93 & 80.07 & $105.3 \pm 2.2$ & $937 \pm 15$ & $832 \pm 416$ & 4966 & 3144 \\
\hline 19.08 & 80.92 & $124.0 \pm 2.5$ & $1000 \pm 15$ & $136 \pm 68$ & 1024 & 723 \\
\hline 29.48 & 70.52 & $127.4 \pm 2.6$ & $942 \pm 15$ & $392 \pm 196$ & 4094 & 2421 \\
\hline 29.65 & 70.35 & $137.6 \pm 2.8$ & $902 \pm 14$ & $840 \pm 420$ & 12742 & 6492 \\
\hline 29.84 & 70.16 & $131.1 \pm 2.7$ & $912 \pm 14$ & $725 \pm 362$ & 9482 & 5076 \\
\hline 29.84 & 70.16 & $140.9 \pm 2.9$ & $940 \pm 15$ & $510 \pm 255$ & 4236 & 2422 \\
\hline
\end{tabular}

Shock tube ignition delays are generally computed with the constant volume and adiabatic assumptions (UV assumptions). However, with the concentrated MMH/Ar mixtures studied here the assumption of constant volume during the experiment time may be questionable. Hanson and Davidson ${ }^{22}$ have underlined that the adiabatic constant volume assumption leads to an over-prediction of the temperature and pressure profiles when a significant energy release exists during the induction delay. Figure 2 compares an experimental and a computed pressure profiles with the UV assumption. Unlike the experimental pressure trace, the computed profile exhibits a slow but continuous increase of pressure before the ignition. Therefore, a protocol has been devised to recover much closer the measured pressure. It consists of a two-step calculation. First, the adiabatic constant pressure assumption (HP) is used from time zero up to $80 \%$ of the measured induction delay time, which represents the period during which the pressure remains constant according to experimental traces (see Figure 1). Then follows a second calculation (the mixture composition at the end of the first calculations is passed over as the input mixture for the second calculation) with the UV-assumption until the mixture ignition. The pressure 
profile computed with this methodology is displayed in Figure 2. This approach clearly improves the agreement with the experimental pressure signal. However, it does not affect significantly the value of the induction delays $(13798 \mu$ s vs. $12171 \mu$ s at $905 \mathrm{~K}$ and $799 \mu$ s vs. $720 \mu$ s at $1016 \mathrm{~K}$, for the two-step and one-step calculations respectively). This may be explained by the relatively short duration of the delays $(<1.5 \mathrm{~ms})$. Consequently, the two-step procedure was not used hereafter but may be of interest for other concentrated mixtures with longer induction delays.

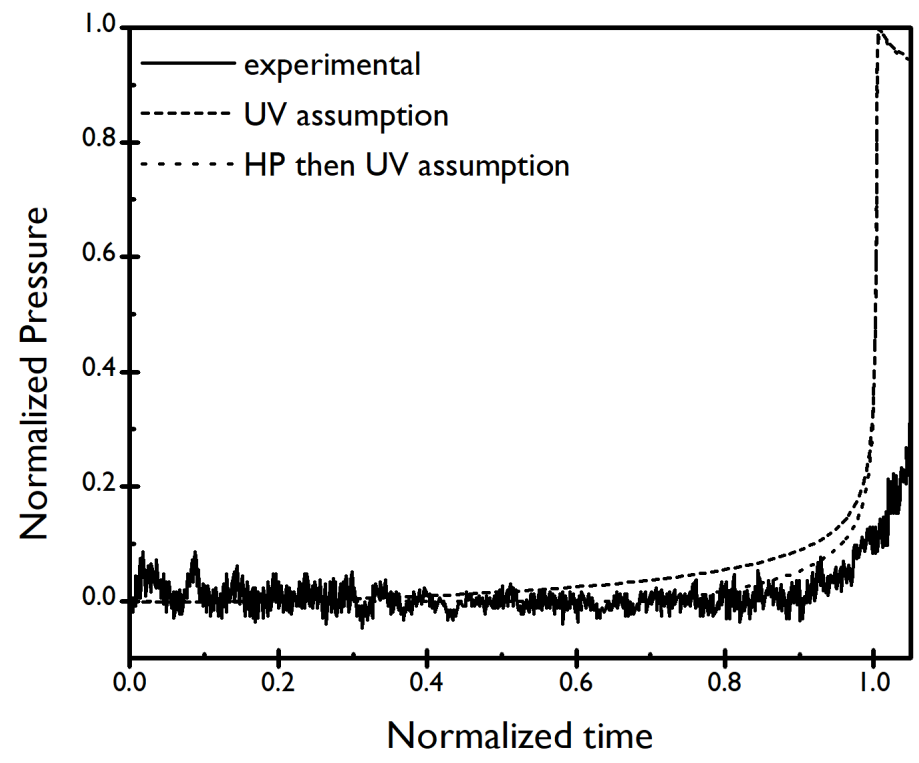

Figure 2: Experimental pressure signal for the thermal decomposition of MMH compared to the signal obtained by using the constant volume assumption (short dashed line) and by using the protocol described here (long dashed line).

The model of Li et al. ${ }^{5}$ has first been considered to compute the induction delays, and the values are presented in Table 1 . This model had been mainly validated against $\mathrm{NH}_{2}$ time profiles recorded during the pyrolysis of highly diluted mixtures of $\mathrm{MMH}$ in Ar.The model strongly overpredicts the induction delay, by a factor of 5 to 15 depending on the initial temperature, which is far beyond the uncertainties of the present measurements.

Improvements to the model of $\mathrm{Li}$ et al. are therefore needed. When updating the literature model, Li et al. did not consider the recent theoretical calculations of Sun et al. ${ }^{11}$ regarding the pressure dependence of MMH radicals decomposition channels. We have included in the model of Li et al. these theoretical predictions, and the modified model is thereafter denominated as the " $\mathrm{Li}+\mathrm{Sun}$ " model. 
Although not shown here, the "Li + Sun" model retains the ability of the non-modified model in simulating the $\mathrm{NH}_{2}, \mathrm{MMH}$, and $\mathrm{NH}_{3}$ time profiles in diluted mixtures. However, the computed induction delays, reported in Table 1, are much shorter: they are now overpredicted by a factor 6 on average, to compare with a factor 9 for the original model. On the other side, the explosive behavior of MMH is well captured by the model as illustrated in Figure 2 .

In spite of the deficiencies of the " $\mathrm{Li}+\mathrm{Sun}$ " model, and regarding that the relative reported uncertainties on the $\mathrm{NH}_{2}, \mathrm{NH}_{3}$ and $\mathrm{MMH}$ time profiles are $30 \%, 15 \%$ and $15 \%$, respectively, and $1.5 \%$ for temperature and $2 \%$ for pressure, a unique detailed kinetic model must be able to rationalize all the experimental results. Nevertheless developing such a model is not an easy task since even for diluted mixtures the model proposed may not be unique. Concentrated mixtures are often disregarded for the measurements of elementary rate constants because highly diluted mixtures are mandatory to reach chemical isolation of the reaction of interest. Still, if care is taken both experimentally (induction delay shorter than $1 \mathrm{~ms}$ to ensure adiabaticity, observation near the end of the tube) and numerically (numerical assumptions), an elementary-like kinetic approach is still appropriate for concentrated mixtures. In that respect Petersen et al. measured the induction delays of $\mathrm{CH}_{4} / \mathrm{O}_{2} /$ diluent mixtures with as much as $50 \mathrm{~mol} \%$ of fuel and succeeded simulating the ignition delays observed with an extended methane oxidation kinetic model encompassing reactions only relevant to the concentrated mixtures.

In this context, we aim to develop a kinetic model for $\mathrm{MMH}$ able to recover the experimental profiles within their uncertainty ranges, as well as the experimental ignition delays, within a factor of about 3 consistent with temperature and pressure uncertainties. The development of this model is discussed below, along with its performance against the overall experimental database.

\subsection{A wide range kinetic model for MMH pyrolysis}

The model published by Li et al. ${ }^{5}$ was the last effort to improve the model initially proposed by Catoire and co-workers. Since then, the core mechanism, that is to say the $\mathrm{C}_{0}-\mathrm{C}_{2}$ and the ammonia reaction set, had not been updated, although significant improvement has been made on the chemical kinetics of the species involved in this core mechanism. Therefore, the present kinetic model has been 
developed around the $\mathrm{C}_{0}-\mathrm{C}_{2}$ reaction subset developed by the Curran's group in Aramco-Mech ${ }^{23}$, and the ammonia and hydrazine subsets recently released by Otomo et al. ${ }^{24}$, excluding reactions involving oxygenated species. Finally, the reactions relevant to MMH pyrolysis were added. Nevertheless, thermochemical data and kinetic parameters identified to be highly sensitive for MMH pyrolysis have been reinvestigated and are discussed below. The final model encompasses 51 species involved in 225 reactions.

\subsubsection{Thermochemistry}

Thermochemical data are key information in chemical kinetic modeling as they are involved at first in the calculation of the reverse rate constants and later on in the heat release rate calculation. While $\mathrm{C}_{\mathrm{x}} \mathrm{H}_{\mathrm{y}} \mathrm{O}_{\mathrm{z}}$ chemical species have received much attention over the past decades ${ }^{25,26}$, nitrogen species are less documented (only 14\% of species listed in the Active Thermochemical Tables, $\mathrm{ATcT}^{27}$, contain nitrogen). As a consequence, thermochemical data for intermediates species and products belonging to the MMH pyrolysis subset are not available whereas data used in current ammonia mechanism may be dubious.

A review of the thermochemical data used in the recent ammonia models showed a large disparity in the heat of formation at $298 \mathrm{~K}$ of the hydrazino $\mathrm{N}_{2} \mathrm{H}_{3}$ radical. Whereas recent models ${ }^{24,28}$ adopt a value of $36.6 \mathrm{kcal} \mathrm{mol}^{-1}$, the heat of formation in the model of Li et al. ${ }^{5}$ is $47.8 \mathrm{kcal} \mathrm{mol}^{-1}$, and the AtcT ${ }^{27}$ and the Extended Third Millennium Ideal Gas Database ${ }^{29}$ recommend a value of $53.6 \mathrm{kcal} \mathrm{mol}^{-1}$. The hydrazino radical is a primary product of $\mathrm{MMH}$ decomposition and an intermediate in the production of $\mathrm{NH}_{2}$ radicals through the reaction $\mathrm{N}_{2} \mathrm{H}_{3}+\mathrm{H} \rightleftarrows 2 \mathrm{NH}_{2}$. Regarding the heat of formation supplied, the equilibrium constants of the reactions involving $\mathrm{N}_{2} \mathrm{H}_{3}$ differ by three orders of magnitude around $1200 \mathrm{~K}$, thus affecting heavily the pyrolysis reaction paths of this intermediate species. In order to elucidate the correct heat of formation of this radical, ROCBS-QB3 and G3B3 calculations have been performed, returning a heat of formation through atomization scheme of 53.8 and $54.6 \mathrm{kcal} \mathrm{mol}^{-1}$, in good agreement with the ATcT and Third Millennium Database values. Therefore, the NASA polynomials of the Extended Third Millennium Ideal Gas Database were adopted in the present study. 
Table 2: Ideal gas-phase thermochemical properties of $\mathrm{MMH}$ subset relevant species (enthalpy of formation in $\mathrm{kcal}^{\mathrm{mol}}{ }^{-1}$, entropy and heat capacities en cal mol-1 $\mathrm{K}^{-1}$ ). Values in brackets and square brackets are from ${ }^{11}$ and ${ }^{9}$, respectively.

\begin{tabular}{|c|c|c|c|c|c|c|c|c|c|c|}
\hline \multirow{2}{*}{ Species } & \multicolumn{4}{|l|}{$\Delta H_{f}(298 K)$} & \multicolumn{3}{|l|}{$\mathbf{S}$} & \multicolumn{3}{|l|}{$\mathbf{c}_{\mathrm{p}}$} \\
\hline & $R O C B S-Q B 3$ & G3B3 & $C C S D(T) / C B S / /$ & average & $298 K$ & $300 \mathrm{~K}$ & $500 \mathrm{~K}$ & $1000 \mathrm{~K}$ & $2000 \mathrm{~K}$ & $3000 \mathrm{~K}$ \\
\hline $\mathrm{CH}_{3} \mathrm{NHNH}_{2}$ & 22.27 & 22.35 & 22.44 & $\begin{array}{l}22.35 \\
(22.12) \\
{[22.90]}\end{array}$ & $\begin{array}{l}65.39 \\
(65.60)\end{array}$ & $\begin{array}{l}17.28 \\
(15.78)\end{array}$ & $\begin{array}{l}24.05 \\
(23.08)\end{array}$ & $\begin{array}{l}34.24 \\
(34.17)\end{array}$ & $\begin{array}{l}42.51 \\
(42.48)\end{array}$ & $\begin{array}{l}45.14 \\
(42.48)\end{array}$ \\
\hline $\mathrm{CH}_{3} \mathrm{NNH}_{2}$ & 49.37 & 49.50 & 49.79 & $\begin{array}{l}49.55 \\
(49.83) \\
{[50.72]}\end{array}$ & $\begin{array}{l}64.28 \\
(64.36)\end{array}$ & $\begin{array}{l}15.01 \\
(14.69)\end{array}$ & $\begin{array}{l}20.68 \\
(20.45)\end{array}$ & $\begin{array}{l}30.20 \\
(30.05)\end{array}$ & $\begin{array}{l}37.89 \\
(37.79)\end{array}$ & $\begin{array}{l}40.24 \\
(40.27)\end{array}$ \\
\hline $\mathrm{CH}_{3} \mathrm{NHNH}$ & 51.64 & 51.74 & 51.88 & $\begin{array}{l}51.75 \\
(52.04) \\
{[52.72]}\end{array}$ & $\begin{array}{l}64.33 \\
(64.34)\end{array}$ & $\begin{array}{l}14.64 \\
(14.61)\end{array}$ & $\begin{array}{l}20.23 \\
(20.28)\end{array}$ & $\begin{array}{l}29.85 \\
(29.94)\end{array}$ & $\begin{array}{l}37.65 \\
(37.75)\end{array}$ & $\begin{array}{l}40.13 \\
(40.26)\end{array}$ \\
\hline $\mathrm{CH}_{2} \mathrm{NHNH}_{2}$ & 62.99 & 63.63 & 63.49 & $\begin{array}{l}63.37 \\
(63.31) \\
{[66.04]}\end{array}$ & $\begin{array}{l}63.40 \\
(64.89)\end{array}$ & $\begin{array}{l}17.62 \\
(16.05)\end{array}$ & $\begin{array}{l}23.44 \\
(22.34)\end{array}$ & $\begin{array}{l}31.62 \\
(31.43)\end{array}$ & $\begin{array}{l}37.90 \\
(38.32)\end{array}$ & $\begin{array}{l}39.86 \\
(40.54)\end{array}$ \\
\hline $\mathrm{CH}_{3} \mathrm{NNH}$ & 42.07 & 42.10 & 42.12 & $\begin{array}{l}42.10 \\
{[41.78]}\end{array}$ & 62.01 & 12.80 & 17.70 & 26.29 & 32.85 & 34.83 \\
\hline $\mathrm{CH}_{2} \mathrm{NNH}_{2}$ & 40.14 & 40.32 & 40.45 & $\begin{array}{l}40.31 \\
{[40.29]}\end{array}$ & 62.31 & 13.60 & 19.38 & 27.54 & 33.40 & 35.15 \\
\hline $\mathrm{CH}_{3} \mathrm{~N}_{2}$ & 55.52 & 55.88 & 55.90 & $\begin{array}{l}55.76 \\
{[56.88]}\end{array}$ & 60.90 & 12.32 & 16.08 & 22.70 & 27.79 & 29.32 \\
\hline $\mathrm{CH}_{2} \mathrm{NNH}$ & 79.07 & 79.05 & 79.71 & $\begin{array}{l}79.27 \\
{[80.48]}\end{array}$ & 58.96 & 13.51 & 18.45 & 24.61 & 29.17 & 30.14 \\
\hline $\mathrm{HCNNH}_{2}$ & 89.57 & 90.07 & 90.12 & $\begin{array}{l}89.92 \\
{[92.01]}\end{array}$ & 60.64 & 13.45 & 17.95 & 24.04 & 28.28 & 29.55 \\
\hline
\end{tabular}


The thermochemical data of MMH related species $\left(\mathrm{CN}_{2} \mathrm{H}_{5}, \mathrm{CN}_{2} \mathrm{H}_{4}\right.$, and $\left.\mathrm{CN}_{2} \mathrm{H}_{3}\right)$ have been calculated based on the present ROCBS-QB3, G3B3, and RCCSD(T)/aug-cc-pVoOZ//M06-2x-D3/augcc-pVTZ calculations and are listed in Table 2. The heats of formation at $298 \mathrm{~K}$ were obtained by isodesmic reactions (available in Supporting information), with enthalpies of the reference species adopted from the Active Thermochemical Tables ${ }^{27}$. The three theoretical methods employed yield similar enthalpies of formation, with an average standard deviation of $0.2 \mathrm{kcal} \mathrm{mol}^{-1}$., and these values are also in excellent agreement with the standard heats of formation of $\mathrm{MMH}$ and its radicals reported by Sun et al. ${ }^{11}$ using QCISD(T)/cc-pVœZ//CASPT2/aug-cc-pVTZ energetics and Catoire and Swihart ${ }^{9}$ from G2 energetics. Entropy and constant pressure heat capacities were determined from the scaled M06-2x-D3/aug-cc-pVTZ rovibrational properties. The Pitzer-Gwinn approximation ${ }^{30}$ was employed to take into account the contributions of the hindered internal rotors along the $\mathrm{C}-\mathrm{N}$ and $\mathrm{N}-\mathrm{N}$ bonds. The present $S$ and $c_{p}$ values are again in excellent agreement with the previously calculated values. The theoretical thermochemical data discussed above were then turned into NASA polynomials in order to be implemented in the kinetic model thermodatabase.

\subsubsection{Reaction of $\mathrm{NH}_{2}+\mathrm{H}$}

The reaction of amidogen radical with an $\mathrm{H}$ atom is the main sink for $\mathrm{NH}_{2}$ radicals in oxygen-free conditions. It proceeds either on the singlet state potential surface to yield ammonia or on the triplet state surface for the $\mathrm{H}$ abstraction channel. The decomposition of ammonia has been the focus of several experimental and numerical efforts, and thus no attempt to further reanalyze this reaction was undertaken. The abstraction channel has not received this much attention, nevertheless direct experimental measurements have been reported by Yumura and Asabe ${ }^{31}$ and Davidson et al. ${ }^{32}$ while Rohrig et al. ${ }^{33}$ and Dove and $\mathrm{Nip}^{34}$ derived rate coefficients by fitting a reaction mechanism to experimental data. Most of studies were performed at high temperatures (>2200 K) and a large scattering among the four sets of data can be seen in Figure 3. 
Table 3: Rovibrational properties (at CCSD/aug-cc-pVTZ level of theory) and relative energies (with respect to the reactants) of the stationary points on the $\mathrm{NH}_{3}$ triplet surface

\begin{tabular}{|c|c|c|c|c|}
\hline Stationary point & $\mathrm{NH}_{2}+\mathrm{H}$ & $\mathrm{NH}_{2}+\mathrm{H} \rightarrow \mathrm{NH}+\mathrm{H}_{2}$ & \multicolumn{2}{|c|}{$\mathrm{NH}+\mathrm{H}_{2}$} \\
\hline RCCSD(T)/CBS//M06-2x-D3/aug-cc-pVTZ & 0.0 & 6.1 & -11.1 & \\
\hline RCCSD(T)/CBS//CCSD/aug-cc-pVTZ & 0.0 & 6.3 & -11.3 & \\
\hline RCCSD(T)/CBS//CCSD/aug-cc-pVTZ & 0.0 & 6.2 & -11.2 & \\
\hline UCCSD(T)-F12/CBS//CCSD/aug-cc-pVTZ & 0.0 & 6.3 & -11.2 & \\
\hline NEVPT2(8,9)/CBS//NEVPT2/aug-cc-pVTZ & 0.0 & 7.23 & -10.3 & \\
\hline $\mathrm{T}_{1}$ diagnostic & 0.015 & 0.028 & 0.020 & 0.006 \\
\hline Frequencies & $\begin{array}{l}1531 \\
3348 \\
3439\end{array}$ & $\begin{array}{l}620 \\
878 \\
1276 \\
1514 \\
3314\end{array}$ & 3251 & 4344 \\
\hline B & $\begin{array}{l}8.368 \\
12.982 \\
23.541\end{array}$ & $\begin{array}{l}2.518 \\
2.975 \\
16.392\end{array}$ & 4.667 & 16.970 \\
\hline
\end{tabular}

Rovibrational properties of the stationary points on the $\mathrm{NH}_{3}$ triplet surface have been determined from M06-2x-D/aug-cc-pVTZ and CCSD/aug-cc-pVTZ geometries, and the latter are reported in Table 3. Final extrapolated CCSD(T)/CBS energies have been obtained with and without DLPNO assistance (spin-restricted and D,T,Q Dunning basis sets) or with spin-unrestricted explicitly correlated (F12) D, $\mathrm{T}$, Q single point energies. Even if the T1 diagnostic for the transition state is relatively low (0.028), a NEVPT2(8,9)/CBS//NEVPT2/aug-cc-pVTZ analysis have been performed, which yields an energy barrier of $7.2 \mathrm{kcal} \mathrm{mol}^{-1}$, in reasonable agreement with the $\operatorname{CCSD}(\mathrm{T})$ values of 6.1 and $6.3 \mathrm{kcal} \mathrm{mol}^{-1}$ obtained from the M06-2x and CCSD geometries, respectively. 


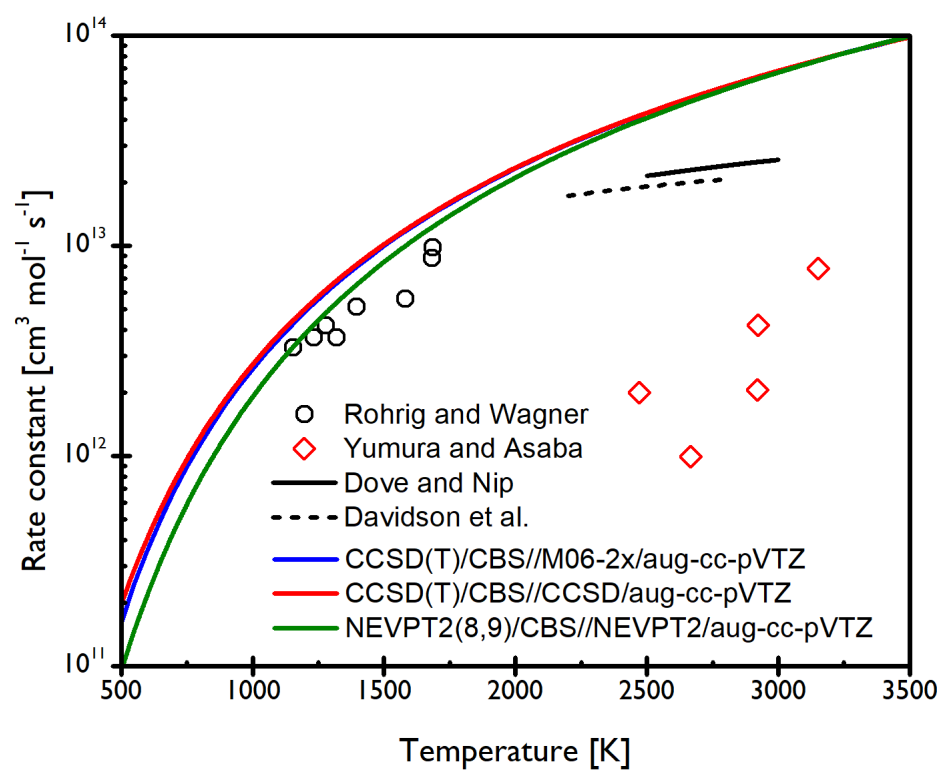

Figure 3: Rate coefficient for the $\mathrm{NH}_{2}+\mathrm{H}={ }^{3} \mathrm{NH}+\mathrm{H}_{2}$ abstraction reaction. The colored solid lines denote present predictions with properties obtained at different level of theory. Symbols ${ }^{31,33}$, solid $^{34}$ and dashed $^{32}$ black lines denote literature experimental data.

Rate constant predictions are displayed in Figure 3. The use of either CCSD or M06-2x rovibrational properties does not yield any significant difference on the rate coefficient, and therefore the M06-2x method has been systematically employed hereafter for structure optimization. On the contrary, the NEVPT2 predicted rate constant is slightly smaller at low temperatures, as the result of $0.9 \mathrm{kcal} \mathrm{mol}^{-1}$ larger energy barrier, but remains within the uncertainty of the calculations. The intermediate temperature data of Rohrig and Wagner show a reasonable agreement with these predictions, with are about $50 \%$ greater over the $1150-1700 \mathrm{~K}$ temperature range. This deviation increases to a factor 2 above $2200 \mathrm{~K}$ when comparing the computed rate constant to the data sets of Davidson et al. and Dove and Nip. A three parameter Arrhenius fit to the CCSD(T)//CCSD data is given in Table 9.

\subsubsection{MMH $H$ abstraction reactions}

Although the thermal unimolecular decomposition of MMH is fast (see section 4.4), reactions of MMH with atoms and radicals may be of importance, especially in concentrated mixtures or to capture the time evolution of $\mathrm{NH}_{2}$. MMH offers three abstraction sites for reactions to occur, to generate the 
radicals $\mathrm{CH}_{2} \mathrm{NHNH}_{2}, \mathrm{CH}_{3} \mathrm{NNH}_{2}$, and $\mathrm{CH}_{3} \mathrm{NHNH}$. Based on the postulated decomposition path of $\mathrm{MMH}$ and its radical, the major scavengers are expected to be $\mathrm{H}, \mathrm{NH}_{2}$, and $\mathrm{CH}_{3}$. Experimental data for $\mathrm{H}$ abstraction reactions from $\mathrm{MMH}$ are scarce, and limited to low temperatures.

Table 4: Calculated energies of the stationary point for the $\mathrm{CH}_{3} \mathrm{NHNH}_{2}+\mathrm{X}\left(\mathrm{X}=\mathrm{H}, \mathrm{NH}_{2}, \mathrm{CH}_{3}\right)$ Abstraction channels

\begin{tabular}{|c|c|c|c|}
\hline Species & Energy $^{1}$ & Relative energy $^{2}$ & $T_{1}$ diagnostic \\
\hline $\mathrm{CH}_{3} \mathrm{NHNH}_{2}$ & -150.927340 & & 0.010 \\
\hline $\mathrm{H}$ & -0.500017 & & 0.000 \\
\hline $\mathrm{NH}_{2}$ & -55.801682 & & 0.015 \\
\hline $\mathrm{CH}_{3}$ & -39.749468 & & 0.015 \\
\hline $\mathrm{CH}_{3} \mathrm{NHNH}$ & -150.299578 & & 0.023 \\
\hline $\mathrm{CH}_{3} \mathrm{NNH}_{2}$ & -150.302898 & & 0.021 \\
\hline $\mathrm{CH}_{2} \mathrm{NHNH}_{2}$ & -150.281324 & & 0.020 \\
\hline $\mathrm{MMH}+\mathrm{H} \rightarrow \mathrm{H}_{2}+\mathrm{CH}_{3} \mathrm{NHNH}$ & -151.421559 & $3.64(8.3)$ & 0.031 \\
\hline $\mathrm{MMH}+\mathrm{H} \rightarrow \mathrm{H}_{2}+\mathrm{CH}_{3} \mathrm{NNH}_{2}$ & -151.423186 & $2.62(5.9)$ & 0.029 \\
\hline $\mathrm{MMH}+\mathrm{H} \rightarrow \mathrm{H}_{2}+\mathrm{CH}_{2} \mathrm{NHNH}_{2}$ & -151.418477 & $5.57(12.8)$ & 0.021 \\
\hline $\mathrm{MMH}+\mathrm{NH}_{2} \rightarrow \mathrm{NH}_{3}+\mathrm{CH}_{3} \mathrm{NHNH}$ & -206.724797 & $2.65(3.4)$ & 0.029 \\
\hline $\mathrm{MMH}+\mathrm{NH}_{2} \rightarrow \mathrm{NH}_{3}+\mathrm{CH}_{3} \mathrm{NNH}_{2}$ & -206.726532 & $1.56(1.8)$ & 0.028 \\
\hline $\mathrm{MMH}+\mathrm{NH}_{2} \rightarrow \mathrm{NH}_{3}+\mathrm{CH}_{2} \mathrm{NHNH}_{2}$ & -206.720442 & $5.38(3.8)$ & 0.028 \\
\hline $\mathrm{MMH}+\mathrm{CH}_{3} \rightarrow \mathrm{CH}_{4}+\mathrm{CH}_{3} \mathrm{NHNH}$ & -190.665156 & $7.31(7.6)$ & 0.026 \\
\hline $\mathrm{MMH}+\mathrm{CH}_{3} \rightarrow \mathrm{CH}_{4}+\mathrm{CH}_{3} \mathrm{NNH}_{2}$ & -190.667788 & $5.66(5.4)$ & 0.025 \\
\hline $\mathrm{MMH}+\mathrm{CH}_{3} \rightarrow \mathrm{CH}_{4}+\mathrm{CH}_{2} \mathrm{NHNH}_{2}$ & -190.658936 & $11.21(9.7)$ & 0.020 \\
\hline $\mathrm{MMH}+\mathrm{NH} \rightarrow \mathrm{NH}_{2}+\mathrm{CH}_{3} \mathrm{NHNH}$ & -206.070510 & $7.6(8.6)$ & 0.038 \\
\hline $\mathrm{MMH}+\mathrm{NH} \rightarrow \mathrm{NH}_{2}+\mathrm{CH}_{3} \mathrm{NNH}_{2}$ & -206.073062 & $6.0(6.6)$ & 0.037 \\
\hline $\mathrm{MMH}+\mathrm{NH} \rightarrow \mathrm{NH}_{2}+\mathrm{CH}_{2} \mathrm{NHNH}_{2}$ & -206.064525 & $11.3(13.1)$ & 0.025 \\
\hline
\end{tabular}

${ }^{1}$ Zero point vibrational corrected energy in Hartree. Energies evaluated at the RCCSD(T)/aug-cc-pVoZ//M06-2x-D3/augcc-pVTZ level of theory

${ }^{2}$ Energy in kcal mol-1 relative to $\mathrm{CH}_{3} \mathrm{NHNH}_{2}+\mathrm{X}$. Energies in brackets are from Sun et al. ${ }^{7}$

$M M H+H$ reaction. Vaghjiani ${ }^{35}$ have monitored by $\mathrm{CW}$ resonance fluorescence the $\mathrm{H}$ atom concentration decay in the presence of excess $\mathrm{MMH}$, and obtained an overall rate constant at $298 \mathrm{~K}$ of (4.58 \pm 0.69$) 10^{11} \mathrm{~cm}^{3} \mathrm{~mol}^{-1} \mathrm{~s}^{-1}$. Sun and Law have theoretically investigated the title reaction at the $\operatorname{CCSD}(\mathrm{T}) / 6-31+\mathrm{G}(\mathrm{d}, \mathrm{p}) / / \mathrm{UMP} 2$ (Full)/6-31G(d,p) level of theory whereas Wang et al. ${ }^{36}$ employed MCG3-MPWPW91//MPW1K/6-311G(d,p) energetics. The overall rate constant reported in these two studies are displayed in Figure 4, along with the branching ratios between the three abstraction positions. There is large discrepancy between the two computed values over the entire temperature range: the rates of Sun and Law are two or three order of magnitude lower than the rates of Wang et al, whose calculated rate constant is in good agreement with the single experimental value. Similar 
disparities are observed for the branching ratios, with the $\mathrm{CH}_{3} \mathrm{NNH}_{2}$ radical being the major reaction outcome (60-100\%) regardless of the temperature according to Sun and Law whereas it is so only below $800 \mathrm{~K}$ in the study of Wang et al. In order to resolve this apparent conflict, the reactions of MMH with $\mathrm{H}$ atom have been explored at the same level of theory as the thermochemical data. The zero-point corrected energy barriers relative to the reactants are listed in Table 4 while the rovibrational properties of the reactants and transition states are provided in the Supplementary Material. The use of spin restricted $\operatorname{CCSD}(\mathrm{T})$ methods results in $\mathrm{T} 1$ diagnostic values lower than 0.03 , attesting of the small multireference character of the chemical structures considered, and thus on the accuracy of the calculated energies. The present energy barriers are much lower than the one reported by Sun and Law (by up to $7 \mathrm{kcal} \mathrm{mol}^{-1}$ for the abstraction on the carbon atom), but slightly higher than those of Wang et al., but all three calculations indicate that $\mathrm{H}$ abstraction on the center nitrogen atom is energetically favored, followed by the abstraction on the terminal amino group. The overall rates and individual branching ratios herein calculated for the reaction of $\mathrm{MMH}$ with an $\mathrm{H}$ atom are shown in Figure 4. Our results are in excellent agreement with the experimental value of Vaghjiani at $298 \mathrm{~K}\left(2.9010^{11} \mathrm{~cm}^{3} \mathrm{~mol}^{-1} \mathrm{~s}^{-1}\right.$ to compare with $4.5810^{11} \mathrm{~cm}^{3} \mathrm{~mol}^{-1} \mathrm{~s}^{-1}$ ) and are consistent with the calculations of Wang et al., although they are twice faster at the temperatures above $1000 \mathrm{~K}$. They also confirm the exceptionally underestimated rate constant of Sun and Law. The present RCCSD(T) base predictions, consistently with the MCG3-MPWPW91 calculations, confirm that entropic effects overcome the energetic contributions above $800 \mathrm{~K}$, where the carbon centered radical $\mathrm{CH}_{2} \mathrm{NHNH}_{2}$ become the major reaction product and the two nitrogen centered radical are formed in similar proportions (29.5\% vs. $24.9 \%$ at $1000 \mathrm{~K}, 21.0 \%$ vs. $21.2 \%$ at $1500 \mathrm{~K}$, for the $\mathrm{CH}_{3} \mathrm{NNH}_{2}$ and $\mathrm{CH}_{3} \mathrm{NHNH}$ radicals, respectively). Rate constants for the individual channels obtained from the RCCSD(T)/aug-cc-pVœZ//M06-2x-D3/aug-ccpVTZ data were fitted into modified Arrhenius expressions (see Table 9) and implemented in the present kinetic model. 


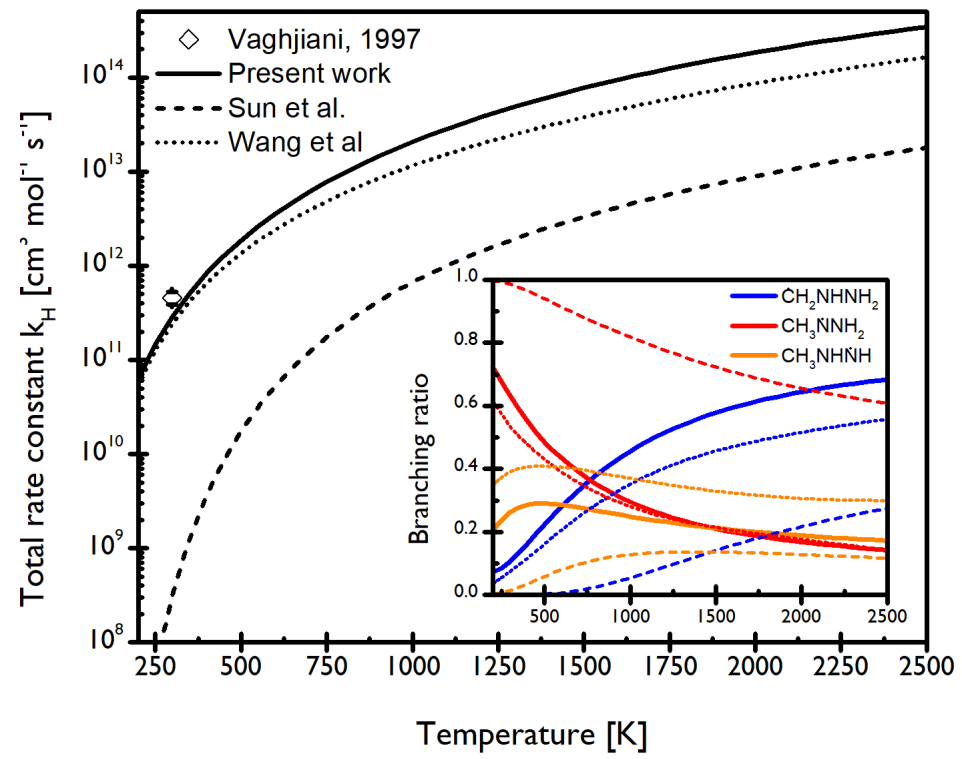

Figure 4: Computed rate constant and branching ratio (insert) for the reaction of $\mathrm{H}$ atom with $\mathrm{MMH}$ (abstraction reaction). The solid, dashed and dotted lines denote the present calculations, the calculations of Sun and $\mathrm{Law}^{7}$ and the calculations of Wang et al., respectively. The symbol represent experimental rate constant measurement of Vaghjiani ${ }^{35}$.

$M M H+\mathrm{NH}_{2}$ reaction. Amidogen $\mathrm{NH}_{2}$ radical is a primary decomposition product of $\mathrm{MMH}$, and therefore may play a substantial role in the fuel consumption. Unlike the reaction of MMH with $\mathrm{H}$ atoms, the reaction of $\mathrm{MMH}$ with the $\mathrm{NH}_{2}$ has not been studied experimentally. The only available data are from Sun and $\mathrm{Law}^{7}$, who calculated the rate constant for each abstraction channel from CBSQB3//B3LYP/6-311G(2d,d,p) stationary points properties. In line with the MMH + H study, the MMH $+\mathrm{NH}_{2}$ reactions has been investigated with the same methodology. Transition states relative energies (with respect to the reactant set) are provided in Table 4. The present $\operatorname{RCCSD}(\mathrm{T})$ energy barriers are in good agreement $\left(<0.75 \mathrm{kcal} \mathrm{mol}^{-1}\right)$, yet lower, with those of Sun and Law, except for the abstraction on the carbon atom, for which our value is $1.6 \mathrm{kcal} \mathrm{mol}^{-1}$ higher than the CBS-QB3 one. Nevertheless, $\mathrm{H}$ abstraction on the centered nitrogen atom is energetically preferred with both methods, while abstraction on the carbon site is the least favored path. Rate constant predictions are compared in Figure 5 to the published rate coefficients of Sun and Law, while the three-parameter Arrhenius expressions used in the kinetic model are reported in Table 9. These predictions are about $100 \%$ to $30 \%$ higher in the 750 - 
$1500 \mathrm{~K}$ temperature range. However, larger discrepancies are observed for the branching ratios. While the CBS-QB3 calculations identify the $\mathrm{CH}_{3} \mathrm{NNH}_{2}$ radical as the main reaction product over the entire temperature range, the $\operatorname{RCCSD}(\mathrm{T})$ calculations predict the abstraction on the terminal nitrogen atom to overtake the abstraction on the centered $\mathrm{N}$ atom above $750 \mathrm{~K}$. Consistently with its highest energy barrier, the abstraction on the $\mathrm{CH}_{3}$ group remains a minor path in both cases, with a branching ratio of 5 to $20 \%$ between 750 and $2000 \mathrm{~K}$. Nevertheless, present and CBS-QB3 predictions are significantly lower than the recommended rate constants of Cook et al. ${ }^{4}$ which were derived by optimizing computed $\mathrm{NH}_{2}$ and $\mathrm{NH}_{3}$ time profiles over experimental measurements.

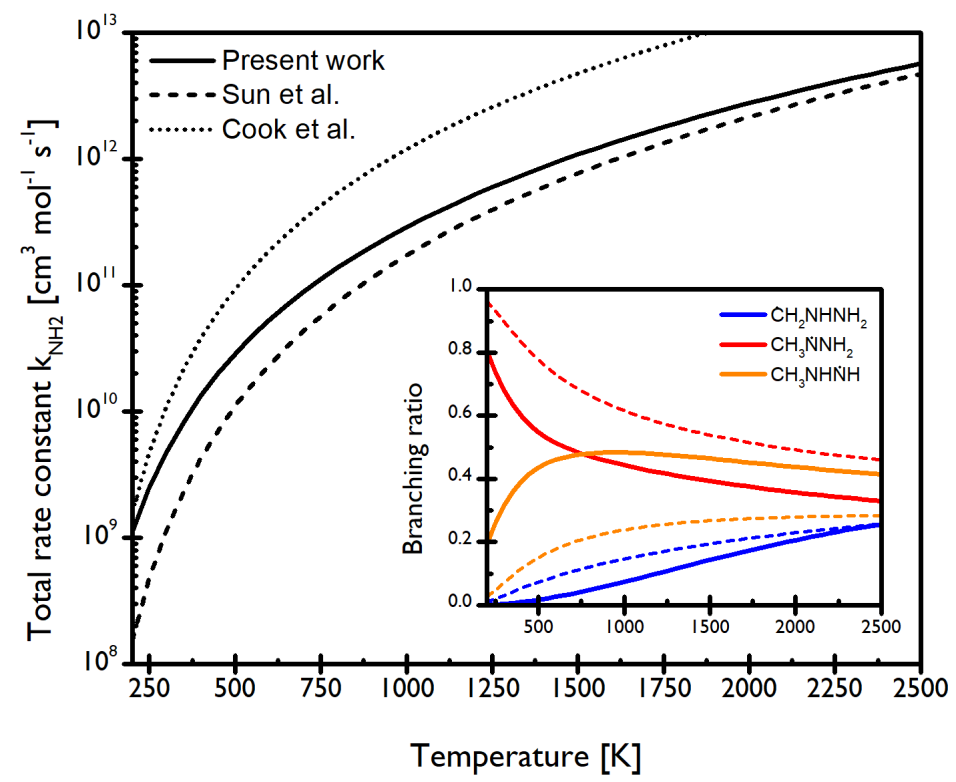

Figure 5: Computed rate constant and branching ratio (insert) for the reaction of $\mathrm{NH}_{2}$ with $\mathrm{MMH}$ (abstraction reaction). The solid, the dashed, and dotted lines denote the present calculations, the calculations of Sun and $\mathrm{Law}^{7}$, and the recommendation of Cook et al. ${ }^{4}$,respectively.

$M M H+\mathrm{CH}_{3}$ reaction. Like $\mathrm{NH}_{2}$, the methyl radical is a primary and a secondary product in the MMH pyrolysis and thus its reaction with the fuel deserves attention. The only experimental study on the reaction of $\mathrm{MMH}$ with $\mathrm{CH}_{3}$ is from Gray et al. ${ }^{37}$. The authors monitored by $\mathrm{UV}$ absorption the decay of methyl radicals generated from acetone photolysis in presence of excess MMH. Rate constants relative to the self-recombination of methyl radicals $\left(\mathrm{CH}_{3}+\mathrm{CH}_{3} \rightleftarrows \mathrm{C}_{2} \mathrm{H}_{6}\right)$ were then derived in the 359$454 \mathrm{~K}$ temperature range. Sun and $\mathrm{Law}$, in addition to the $\mathrm{MMH}+\mathrm{NH}_{2}$ reaction, also employed CBSQB3 properties to access the rate constants of the three $\mathrm{MMH}+\mathrm{CH}_{3}$ individual channels. We have 
investigated the potential energy surface of the title reaction by performing spin-restricted CCSD(T)/aug-cc-pVœZ//M06-2x-D3/aug-cc-pVTZ calculations, and saddle points energies are detailed in Table 4. Such as for the $\mathrm{MMH}+\mathrm{NH}_{2}$ reaction, the present energy barriers are in excellent agreement $\left(<0.3 \mathrm{kcal} \mathrm{mol}^{-1}\right)$ with the CBS-QB3 values for the abstraction on the two nitrogen atoms, while it is $1.5 \mathrm{kcal} \mathrm{mol}^{-1}$ higher than the one reported by Sun and Law for the abstraction on the carbon atom. The overall RCCSD(T) predicted rate constant is displayed in Figure 6 along with available literature data, and modified Arrhenius expression for each individual channel are given in Table 9. This rate constant is in excellent agreement with both the low temperature experimental data and the CBSQB3 one. However, discrepancies are observed regarding the reaction branching ratios (insert of Figure 6). As aboveCH $\mathrm{HNH}_{2}$ is the major reaction outcome according to the CBS-QB3 calculations (more than $60 \%$ over the entire temperature range here considered), whereas the present calculations indicate this radical to be the main reaction product only below $600 \mathrm{~K}$, the temperature at which the $\mathrm{CH}_{3} \mathrm{NHNH}$ radical becomes predominant. Regarding the production of the $\mathrm{CH}_{2} \mathrm{NHNH}_{2}$ radical, although the $\mathrm{RCCSD}(\mathrm{T})$ energy barrier is higher than the CBS-QB3 one, the computed branching ratio is about twice larger at combustion temperatures, and this channel is even the second most favored reaction path above $1300 \mathrm{~K}$ 


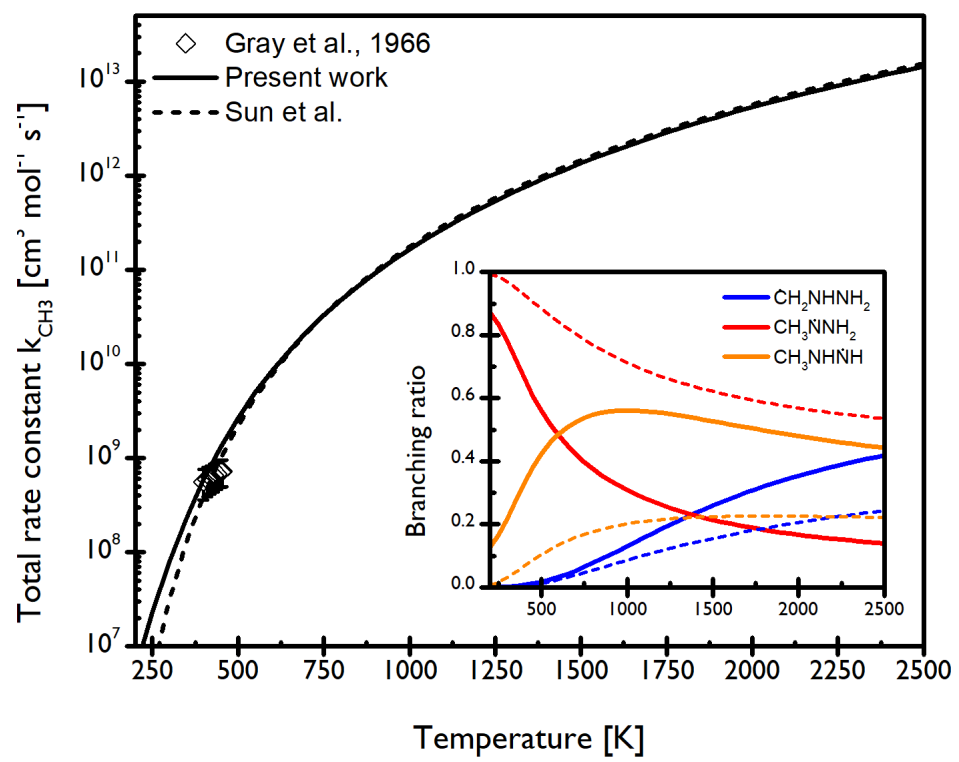

Figure 6: Computed rate constant and branching ratio (insert) for the reaction of $\mathrm{CH}_{3}$ with $\mathrm{MMH}$ (abstraction reaction). The solid and the dashed line denote the present calculations and the calculations of Sun and $\mathrm{Law}^{7}$, respectively.

$M M H+N H$ reaction. Although the reaction of $\mathrm{MMH}$ with imidogen $\mathrm{NH}$ radicals is not expected to play a significant role, the rate constants of the $\mathrm{H}$ abstraction reactions have been calculated at the same level of theory as the three reactions above. Computed properties of the saddle points are given in Table 4 (energies) and in the Supplementary Material (vibrational frequencies and rotational constants). This reaction proceeds on a triplet surface, making $\mathrm{NH}$ a less efficient abstracter than $\mathrm{NH}_{2}$, with energy barriers larger by about 5-6 $\mathrm{kcal} \mathrm{mol}^{-1}$. The triplet multiplicity also results in a more pronounced multireference character as suggested by the higher $\mathrm{T}_{1}$ diagnostics values $(0.038)$ of the two transition states involving the breaking of $\mathrm{N}-\mathrm{H}$ bonds of $\mathrm{MMH}$. Nevertheless, no further multi-reference calculations were performed to refine the energies. The predicted rate constants are displayed and compared to those reported by Sun and Law in Figure 7. The two overall rate constants are in fair agreement, our predictions being $\sim 100 \%$ (low temperature) to $\sim 50 \%$ (high temperature) faster than the CBS-QB3 predicted ones. 


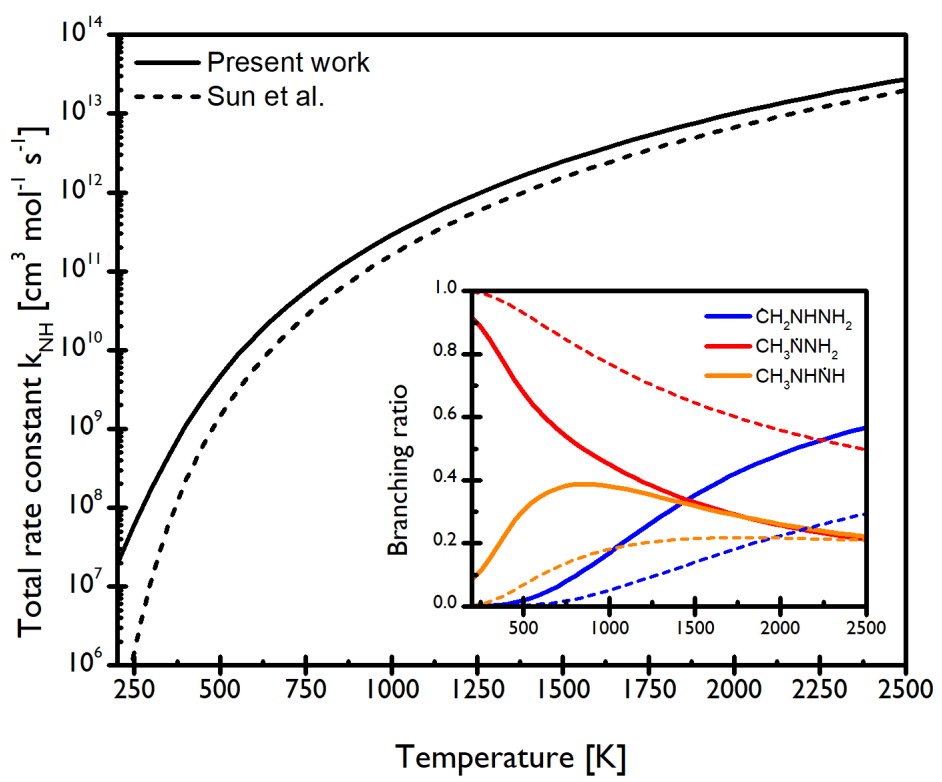

Figure 7: Computed rate constant and branching ratio (insert) for the reaction of ${ }^{3} \mathrm{NH}$ with $\mathrm{MMH}$ (abstraction reaction). The solid and the dashed line denote the present calculations and the calculations of Sun and $\mathrm{Law}^{7}$, respectively.

\subsubsection{MMH decomposition}

In comparison to the $\mathrm{C}-\mathrm{C}$ bonds in alkanes, the bond dissociation energies of the $\mathrm{N}-\mathrm{C}$ and $\mathrm{N}-\mathrm{N}$ bonds are relatively low, calculated here equal to 66.4 and $64.3 \mathrm{kcal} \mathrm{mol}^{-1}$, respectively. Unimolecular decomposition of MMH is thus expected to be a dominant channel in MMH pyrolysis, and its kinetics may be experimentally measured. Kerr and co-workers ${ }^{38}$ flowed a low pressure stream (0.01-0.04 atm) of MMH mixed a free radical trapper (toluene) in a heated reaction chamber (746-862 K), and derived MMH decomposition rate constants by quantifying $\mathrm{NH}_{3}$, which was postulated originating from the reaction of the trapper with the $\mathrm{NH}_{2}$ produced by the direct decomposition of $\mathrm{MMH}\left(\mathrm{CH}_{3} \mathrm{NHNH}_{2} \rightleftarrows\right.$ $\mathrm{CH}_{3} \mathrm{NH}+\mathrm{NH}_{2}$ ). Eberstein and Glassman ${ }^{1}$ measured the decomposition rate of $\mathrm{MMH}$ at atmospheric pressure over the $750-1000 \mathrm{~K}$ temperature range by recording the reaction temperature increase rate in a flow reactor. Finally, Golden et al. ${ }^{39}$ also investigated the thermal decomposition of MMH at very low pressure in a flow reactor and rate constants were derived from the $\mathrm{NH}_{3}$ and $\mathrm{H}_{2}$ production rates.

Besides the MMH H abstraction reactions, Sun and $\mathrm{Law}^{7}$ also studied the $\mathrm{MMH}$ decomposition potential energy surface with a mix of compounds (CBS-QB3) and ab initio (CCSD(T)/6- 
3111++G(3df,2p)//MPWB1K/6-31+G(d,p)) methods, and calculated through a QRRK/Master equation analysis the temperature, pressure dependent rate coefficients for all the identified reaction paths. Regardless of the thermodynamic condition, three and four-center concerted eliminations were found to be negligible and the N-N bond scission reaction dominates the MMH decomposition, followed by the C-N bond scission reaction. In a later study, Sun et al. ${ }^{8}$ refined their analysis of the thermal decomposition of $\mathrm{MMH}$ and provided rate constant expressions in the Troe formalism. Upon the previous computational studies, Zhang et al. ${ }^{10}$ focused on the N-N and C-N bond scission channels. Based on CASPT2(2e,2o)/aug-cc-pVDZ interaction energies, they ran a VRC-TST/ME (Variable Reaction Coordinate Transition State Theory/ Master Equation) analysis for a better description of the temperature and pressure dependence of the two main MMH decomposition channels.

Progress in in-situ laser diagnostics enabled Cook et al. ${ }^{4}$ then Li et al. ${ }^{5}$ to record the early buildup in $\mathrm{NH}_{2}$ radical subsequent to the $\mathrm{MMH}$ thermal decomposition. Using the kinetic model of Sun et al., $\mathrm{CH}_{3} \mathrm{NH}+\mathrm{NH}_{2}$ channel rate constants were determined from $\mathrm{NH}_{2}$ time profiles between 1107 and $1288 \mathrm{~K}$ and 0.32 and $5.2 \mathrm{~atm}$. The experimental values were about $40 \%$ lower than the predictions of Zhang et al., hence Arrhenius expressions for five individual pressures (Plog formalism) were proposed for kinetic modeling purposes.

However, the rate constants obtained with the help of a detailed kinetic modeling depends to some extent on this kinetic model. Therefore the recommended values of Li et al., once in the present model, failed to match the $\mathrm{NH}_{2}$ experimental profiles, mainly because of the fastest $\mathrm{H}$ abstraction rate constants $\left(\mathrm{MMH}+\mathrm{H}\right.$ reaction, with the dominant $\mathrm{MMH}$ radical being $\mathrm{CH}_{2} \mathrm{NHNH}_{2}$ that decomposes into $\mathrm{CH}_{2} \mathrm{NH}$ and $\mathrm{NH}_{2}$ ) and the updated $\mathrm{N}_{2} \mathrm{H}_{3}$ thermochemistry. Indeed, according to the model of Sun et al., $\mathrm{NH}_{2}$ radicals are produced at later times by the $\mathrm{H}$ atom activated decomposition of $\mathrm{N}_{2} \mathrm{H}_{3}$ radicals $\left(\mathrm{N}_{2} \mathrm{H}_{3}+\mathrm{H}\right.$ $\rightleftarrows 2 \mathrm{NH}_{2}$ ) while the thermal dissociation of $\mathrm{MMH}$ now acts as a sink. This $\mathrm{N}_{2} \mathrm{H}_{3}$ reaction occurs only because $\mathrm{N}_{2} \mathrm{H}_{3}$ decomposition (see below) into diazene $\mathrm{N}_{2} \mathrm{H}_{2}$ is killed off by the underestimated $\mathrm{N}_{2} \mathrm{H}_{3}$ heat of formation. With the proper $\Delta \mathrm{H}_{\mathrm{f}}, \mathrm{N}_{2} \mathrm{H}_{3}$ is no more a source of $\mathrm{NH}_{2}$ radicals while the reaction sinks remain. As a consequence, $\mathrm{NH}_{2}$ mole fraction is first overestimated then underestimated along the course of MMH pyrolysis. 
In line with the strategy of Cook et al. and Li et al., the rate coefficients of the $\mathrm{CH}_{3} \mathrm{NHNH}_{2} \rightleftarrows$ $\mathrm{CH}_{3} \mathrm{NH}+\mathrm{NH}_{2}$ reaction were thus varied in order to conciliate the experimental and simulated profiles. The adopted values are compared in Figure 8 to the predictions of Zhang et al. and the reaction rate constants determined by $\mathrm{Li}$ et al.. While the rate coefficients derived in this study are close to those of Li et al. at low and atmospheric pressures, the deviation is larger at higher pressures. The second plot of Figure 8 illustrates the effect of the rate parameters adopted for the $\mathrm{MMH}+\mathrm{H}$ reactions on the recommended thermal decomposition rates. Indeed, substituting the value of Sun et al. by our values in the model of $\mathrm{Li}$ et al. results in a faster initial $\mathrm{NH}_{2}$ production rate. On the other hand, adopting the decomposition rates of Li et al. in the present model increases significantly both the production rate and maximum mole fraction of $\mathrm{NH}_{2}$. This illustrates that deriving rate coefficients from a detailed kinetic model is strongly dependent on the accuracy of rate coefficients employed from secondary reactions.
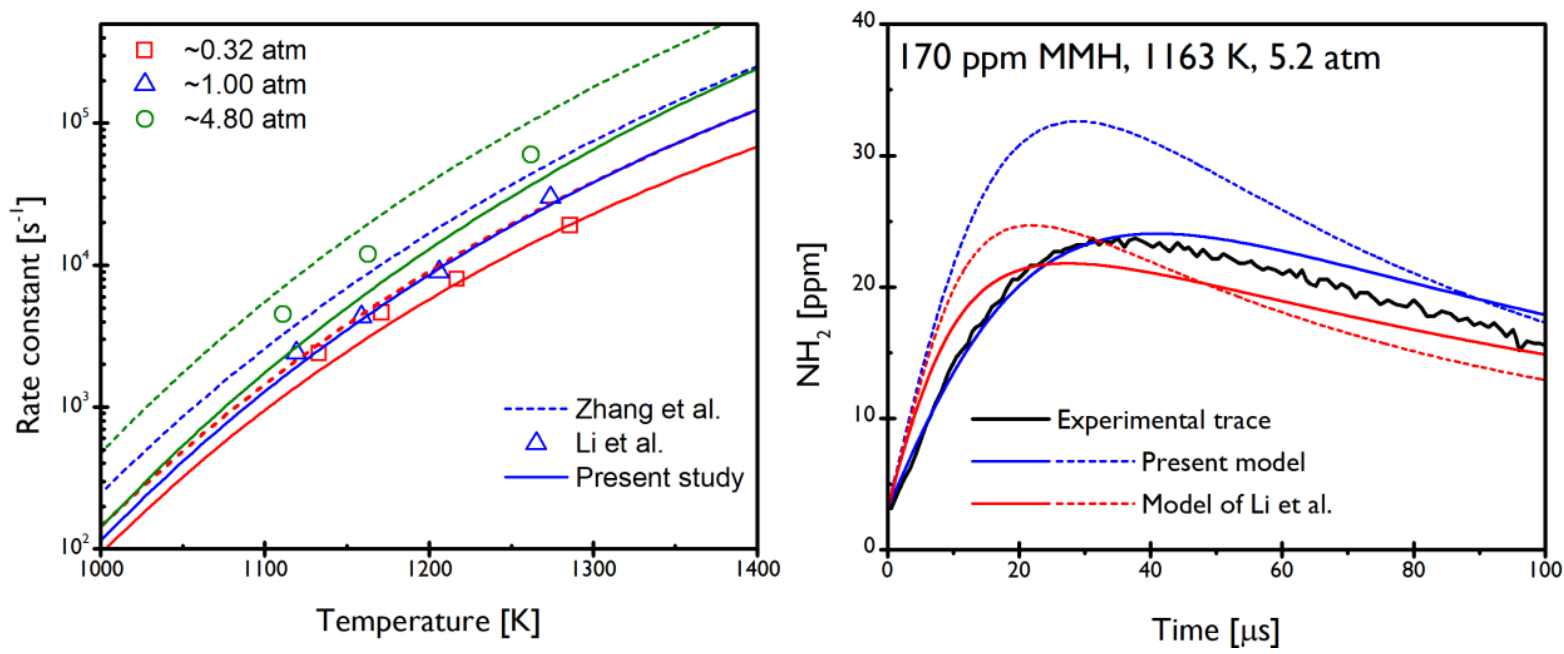

Figure 8: (a)MMH thermal decomposition rate constant (b) Experimental ${ }^{5}$ and simulated $\mathrm{NH}_{2}$ profiles: the solid lines are for the final models while the dashed line are modified models. The modifications are as follow: for the model of $\mathrm{Li}$ et al. the present predicted $\mathrm{MMH}+\mathrm{H}$ rate constants are employed, for the present model the MMH thermal decomposition rate constant recommended by $\mathrm{Li}$ et al. is employed.

The $\mathrm{k}(\mathrm{T}, \mathrm{P})$ values were then turned into a Troe formalism expression (Table 9) in order to (i) keep an extended pressure range validity compared to the Plog formalism and (ii) include Chaperon efficiencies. In highly diluted mixtures, and for temperatures and pressures where some important reactions are in the low-pressure or fall-off regimes, assuming a similar collision efficiency for MMH 
and Ar may lead to an underestimation of the rate constants. However, in the absence of experimental measurements in several bath gases, Chaperon efficiencies remain elusive parameters. Jasper and Miller ${ }^{40}$ numerically investigated the unimolecular kinetics of methane thermal decomposition in eight bath gases. Their predicted low pressure limiting rate constants increases by a factor of $\sim 5$ when the energy transfer collider is changed from $\mathrm{Ar}$ to $\mathrm{CH}_{4}$. Upon this work, and assuming that $\mathrm{MMH}$ is as an efficient collider as $\mathrm{CH}_{4}$, a Chaperon efficiency of $\sim 5.5$ with respect to $\mathrm{Ar}$ was adopted for $\mathrm{MMH}$ in the present model.

\subsubsection{Decomposition of $\mathrm{CH}_{4} \mathrm{~N}$ radicals}

The thermal dissociation of MMH generates the methylamidogen radical as a co-product. $\mathrm{CH}_{3} \mathrm{NH}$ can further decompose into methanimine $\mathrm{CH}_{2} \mathrm{NH}$ or isomerize into an aminomethyl radical $\mathrm{CH}_{2} \mathrm{NH}_{2}$.Moreover, $\mathrm{CH}_{3}$ and $\mathrm{NH}_{2}$ radical recombination in concentrated mixtures may generate methyl amine, which will in turn produce $\mathrm{CH}_{4} \mathrm{~N}$ radicals when reacting with chain carriers. The competition between the isomerization and decomposition channels may affect the overall kinetics of MMH thermal decomposition and thus deserves some attention.

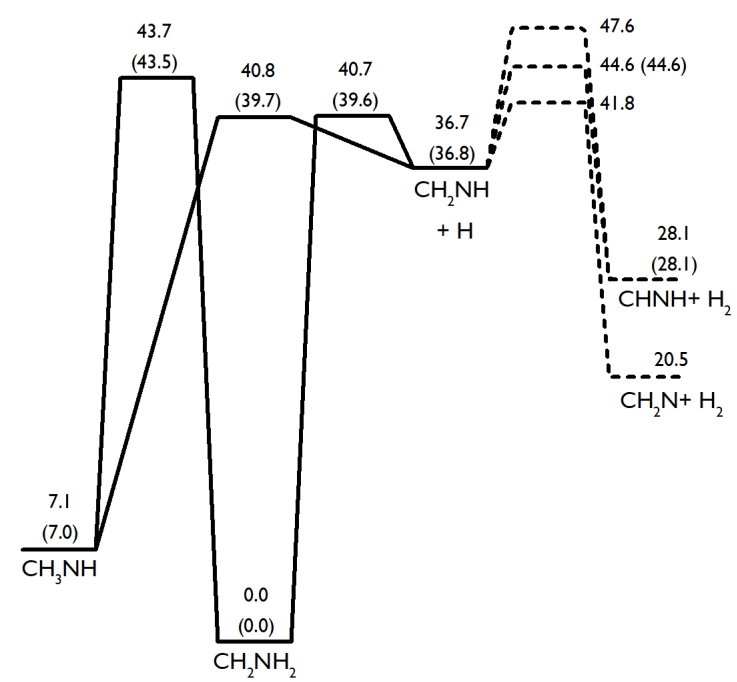

Figure 9: Schematic of $\mathrm{CH}_{4} \mathrm{~N}$ potential energy surface: present values and in brackets energies reported by Balucani et al. ${ }^{41}$. All energies are in $\mathrm{kcal} \mathrm{mol}^{-1}$. 
Dean and Bozzelli ${ }^{42}$ recommended pressure dependent rate constants obtained by a QRRK analysis for the $\mathrm{C}-\mathrm{H}$ and $\mathrm{N}-\mathrm{H}$ bond breaking in $\mathrm{CH}_{3} \mathrm{NH}$ and $\mathrm{CH}_{2} \mathrm{NH}_{2}$ respectively. Balucani et al. ${ }^{41}$ explored the potential energy surface of the $\mathrm{CH}_{4}+\mathrm{N}$ system with energetics evaluated with the W1 composite method. This PES includes the $\mathrm{CH}_{4} \mathrm{~N}$ radicals, but the authors did not provide any rate parameters. As a consequence, this PES has been reexamined at the RCCSD(T)/CBS//M06-2x-D3/augcc-pVTZ level since no pronounced multi-reference character was detected (T1 values lower than 0.03). A schematic of the reaction diagram is shown in Figure 9. There is good agreement between the present stationary points energies and the ones reported by Balucani et al., with a maximum deviation of $1.1 \mathrm{kcal} \mathrm{mol}^{-1}$. Decomposition reactions for the two $\mathrm{CH}_{4} \mathrm{~N}$ radical isomers proceed through transition states of identical energy (40.8 and $\left.40.7 \mathrm{kcal} \mathrm{mol}^{-1}\right)$, while the saddle point for isomerization reaction lies slightly above $\left(+2.9 \mathrm{kcal} \mathrm{mol}^{-1}\right)$, suggesting that a competition between the three paths may exist. Methanimine, the decomposition product, offers three attack sites for the $\mathrm{H}$ atoms, but abstraction on the nitrogen atom is energetically favored over those on the carbon atom (5.1 vs. $\left.7.9 \mathrm{kcal} \mathrm{mol}^{-1}\right)$. Several reaction paths identified in the study of Balucani et al. (C-N bond scissions) were herein neglected as these barrierless channels lie far above the other pathways $\left(83.4 \mathrm{kcal} \mathrm{mol}^{-1}\right.$ for $\left.\mathrm{CH}_{3} \mathrm{NH}=\mathrm{CH}_{3}+\mathrm{NH}\right)$.

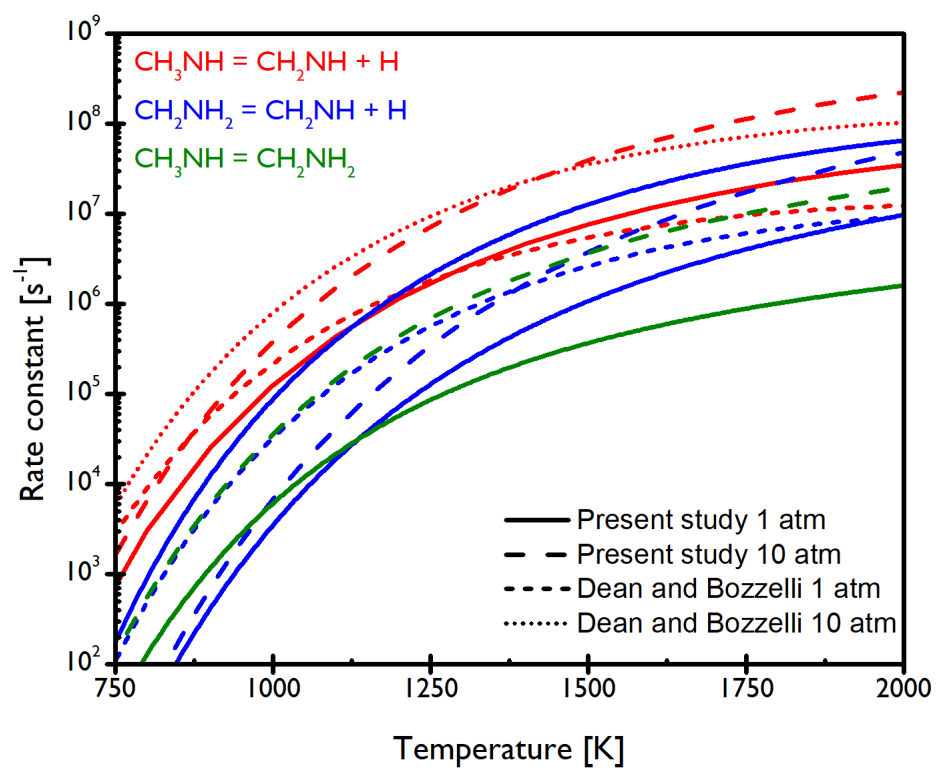

Figure 10: Computed rate constants for the decomposition and isomerization of $\mathrm{CH}_{3} \mathrm{NH}$ and $\mathrm{CH}_{2} \mathrm{NH}_{2}$ radicals at 1 and $10 \mathrm{~atm}$. The solid and the dashed line denote the present calculations and shortdashed and dotted lines the estimations of Dean and Bozzelli ${ }^{42}$. 
A master equation analysis has been performed to assess the temperature and pressure dependence of the three reactions involving the two $\mathrm{CH}_{4} \mathrm{~N}$ radicals. The 12,6-Lennard-Jones parameters of these two wells, mandatory for the modeling of the collision energy transfer rates, were obtained from sphericallyaveraged MP2/aug-cc-pVDZ interaction potentials with Helium according to the methodology devised by Jasper and Miller ${ }^{43}$. We obtained collision diameters of 4.58 and $4.63 \AA$ for $\mathrm{CH}_{3} \mathrm{NH}$ and $\mathrm{CH}_{2} \mathrm{NH}_{2}$ respectively, and well-depth potentials of 129.9 and $118.2 \mathrm{~cm}^{-1}$. Figure 10 compares the predicted rate constants with literature data at two different pressures. Our $\mathrm{CH}_{3} \mathrm{NH}$ decomposition rate coefficients agree well those of Dean and Bozzelli, with a deviation of about a factor 2. On the other side, our predicted $\mathrm{CH}_{2} \mathrm{NH}_{2}$ decomposition rates are much slower, by up to factor 10 around $1000 \mathrm{~K}$. Nevertheless, this reaction is unlikely to play a significant role in MMH pyrolysis since the isomerization reaction is surprisingly slow. Troe fits for the decomposition channels are provided in Table 9 along with a Plog fitting for the isomerization reaction.

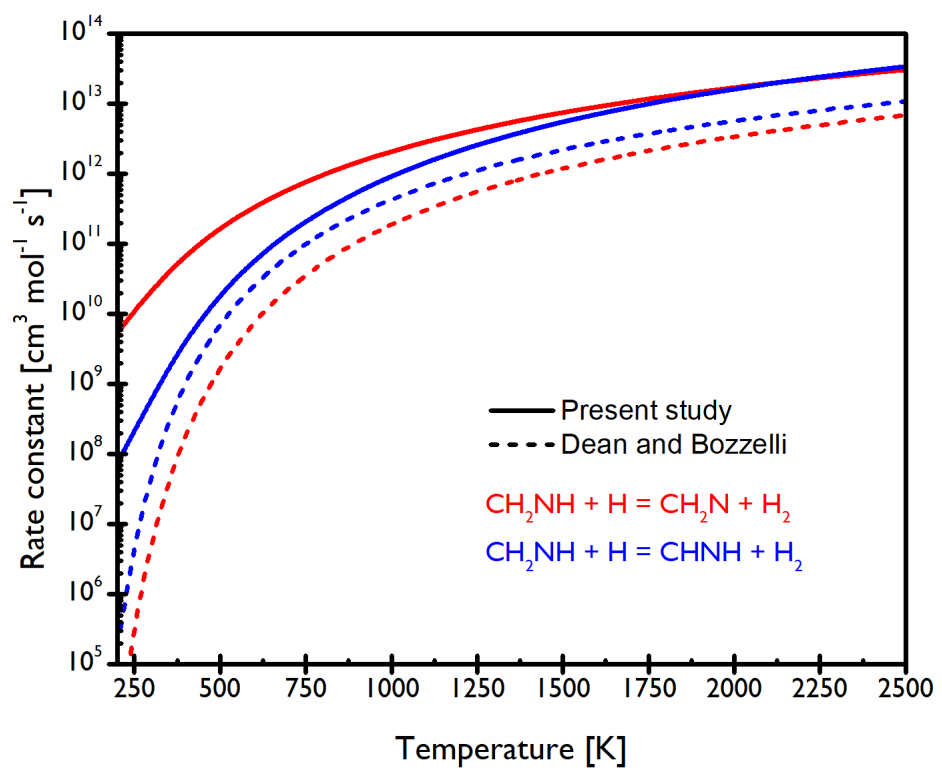

Figure 11: Computed rate constant for the reaction of $\mathrm{H}$ atom with $\mathrm{CH}_{2} \mathrm{NH}$ (abstraction reaction). The solid and the dashed line denote the present calculations and the estimations of Dean and Bozzelli ${ }^{42}$.

The pressure independent rate constants for the $\mathrm{H}$ abstraction reactions on the $\mathrm{CH}_{4} \mathrm{~N}$ potential energy surface have been calculated and are compared to the values recommended by Dean and Bozzelli in Figure 11. Abstraction of the $\mathrm{H}$ atom bonded to the nitrogen is the preferred pathway at low temperatures (below $1250 \mathrm{~K}$ ) but there is a nearly balanced production of both $\mathrm{H}_{2} \mathrm{CN}$ and $\mathrm{CHNH}$ at 
higher temperatures. Our rate coefficients are faster that those recommended by Dean and Bozzelli, especially for the production of the $\mathrm{H}_{2} \mathrm{CN}$ isomer which had been identified as the minor product unlike the present study. Modified Arrhenius fits for the two reactions are given in Table 9.

\subsubsection{Reactions of methyl diazene $\left(\mathrm{CH}_{3} \mathrm{NNH}\right)$ and $\mathrm{N}$ - aminomethanimine $\left(\mathrm{CH}_{2} \mathrm{NNH}_{2}\right)$}

$\mathrm{CH}_{3} \mathrm{NNH}$ and $\mathrm{CH}_{2} \mathrm{NNH}_{2}$ are both $\beta$-scission decomposition products of the MMH radicals. As such, they are expected to be produced in significant amounts, especially from the $\mathrm{CH}_{3} \mathrm{NNH}_{2}$ radical since they are the only decomposition channels. $\mathrm{H}$ abstraction reactions with the $\mathrm{H}, \mathrm{CH}_{3}$, and $\mathrm{NH}_{2}$ scavengers were therefore investigated.

Table 5: Calculated energies of the stationary point for the $\mathrm{CH}_{3} \mathrm{NHNH} / \mathrm{CH}_{2} \mathrm{NNH}+\mathrm{X}\left(\mathrm{X}=\mathrm{H}, \mathrm{NH}_{2}, \mathrm{CH}_{3}\right)$

Abstraction channels

\begin{tabular}{lccc}
\hline Species & Energy $^{\mathbf{1}}$ & Relative energy $^{\mathbf{2}}$ & T $_{\mathbf{1}}$ diagnostic \\
\hline $\mathrm{CH}_{3} \mathrm{NNH}$ & -149.733185 & & 0.012 \\
$\mathrm{CH}_{2} \mathrm{NNH}_{2}$ & -149.736405 & & 0.013 \\
$\mathrm{CH}_{3} \mathrm{~N}_{2}$ & -149.130460 & & 0.025 \\
$\mathrm{CH}_{2} \mathrm{NNH}$ & -149.092942 & & 0.040 \\
$\mathrm{HCNNH}$ & -149.076467 & & 0.028 \\
$\mathrm{CH}_{3} \mathrm{NNH}+\mathrm{H} \rightarrow \mathrm{H}_{2}+\mathrm{CH}_{3} \mathrm{~N}_{2}$ & -150.230798 & 1.51 & 0.025 \\
$\mathrm{CH}_{3} \mathrm{NNH}+\mathrm{H} \rightarrow \mathrm{H}_{2}+\mathrm{CH}_{2} \mathrm{NNH}$ & -150.218601 & 9.16 & 0.023 \\
$\mathrm{CH}_{3} \mathrm{NNH}+\mathrm{CH}_{3} \rightarrow \mathrm{CH}_{4}+\mathrm{CH}_{3} \mathrm{~N}_{2}$ & -189.477889 & 2.99 & 0.024 \\
$\mathrm{CH}_{3} \mathrm{NNH}+\mathrm{CH}_{3} \rightarrow \mathrm{CH}_{4}+\mathrm{CH}_{2} \mathrm{NNH}$ & -189.463530 & 12.00 & 0.021 \\
{$\left[\mathrm{CH}_{3} \mathrm{NNH}---\mathrm{NH}_{3}\right]$} & -205.539362 & -2.82 & 0.013 \\
$\mathrm{CH}_{3} \mathrm{NNH}+\mathrm{NH}_{2} \rightarrow \mathrm{NH}_{3}+\mathrm{CH}_{3} \mathrm{~N}_{2}$ & -205.535158 & -0.18 & 0.027 \\
$\mathrm{CH}_{3} \mathrm{NNH}+\mathrm{NH}_{2} \rightarrow \mathrm{NH}_{3}+\mathrm{CH}_{2} \mathrm{NNH}$ & -205.519522 & 9.63 & 0.027 \\
$\mathrm{CH}_{2} \mathrm{NNH}_{2}+\mathrm{H} \rightarrow \mathrm{H}_{2}+\mathrm{CH}_{2} \mathrm{NNH}$ & -150.225322 & 6.97 & 0.027 \\
$\mathrm{CH}_{2} \mathrm{NNH}_{2}+\mathrm{H} \rightarrow \mathrm{H}_{2}+\mathrm{HCNNH}_{2}$ & -150.220408 & 10.05 & 0.023 \\
$\mathrm{CH}_{2} \mathrm{NNH}_{2}+\mathrm{CH}_{3} \rightarrow \mathrm{CH}_{4}+\mathrm{CH}_{2} \mathrm{NNH}$ & -189.470583 & 9.59 & 0.025 \\
$\mathrm{CH}_{2} \mathrm{NNH}_{2}+\mathrm{CH}_{3} \rightarrow \mathrm{CH}_{4}+\mathrm{HCNNH}_{2}$ & -189.463931 & 13.77 & 0.021 \\
$\mathrm{CH}_{2} \mathrm{NNH}_{2}+\mathrm{NH}_{2} \rightarrow \mathrm{NH}_{3}+\mathrm{CH}_{2} \mathrm{NNH}$ & -205.531383 & 4.21 & 0.035 \\
$\mathrm{CH}_{2} \mathrm{NNH}_{2}+\mathrm{NH}_{2} \rightarrow \mathrm{NH}_{3}+\mathrm{HCNNH}_{2}$ & -205.525164 & 8.11 & 0.030 \\
\hline
\end{tabular}

${ }^{1}$ Zero point vibrational corrected energy in Hartree. Energies evaluated at the RCCSD(T)/aug-cc-pVoZ//M06-2x-D3/augcc-pVTZ level of theory

${ }^{2}$ Energy in kcal mol ${ }^{-1}$ relative to $\mathrm{CH}_{3} \mathrm{NNH}+\mathrm{X}$ or $\mathrm{CH}_{2} \mathrm{NNH}_{2}+\mathrm{X}$.

Methyldiazene offers two abstraction locations to yield either the $\mathrm{CH}_{3} \mathrm{~N}_{2}$ or the $\mathrm{CH}_{2} \mathrm{NNH}$ radicals. Energetics of the reactant and saddle points are reported in Table 5 whereas their properties (vibrational 
frequencies and rotational constants) are given in the Supplementary Material. The attack on the carbon site is calculated to proceed through an 8 to $10 \mathrm{kcal} \mathrm{mol}^{-1}$ energetically more demanding barrier than on the nitrogen site, causing this channel little to occur at low and intermediate temperatures. The energy of the saddle point for the reaction of $\mathrm{CH}_{3} \mathrm{NNH}+\mathrm{NH}_{2}$ is submerged, suggesting the existence of a molecular complex connecting this saddle point and the reactants. In this complex, there are two intermolecular hydrogen bonds(between the central nitrogen atom and one of the $\mathrm{H}$ atoms of the $\mathrm{NH}_{2}$ radical, and between the $\mathrm{N}$ atom of amidogen and the $\mathrm{H}$ atom carried by the terminal nitrogen group of $\mathrm{CH}_{3} \mathrm{NNH}$ ) lowering the overall energy by $2.8 \mathrm{kcal} \mathrm{mol}^{-1}$.

A comparison of the energy barriers for a radical attack on the $\mathrm{C}-\mathrm{H}$ bond between the similar reactions of $\mathrm{MMH}$ and $\mathrm{CH}_{3} \mathrm{NNH}$ reveals that reactions with the former are easier. The energy barriers for the reaction with $\mathrm{H}$ and $\mathrm{NH}_{2}$ are about $4 \mathrm{kcal} \mathrm{mol}^{-1}$ higher for the unsaturated species, and nearly identical when the abstracter is the methyl radical. This observation is surprising since the reaction product, $\mathrm{CH}_{2} \mathrm{NNH}$, is a resonantly stabilized radical, and as such, one would have expected a faster abstraction rate constant as usually observed for unsaturated hydrocarbons $\left(\mathrm{C}_{3} \mathrm{H}_{6}\right.$ vs. $\mathrm{C}_{3} \mathrm{H}_{8}, 7.6$ vs. 9.9 for the reaction with $\mathrm{H}$ energy barriers).

The CCSD(T)/CBS//M06-2x/aug-cc-pVTZ predictions for the rate constants of methyldiazene with $\mathrm{H}, \mathrm{CH}_{3}$, and $\mathrm{NH}_{2}$ are illustrated in Figure 12. The branching ratios between the two abstraction sites are also displayed. The predictions are in good agreement with the experimental data collected at low temperatures $(296-383 \mathrm{~K})$ by Vidyarthi et al. ${ }^{44}$ for the reaction $\mathrm{CH}_{3} \mathrm{NNH}+\mathrm{CH}_{3}$. Cook et al. ${ }^{4}$, in an attempt to match the experimental and computed $\mathrm{NH}_{3}$ profiles, recommended a rate constant of $3.710^{14} \times \exp (-2620 / \mathrm{T})$. This rate constant is displayed as a dashed line in Figure 12, and is 10 to 35 times greater than the present predictions, well beyond the uncertainties associated to the present calculations. Three parameters Arrhenius expressions for the six reactions are reported in Table 9. 


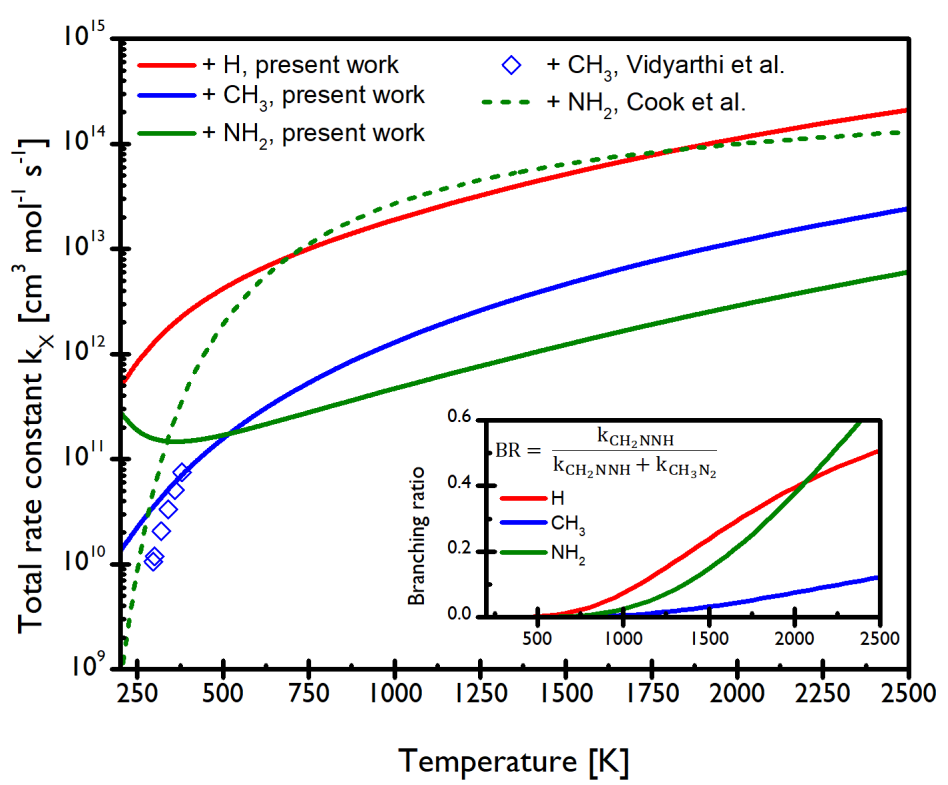

Figure 12: Computed rate constant and branching ratio (insert) for the reaction of $\mathrm{H}, \mathrm{CH}_{3}$, and $\mathrm{NH}_{2}$ with methyldiazene $\mathrm{CH}_{3} \mathrm{NNH}$ (abstraction reactions). The solid denote the present calculations, the dashed line the recommended rate constant of Cook et al. ${ }^{4}$, and the symbols the experimental measurements of Vidyarthi et al. ${ }^{44}$.

$\mathrm{H}$ abstraction on $\mathrm{N}$-aminomethanimine, like on $\mathrm{CH}_{3} \mathrm{NNH}$, can occur at two different locations, either the amino or the methylidene group, to produce $\mathrm{CH}_{2} \mathrm{NNH}$ or $\mathrm{HCNNH}_{2}$ radicals, respectively. Although the breaking of the $\mathrm{N}-\mathrm{H}$ bond is expected to be easier than the $\mathrm{C}-\mathrm{H}$ one, both pathways were examined. Properties and energy of the entrance channel and the transitions states are reported in Table 5. 


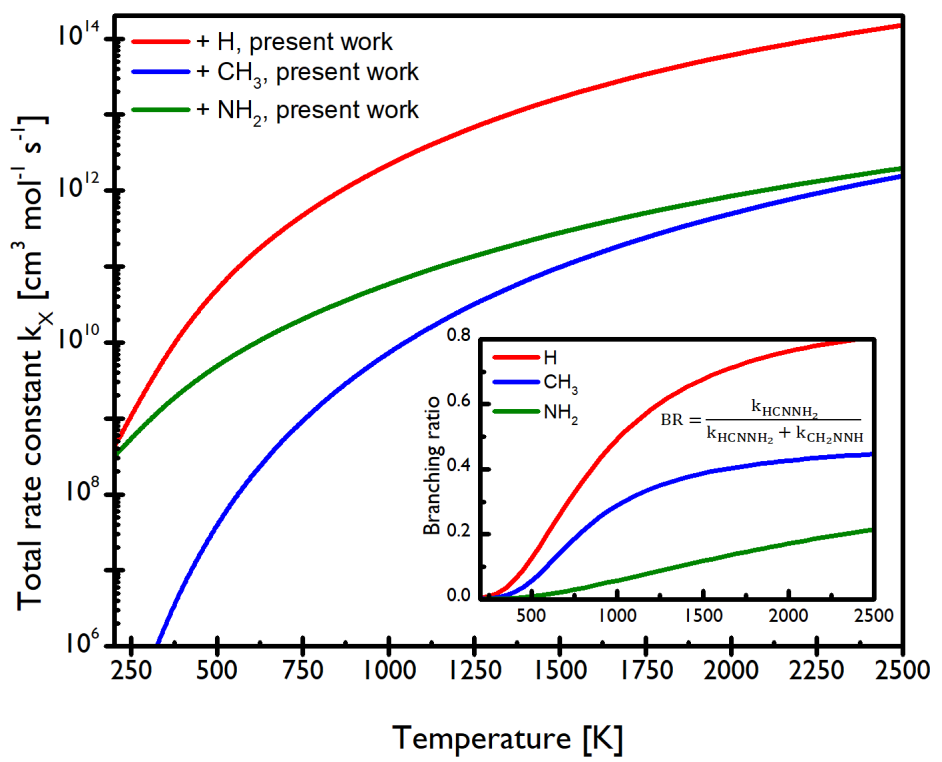

Figure 13: Computed rate constant and branching ratio (insert) for the reaction of $\mathrm{H}, \mathrm{CH}_{3}$, and $\mathrm{NH}_{2}$ with $\mathrm{N}$-aminomethanimine $\mathrm{CH}_{2} \mathrm{NNH}_{2}$ (abstraction reactions).

In line with the C-H and N-H bond energy dissociations, calculated to be 101.7 and $91.1 \mathrm{kcal} \mathrm{mol}^{-}$ ${ }^{1}$ from Table 2, the energy barriers for the abstraction of the $\mathrm{H}$ atoms bonded to the carbon are 3 to $4 \mathrm{kcal} \mathrm{mol}^{-1}$ higher than for the abstraction on the amino group. Regarding the formation of the $\mathrm{CH}_{2} \mathrm{NNH}$ radical, as previously observed from methyldiazene, the computed energy barriers are 1.5 to $3.5 \mathrm{kcal} \mathrm{mol}^{-1}$ higher than for the similar reactions from $\mathrm{MMH}$, despite the resonance in the $\mathrm{CH}_{2} \mathrm{NNH}$ radical. Total rate constant predictions from $\mathrm{RCCSD}(\mathrm{T}) / \mathrm{CBS} / \mathrm{M} 06-2 \mathrm{x} / \mathrm{aug}-\mathrm{cc}-\mathrm{pVTZ}$ energetics are displayed in Figure 13, as well as the branching ratios between the two reaction products. The reaction with the $\mathrm{H}$ atoms is the fastest, followed by the reaction with $\mathrm{NH}_{2}$, and finally with $\mathrm{CH}_{3}$, in contrast with the previous observations for $\mathrm{CH}_{3} \mathrm{NNH}$ for which the $\mathrm{H}$ abstraction with $\mathrm{NH}_{2}$ was the slowest. Moreover, the rate constants with $\mathrm{CH}_{3} \mathrm{NNH}$ are significantly larger (one order of magnitude) than with $\mathrm{CH}_{2} \mathrm{NNH}_{2}$, suggesting that $\mathrm{N}$-aminonethanimine may be a bottle neck in the thermal degradation of $\mathrm{MMH}$, with a substantial residual concentration in the pyrolysis gases. Concerning the distribution between the two radical products, $\mathrm{CH}_{2} \mathrm{NNH}$ is the main reaction output regardless of the temperature in the reaction with $\mathrm{NH}_{2}$ and $\mathrm{CH}_{3}$, although $\mathrm{HCNNH}_{2}$ accounts for 30 to $40 \%$ above $1000 \mathrm{~K}$ in the latter reaction, and more surprisingly is the main channel in the reaction with $\mathrm{H}$ atoms for temperature larger than $1000 \mathrm{~K}$. Modified Arrhenius expressions for these rate coefficients are given in Table 8. 


\subsection{7. $\mathrm{N}_{2} \mathrm{H}_{3} / \mathrm{N}_{2} \mathrm{H}_{2}$ subset}

$\mathrm{N}_{2} \mathrm{H}_{3}$ decomposition. $\mathrm{N}_{2} \mathrm{H}_{3}$ is an intermediate in the pyrolysis of $\mathrm{MMH}$, produced either by direct thermal decomposition of the fuel, or through the chemically activated recombination of $\mathrm{NH}_{2}$ radicals. The doublet and quartet state potential energy surfaces of $\mathrm{N}_{2} \mathrm{H}_{3}$ have been explored by Klippenstein et al. ${ }^{45}$ at the $\operatorname{CCSD}(\mathrm{T}) / \mathrm{CBS} / / \mathrm{CCSD}(\mathrm{T}) /$ aug-cc-pVDZ level of theory. While rate constant were derived for the $\mathrm{NH}_{2}+\mathrm{NH} \rightleftarrows \mathrm{N}_{2} \mathrm{H}_{2}+\mathrm{H}$ channel and published, no data were proposed for the $\mathrm{N}_{2} \mathrm{H}_{3}$ decomposition channels that are required for the present work. Therefore, a master equation analysis was performed with $\mathrm{RCCSD}(\mathrm{T}) / \mathrm{CBS} / / \mathrm{M} 06-2 \mathrm{x}-\mathrm{D} 3 /$ aug-cc-pVTZ energetics. A schematic diagram of the reactions pathways considered is given in Figure 14. Our energies are in excellent agreement with those reported in Klippenstein and co-workers ${ }^{45}$. The high pressure limit recombination rate constant for the entrance channel $\mathrm{NH}_{2}+\mathrm{NH}$ determined by Klippenstein et al. was used as an input parameter in the master equation analysis through the ILT option of the MESMER code. Lennard-Jones parameters from the Chemkin database were adopted for the well $\left(\sigma=3.90 \AA\right.$ and $\left.\varepsilon / \mathrm{k}=287.8 \mathrm{~cm}^{-1}\right)$. The predicted rate constant for the $\mathrm{NH}_{2}+\mathrm{NH} \rightleftarrows \mathrm{N}_{2} \mathrm{H}_{2}+\mathrm{H}$ reaction agrees very well with the literature value (within 10\%) indicating that predictions for the other channels are reliable. Rate coefficients for the $\mathrm{N}_{2} \mathrm{H}_{3}$ decomposition channels $\left(\mathrm{N}_{2} \mathrm{H}_{3} \rightleftarrows \mathrm{N}_{2} \mathrm{H}_{2}+\mathrm{H}\right.$ and $\left.\mathrm{N}_{2} \mathrm{H}_{3} \rightleftarrows \mathrm{NH}_{2}+\mathrm{NH}\right)$ were fitted into modified Arrhenius expressions within the Troe formalism and are given in Table 9. 


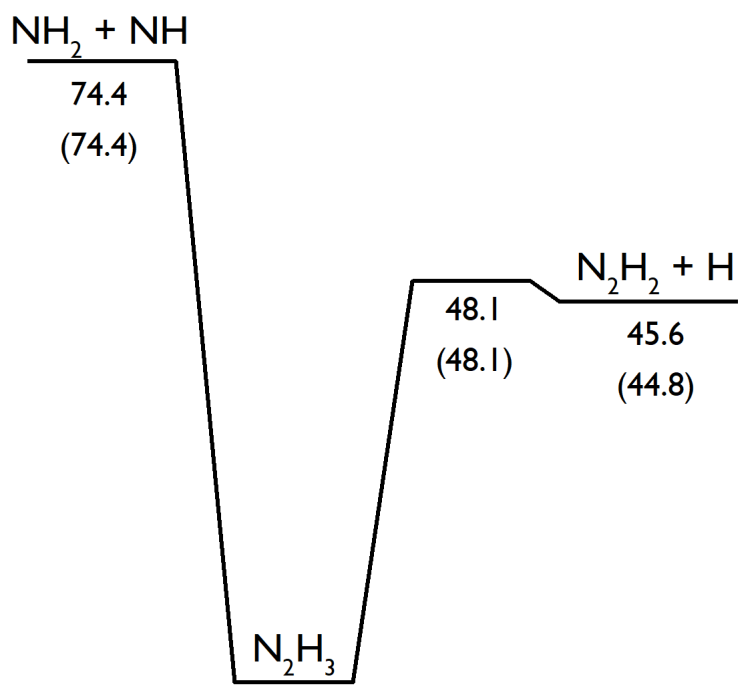

Figure 14: Schematic of the doublet state $\mathrm{N}_{2} \mathrm{H}_{3}$ potential energy surface:present values and value of Klippenstein et al. ${ }^{45}$ in brackets. All energies are in $\mathrm{kcal} \mathrm{mol}^{-1}$

$N_{2} H_{3}+X$. The $\mathrm{H}$ abstraction reactions from $\mathrm{N}_{2} \mathrm{H}_{3}$ by $\mathrm{H}, \mathrm{CH}_{3}$, and $\mathrm{NH}_{2}$ have also been investigated. Either diazene $\mathrm{N}_{2} \mathrm{H}_{2}$ or isodiazene $\mathrm{H}_{2} \mathrm{NN}$ can be produced through these reactions. The rovibrationnal properties and energies of the relevant stationary points are given in Table 6. The triplet state configuration of the transition states results in $\mathrm{T}_{1}$ diagnostics values that are relatively large $(0.029$ 0.038), but still within the reliability of single reference calculations. Calculated energy barriers show that abstraction on the nitrogen radical site is favored with $\mathrm{H}$ and $\mathrm{NH}_{2}$ as the abstracter, whereas the formation of trans-diazene is the preferred path when reacting with $\mathrm{CH}_{3}$. Regardless of the co-reactant, the formation of cis-diazene from these $\mathrm{H}$ abstraction reactions is very unlikely since the associated saddle points lie about 3 to $9 \mathrm{kcal} \mathrm{mol}^{-1}$ above the $\mathrm{t}-\mathrm{N}_{2} \mathrm{H}_{2}$ ones. Rate constants for these six channels are displayed in Figure 15, and are in line with the energetic trend, with the exception of the reaction with $\mathrm{NH}_{2}$, for which the formation of $\mathrm{H}_{2} \mathrm{NN}$ is indeed the main reaction outcome below $950 \mathrm{~K}$ but beyond is submerged by the diazene channel. 
Table 6: Calculated stationary point properties for $\mathrm{NH}_{2} \mathrm{NH}+\mathrm{X}\left(\mathrm{X}=\mathrm{H}, \mathrm{NH}_{2}, \mathrm{CH}_{3}\right)$ Abstraction channels

\begin{tabular}{|c|c|c|c|c|c|}
\hline Species & Energy ${ }^{1}$ & $\begin{array}{l}\text { Relative } \\
\text { energy }^{2}\end{array}$ & $\mathbf{T}_{1}$ diagnostic & Frequencies $^{3}$ & $\mathbf{B}^{4}$ \\
\hline $\mathrm{NH}_{2} \mathrm{NH}$ & -111.075511 & & 0.025 & $512,698,1130,1269,1467,1638,3400,3477,3623$ & $0.913,1.038,6.903$ \\
\hline $\mathrm{NH}_{2} \mathrm{NH}+\mathrm{H} \rightarrow \mathrm{H}_{2} \mathrm{NN}+\mathrm{H}_{2}$ & -111.571192 & 2.7 & 0.035 & $\begin{array}{l}387,441,572,788,1089,1256,1328,1599,1644,3468, \\
3607,1182 \mathrm{i}\end{array}$ & $0.706,0.952,2.621$ \\
\hline $\mathrm{NH}_{2} \mathrm{NH}+\mathrm{H} \rightarrow \mathrm{N}_{2} \mathrm{H}_{2}+\mathrm{H}_{2}$ & -111.560191 & 9.6 & 0.036 & $\begin{array}{l}258,405,520,826,1072,1247,1415,1435,1509,3424, \\
3509,1931 \mathrm{i}\end{array}$ & $0.684,0.859,3.157$ \\
\hline $\mathrm{NH}_{2} \mathrm{NH}+\mathrm{NH}_{2} \rightarrow \mathrm{H}_{2} \mathrm{NN}+\mathrm{NH}_{3}$ & -166.871932 & 3.3 & 0.034 & $\begin{array}{l}97,129,279,466,514,568,779,1106,1152,1364,1418, \\
1443,1539,3378,3388,3472,3545,1911 \mathrm{i}\end{array}$ & $0.160,0.174,1.433$ \\
\hline $\mathrm{NH}_{2} \mathrm{NH}+\mathrm{NH}_{2} \rightarrow \mathrm{H}_{2} \mathrm{NN}+\mathrm{NH}_{3}$ & -166.867294 & 6.9 & 0.038 & $\begin{array}{l}144,176,386,535,590,662,894,990,1257,1280,1507, \\
1534,1613,3361,3433,3454,3592,1044 \mathrm{i}\end{array}$ & $0.181,0.211,1.079$ \\
\hline $\mathrm{NH}_{2} \mathrm{NH}+\mathrm{CH}_{3} \rightarrow \mathrm{H}_{2} \mathrm{NN}+\mathrm{CH}_{4}$ & -150.815547 & 5.9 & 0.029 & $\begin{array}{l}109,164,315,499,523,590,611,1021,1102,1223,1263 \\
1404,1415,1485,1609,3051,3193,3205,3451,3587,1366 \mathrm{i}\end{array}$ & $0.169,0.193,1.029$ \\
\hline $\mathrm{NH}_{2} \mathrm{NH}+\mathrm{CH}_{3} \rightarrow \mathrm{H}_{2} \mathrm{NN}+\mathrm{CH}_{4}$ & -150.816981 & 5.0 & 0.029 & $\begin{array}{l}39,130,233,386,491,537,590,1067,1117,1160,1323, \\
1412,1415,1421,1512,3047,3187,3189,3397,3526,1778 \mathrm{i}\end{array}$ & $0.153,0.168,1.273$ \\
\hline
\end{tabular}

${ }^{1}$ Zero point vibrational corrected energy in Hartree. Energies evaluated at the RCCSD(T)/aug-cc-pVœZ//M06-2x-D3/aug-cc-pVTZ level of theory

${ }^{2}$ Energy in kcal $\mathrm{mol}^{-1}$ relative to $\mathrm{NH}_{2} \mathrm{NH}+\mathrm{X}$.

${ }^{3}$ Scaled harmonic vibrational frequencies in $\mathrm{cm}^{-1}$, italic values are associated to hindered internal rotors

${ }^{4}$ Rotational constants in $\mathrm{cm}^{-1}$ 


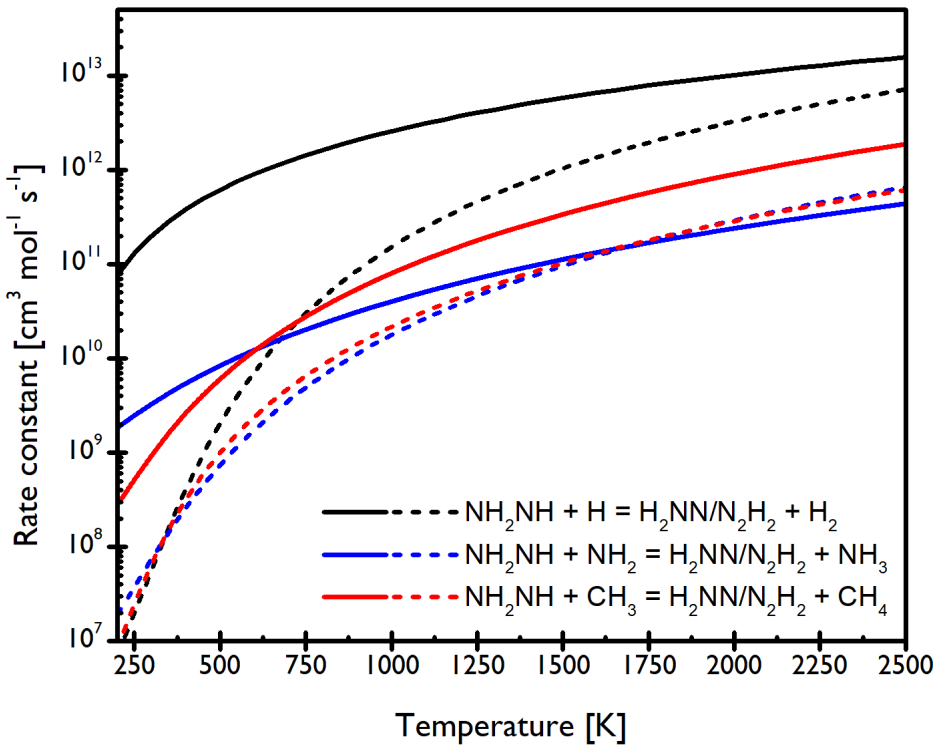

Figure 15: Computed rate constants for the $\mathrm{H}$ abstraction reactions from $\mathrm{NH}_{2} \mathrm{NH}$ by $\mathrm{H}, \mathrm{NH}_{2}$, and $\mathrm{CH}_{3}$. Channels producing $\mathrm{H}_{2} \mathrm{NN}$ and $\mathrm{N}_{2} \mathrm{H}_{2}$ are displayed as solid and dashed lines, respectively.

$\mathrm{N}_{2} \mathrm{H}_{2}+\mathrm{X}$. The reactions of diazene with several scavengers $\left(\mathrm{H}, \mathrm{CH}_{3}, \mathrm{NH}_{2}\right)$ through direct $\mathrm{H}$ abstraction to produce the diazenyl radical $\mathrm{N}_{2} \mathrm{H}$ have been studied. There exist two isomers of diazene, trans and cis, and the interconversion between the two proceeds by internal rotation along the double bond. The insert of Figure 16 shows the relative distribution between the two isomers as a function of the temperature. Trans-diazene, because of its lower heat of formation, is predominant but at combustion temperatures, the cis form accounts for about 20 to $30 \%$ of total diazene. As a consequence reactions with both isomers have to be considered and the saddle points properties of these six reactions are reported in Table 7.

Linder and co-workers ${ }^{46}$ have also reported energy barriers for the reactions trans- $\mathrm{N}_{2} \mathrm{H}_{2}+\mathrm{H}$ and trans- $\mathrm{N}_{2} \mathrm{H}_{2}+\mathrm{NH}_{2}$. Those energies have been obtained from ab initio MCSCF and multireference CI calculations, and used to derive the reaction rate constants through VTST. The present calculations did not exhibit a strong multireference character, as indicated by the relatively small $\mathrm{T} 1$ diagnostic values (0.028-0.033). For the two aforementioned reactions, both the energy barrier and the heat of reactions herein calculated are lower than the MCSCF values, by about 2.9 and $4.5 \mathrm{kcal} \mathrm{mol}^{-1}$ for $\mathrm{H}$ and $\mathrm{NH}_{2}$ as co-reactant, respectively. On the other hand, the trans- $\mathrm{N}_{2} \mathrm{H}_{2}+\mathrm{X}$ reactions exhibit the same features as 
the similar reactions $\mathrm{CH}_{3} \mathrm{NNH}+\mathrm{X} \rightleftarrows \mathrm{CH}_{3} \mathrm{~N}_{2}+\mathrm{HX}$ with energy barriers in very close agreement and the existence of a molecular complex when reacting with $\mathrm{NH}_{2}$. Regarding the cis isomer, its energy barriers are consistently lower than the trans-isomer, by $1.5,2.5$, and $4.6 \mathrm{kcal} \mathrm{mol}^{-1}$ for the reactions with $\mathrm{H}, \mathrm{CH}_{3}$, and $\mathrm{NH}_{2}$, respectively.

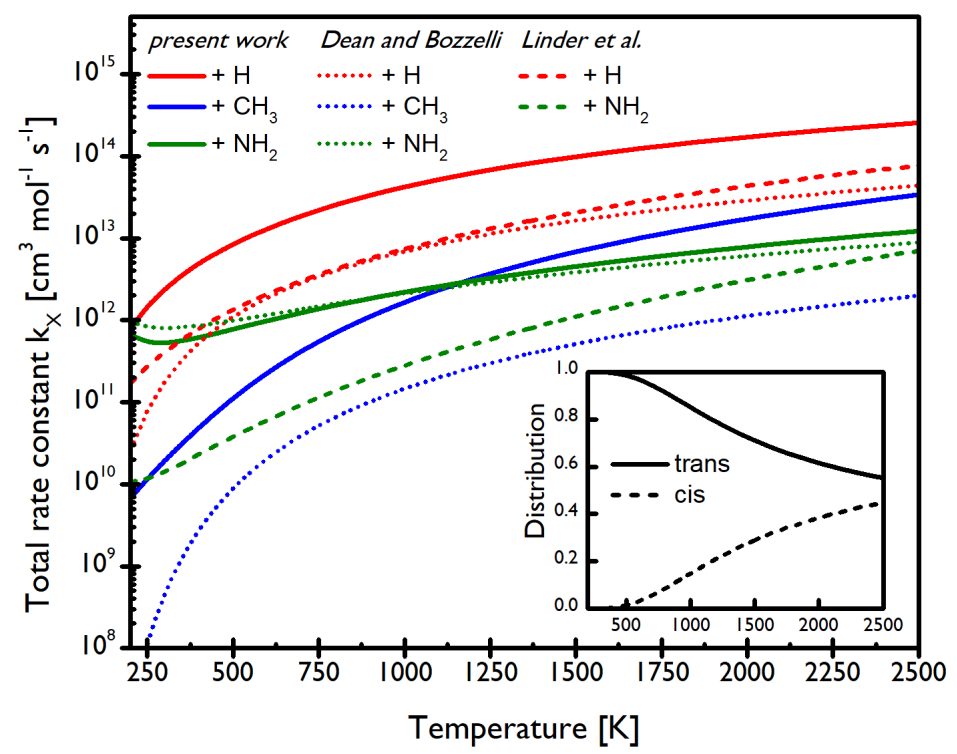

Figure 16: Computed rate constants for the $\mathrm{H}$ abstraction reactions from $\mathrm{N}_{2} \mathrm{H}_{2}$ by $\mathrm{H}, \mathrm{NH}_{2}$, and $\mathrm{CH}_{3}$. The solid lines denote the present predictions, the dashed line the computed rate constants of Linder et al. ${ }^{46}$, and the dotted lines the estimations of Dean and Bozzelli ${ }^{42}$. The insert shows the temperature distribution between the two $\mathrm{N}_{2} \mathrm{H}_{2}$ isomers.

Computed rate constants are displayed in Figure 16. They are distribution-weighted averages of the cis and trans single rate constants, with the trans rate constant being systematically lower than the cis one, resulting in overall rate constants that are higher than if only the trans isomer would have been considered. As it could be expected from the saddle point energies, the rate coefficient of Linder et al. are 4 to 20 times smaller than the present predictions in the temperature range $500-1500 \mathrm{~K}$. Dean and Bozzelli have estimated rate constants from analogy rules and Evans-Polanyi relationships. These estimations are about 10 times smaller than the present predictions for the reactions with $\mathrm{H}$ and $\mathrm{CH}_{3}$, while they are in excellent agreement for $\mathrm{NH}_{2}$. The rate coefficients have been fitted by three-parameter Arrhenius expressions that are given in Table 9. 
Table 7: Calculated stationary point properties for $\mathrm{N}_{2} \mathrm{H}_{2}+\mathrm{X}\left(\mathrm{X}=\mathrm{H}, \mathrm{NH}_{2}, \mathrm{CH}_{3}, \mathrm{NH}_{2} \mathrm{NH}\right)$ abstraction channels

\begin{tabular}{|c|c|c|c|c|c|}
\hline Species & Energy $^{1}$ & $\begin{array}{l}\text { Relative } \\
\text { energy }^{2}\end{array}$ & $\mathbf{T}_{1}$ diagnostic & Frequencies $^{3}$ & $\mathbf{B}^{4}$ \\
\hline $\mathrm{tN}_{2} \mathrm{H}_{2}$ & -110.502850 & & 0.012 & $1336,1346,1590,1695,3241,3275$ & $1.185,1.341,10.232$ \\
\hline $\mathrm{N}_{2} \mathrm{H}$ & -109.903040 & & 0.029 & $1099,1927,2868$ & $1.475,1.579,22.319$ \\
\hline $\mathrm{tN}_{2} \mathrm{H}_{2}+\mathrm{H} \rightarrow \mathrm{N}_{2} \mathrm{H}+\mathrm{H}_{2}$ & -111.000069 & $\begin{array}{l}1.76 \\
{[4.3]}\end{array}$ & 0.028 & $250,418,1296,1296,1512,1688,2105,3231,676 \mathrm{i}$ & $0.814,1.079,3.317$ \\
\hline $\mathrm{cN}_{2} \mathrm{H}_{2}+\mathrm{H} \rightarrow \mathrm{N}_{2} \mathrm{H}+\mathrm{H}_{2}$ & -110.994515 & 0.29 & 0.021 & $268,305,1261,1354,1514,1689,2692,3155,546 \mathrm{i}$ & $0.807,1.231,2.338$ \\
\hline $\mathrm{tN}_{2} \mathrm{H}_{2}+\mathrm{CH}_{3} \rightarrow \mathrm{N}_{2} \mathrm{H}_{2}+\mathrm{CH}_{4}$ & -150.247374 & 3.10 & 0.027 & $\begin{array}{l}115,171,310,505,609,615,1129,1329,1394,1404,1406, \\
1529,1730,3065,3192,3223,3226,1304 \mathrm{i}\end{array}$ & $0.169,0.186,1.358$ \\
\hline $\mathrm{cN}_{2} \mathrm{H}_{2}+\mathrm{CH}_{3} \rightarrow \mathrm{N}_{2} \mathrm{H}_{2}+\mathrm{CH}_{4}$ & -150.243532 & 0.56 & 0.027 & $\begin{array}{l}115,158,292,426,566,656,1284,1321,1397,1399,1405, \\
1564,1791,3056,3100,3211,3228,888 \mathrm{i}\end{array}$ & $0.166,0.185,1.225$ \\
\hline$\left[\mathrm{tN}_{2} \mathrm{H}_{2}---\mathrm{NH}_{2}\right]$ & -166.308951 & -2.77 & 0.014 & $\begin{array}{l}146,173,181,238,276,301,1345,1352,1501,1602,1694, \\
3225,3263,3363,3455\end{array}$ & $0.154,0.175,1.272$ \\
\hline $\mathrm{tN}_{2} \mathrm{H}_{2}+\mathrm{NH}_{2} \rightarrow \mathrm{N}_{2} \mathrm{H}+\mathrm{NH}_{3}$ & -166.304440 & $\begin{array}{l}0.06 \\
{[4.4]}\end{array}$ & 0.030 & $\begin{array}{l}79,151,345,564,639,1172,1337,1508,1557,1585,1809, \\
3227,3346,3438,712 \mathrm{i}\end{array}$ & $0.175,0.195,1.480$ \\
\hline$\left[\mathrm{cN}_{2} \mathrm{H}_{2}---\mathrm{NH}_{2}\right]$ & -166.304021 & -4.63 & 0.019 & $\begin{array}{l}111,145,165,204,369,462,1302,1388,1514,1533,1693 \text {, } \\
3024,3090,3380,3468\end{array}$ & $0.165,0.185,1.231$ \\
\hline $\mathrm{cN}_{2} \mathrm{H}_{2}+\mathrm{NH}_{2} \rightarrow \mathrm{N}_{2} \mathrm{H}+\mathrm{NH}_{3}$ & -166.303863 & -4.53 & 0.028 & $\begin{array}{l}110,166,351,532,656,1307,1349,1474,1523,1667,2556, \\
2942,3364,3455,211 \mathrm{i}\end{array}$ & $0.187,0.213,1.258$ \\
\hline $\mathrm{tN}_{2} \mathrm{H}_{2}+\mathrm{NH}_{2} \mathrm{NH} \rightarrow \mathrm{N}_{2} \mathrm{H}+\mathrm{N}_{2} \mathrm{H}_{4}$ & -221.565060 & 8.35 & 0.033 & $\begin{array}{l}92,141,252,365,451,596,619,780,1147,1196,1342, \\
1362,1470,1629,1655,1760,3097,3439,3502,3621,1951 \mathrm{i}\end{array}$ & $0.115,0.138,0.574$ \\
\hline
\end{tabular}

${ }^{1}$ Zero point vibrational corrected energy in Hartree. Energies evaluated at the RCCSD(T)/aug-cc-pVœZ//M06-2x-D3/aug-cc-pVTZ level of theory

${ }^{2}$ Energy in kcal mol ${ }^{-1}$ relative to $\mathrm{N}_{2} \mathrm{H}_{2}+\mathrm{X}$.

${ }^{3}$ Scaled harmonic vibrational frequencies in $\mathrm{cm}^{-1}$, italic values are associated to hindered internal rotors

${ }^{4}$ Rotational constants in $\mathrm{cm}^{-1}$ 


\subsection{8. $\mathrm{CH}_{4} / \mathrm{C}_{2} \mathrm{H}_{6}+\mathrm{NH}_{2}$}

Due to the presence of a methyl group in $\mathrm{MMH}$, methane and ethane are likely to be the two main hydrocarbon species produced during $\mathrm{MMH}$ pyrolysis by $\mathrm{H}$ abstraction reaction of the first one and by methyl radical self-recombination for the second. They may then further react with the chain carriers. While the reactions $\mathrm{CH}_{4} / \mathrm{C}_{2} \mathrm{H}_{6}+\mathrm{H}$ and $\mathrm{C}_{2} \mathrm{H}_{6}+\mathrm{CH}_{3}$ have been extensively studied and are well documented, data for the reactions with $\mathrm{NH}_{2}$ are scarcer. Experimental rate coefficients for the reactions of small hydrocarbons with $\mathrm{NH}_{2}$ have been measured at low temperatures (300-500 K) by Lesclaux and Demissy ${ }^{47,48}$ in a flash photolysis cell. Later, the Wagner group ${ }^{49,50}$ extended the database to higher temperatures $(600-1000 \mathrm{~K})$ by using an isothermal discharge flow reactor where $\mathrm{NH}_{2}$ were produced by the reaction of $\mathrm{NH}_{3}$ with fluorine atoms. The use of shock tube finally enabled accessing experimental rate constants for temperatures ranging from 1600 to $2200 \mathrm{~K}$, with hydrazine ${ }^{51}$ or methylamine $^{52}$ as the source of amidogen radicals. Mebel and $\operatorname{Lin}^{53}$ first investigated the potential energy surface of the $\mathrm{CH}_{4} / \mathrm{C}_{2} \mathrm{H}_{6}+\mathrm{NH}_{2}$ reactions based on G2M energetics. Song et al. ${ }^{52}$ combined their high temperature data with QCISD(T)/6-311++G(3df,2p)//QCISD/6-311G(d,p) theoretical calculations to recommend a rate constant expression for the reaction $\mathrm{CH}_{4}+\mathrm{NH}_{2}$. Recently, Siddique et al. ${ }^{54}$ performed CBS-QB3 calculations to access the rate constants of a series of $n$-alkanes with $\mathrm{NH}_{2}$.

Saddle points properties (Table 8) for the two title reactions have been calculated with RCCSD[T]/CBS//M06-2x/aug-cc-pVTZ methods. The present energy barrier, $13.45 \mathrm{kcal} \mathrm{mol}^{-1}$, for the $\mathrm{CH} 4$ reaction is in good agreement with the experimental adiabatic barrier of Song et al. $\left(13.1 \mathrm{kcal} \mathrm{mol}^{-}\right.$ 1) and the CBS-QB3 barrier of Saddique et al. $\left(13.2 \mathrm{kcal} \mathrm{mol}^{-1}\right)$, but is $1 \mathrm{kcal} \mathrm{mol}^{-1}$ lower than the adjusted energy barrier of Mebel and Lin (14.4). On the other hand, the discrepancies between our barrier, $10.5 \mathrm{kcal} \mathrm{mol}^{-1}$, and the ones of Mebel and Lin, $10.2 \mathrm{kcal} \mathrm{mol}^{-1}$, and Saddique et al., $9.8 \mathrm{kcal} \mathrm{mol}^{-1}$, are well within the uncertainties for the $\mathrm{C}_{2} \mathrm{H}_{6}+\mathrm{NH}_{2}$ reaction. Predicted rate constants, inclusive asymmetric Eckart tunneling and Pitzer-Gwinn approximation for hindered rotors, are compared to experimental data and previous theoretical calculations in Figure 17. Our predicted rate constant for the methane reaction is in good agreement with the low and intermediate temperature experimental data, and is a compromise between the high temperature data of Song et al. and Hennig 
and Wagner ${ }^{55}$. Despite the largest energy barrier, the rate constant of Mebel and Lin is about thrice and twice higher than our predictions and those of Song et al., respectively, but nonetheless still lower than the predictions of Siddique et al. below $1300 \mathrm{~K}$. This may be attributed to the rovibrational properties, and thus the method/basis set employed for the structure optimization, since the difference remains at high temperatures where the rate constant is mostly governed by the entropic contribution. Regarding the reaction of ethane, the present rate constants are consistent with the 300-1000 K measurements of Lesclaux and Demissy and Ehbrecht et al. but are four times larger than the high temperature measurements of Hennig and Wagner. All three computed rate coefficients are in good agreement with each other's below $1250 \mathrm{~K}$, temperature at which the predictions of Siddique et al. start diverging, with lower values consistent with the high temperature data. Finally, modified Arrhenius expressions are reported in Table 9 for the two reactions.

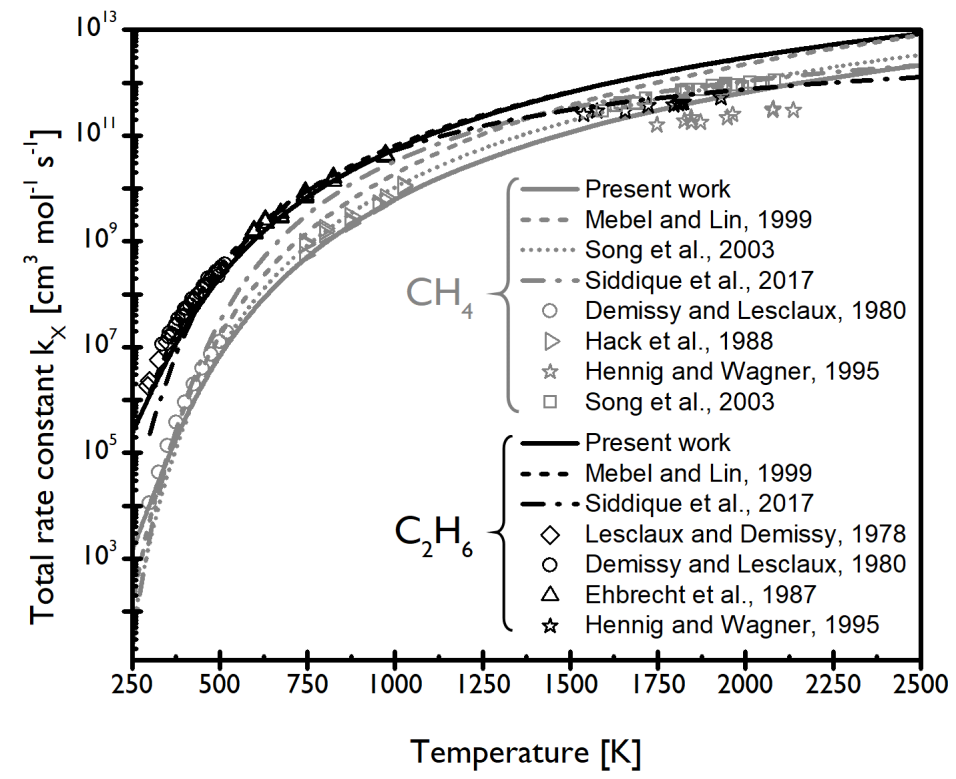

Figure 17: Rate constant for the $\mathrm{H}$ abstraction reactions $\mathrm{CH}_{4}+\mathrm{NH}_{2}$ and $\mathrm{C}_{2} \mathrm{H}_{6}+\mathrm{NH}_{2}$. The solid, dashed, dotted, and dash-dotted lines denote the present theoretical predictions, the predictions of Mebel and $\operatorname{Lin}^{53}$, Song et al. ${ }^{52}$ and Siddique et al. ${ }^{54}$, respectively. Symbols depict experimental data. 
Table 8: Calculated stationary point properties for $\mathrm{CH}_{4} / \mathrm{C}_{2} \mathrm{H}_{6}+\mathrm{NH}_{2}$ abstraction channels

\begin{tabular}{|c|c|c|c|c|c|}
\hline Species & Energy $^{1}$ & $\begin{array}{l}\text { Relative } \\
\text { energy }^{2}\end{array}$ & $\mathbf{T}_{1}$ diagnostic & Frequencies $^{3}$ & $\mathbf{B}^{4}$ \\
\hline $\mathrm{CH}_{4}$ & -40.413567 & & 0.008 & $1331,1331,1331,1550,1550,3024,3140,3140,3140$ & $5.308,5.308,5.308$ \\
\hline $\mathrm{C}_{2} \mathrm{H}_{6}$ & -79.638837 & & 0.008 & $\begin{array}{l}290,799,799,1009,1202,1202,1383,1401,1486,1486, \\
1488,1488,3010,3012,3066,3066,3089,3089\end{array}$ & $0.671,0.671,2.703$ \\
\hline $\mathrm{CH}_{4}+\mathrm{NH}_{2} \rightarrow \mathrm{CH}_{3}+\mathrm{NH}_{3}$ & -96.193818 & $\begin{array}{l}13.45 \\
(14.4) \\
{[13.2]} \\
\{13.1\}\end{array}$ & 0.022 & $\begin{array}{l}86,354,358,574,789,866,1159,1304,1381,1432,1459, \\
1527,3039,3167,3169,3363,3455,1648 \mathrm{i}\end{array}$ & $0.293,0.296,3.183$ \\
\hline $\mathrm{C}_{2} \mathrm{H}_{6}+\mathrm{NH}_{2} \rightarrow \mathrm{C}_{2} \mathrm{H}_{5}+\mathrm{NH}_{3}$ & -135.423814 & $\begin{array}{l}10.48 \\
(10.2) \\
{[9.8]}\end{array}$ & 0.022 & $\begin{array}{l}64,105,131,397,508,738,757,865,930,1045,1192,1211, \\
1291,1380,1431,1449,1466,1472,1522,2999,3056,3067, \\
3079,3135,3135,3367,3461,1643 \mathrm{i}\end{array}$ & $0.146,0.162,0.833$ \\
\hline
\end{tabular}

${ }^{1}$ Zero point vibrational corrected energy in Hartree. Energies evaluated at the RCCSD(T)/aug-cc-pVœZ//M06-2x-D3/aug-cc-pVTZ level of theory

${ }^{2}$ Energy in kcal mol ${ }^{-1}$ relative to $\mathrm{CH}_{4} / \mathrm{C}_{2} \mathrm{H}_{6}+\mathrm{NH}_{2}$. The first entry is from the present work, the values in brackets are from Mebel and Lin ${ }^{53}$ (adjusted G2M), the values in square brackets are from Siddique et al. ${ }^{54}$ (CBS-QB3), and the value in braces is from Song et al. ${ }^{52}$.

${ }^{3}$ Scaled harmonic vibrational frequencies in $\mathrm{cm}^{-1}$, italic values are associated to hindered internal rotors

${ }^{4}$ Rotational constants in $\mathrm{cm}^{-1}$ 


\subsection{Model confrontation}

As mentioned before, MMH thermal decomposition has received little experimental attention. Available experimental data were collected in shock tubes, by following either the MMH decay rate or the production of reaction intermediates $\left(\mathrm{NH}_{2}\right)$ or final products $\left(\mathrm{NH}_{3}, \mathrm{CH}_{4}\right)$. To make even the task of understanding MMH pyrolysis, none of the different speciation data available were obtained at similar temperature, pressure, or mixture composition. Nevertheless, below are presented and discussed the performance of the present model, comprising 51 species involved in 225 reactions, against this collection of experimental data, and flux analyses employed to delineate the main reaction paths in MMH pyrolysis.

\subsubsection{MMH speciation profiles}

Direct MMH consumption rate have been measured by Cook et al. ${ }^{4}$. Using infrared absorption at $10.22 \mu \mathrm{m}$, they monitored MMH concentration behind a reflected shock wave at 1.9 atm and temperatures of 1009 and $1112 \mathrm{~K}$. Experimental traces are compared to the present model predictions in Figure 18. Also displayed are the effect of the temperature uncertainty (1\%) on the results, and the time profile computed with the model of Li et al. In those conditions, the two models propose a fair quantitative prediction of $\mathrm{MMH}$ consumption. However, the present model predicts a faster consumption rate of the fuel, which can be partly attributed to lower rate constants for the $\mathrm{MMH}+\mathrm{H}$ reactions in the model of $\mathrm{Li}$ et al. The effect of the temperature uncertainty is rather modest and decreases with the temperature.

Catoire et al. ${ }^{2,8}$ have also reported MMH time profiles behind a shock wave, in the same temperature range (770-1390 K) but at slightly higher pressures (1.5-4.5 atm). Experiments have been performed by using UV global absorption at $220 \mathrm{~nm}$. Because absorbance at this wavelength cannot be attributed solely to $\mathrm{MMH}\left(\mathrm{NH}_{3}\right.$, among others, is known to absorb around $\left.230 \mathrm{~nm}\right)$, a protocol has been used to extract MMH profiles from experimental signals. The relative uncertainty of these indirect MMH profiles is much higher than the one of direct MMH profiles and these experimental data are no further considered for this study as it relies only on direct measurements. 
Table 9: Arrhenius expressions of key reactions of the MMH thermal decomposition kinetic model (units: $\mathrm{cm}^{3}$, mol and $\mathrm{s}$ for the preexponential factor, $\mathrm{K}$ for the activation energies)

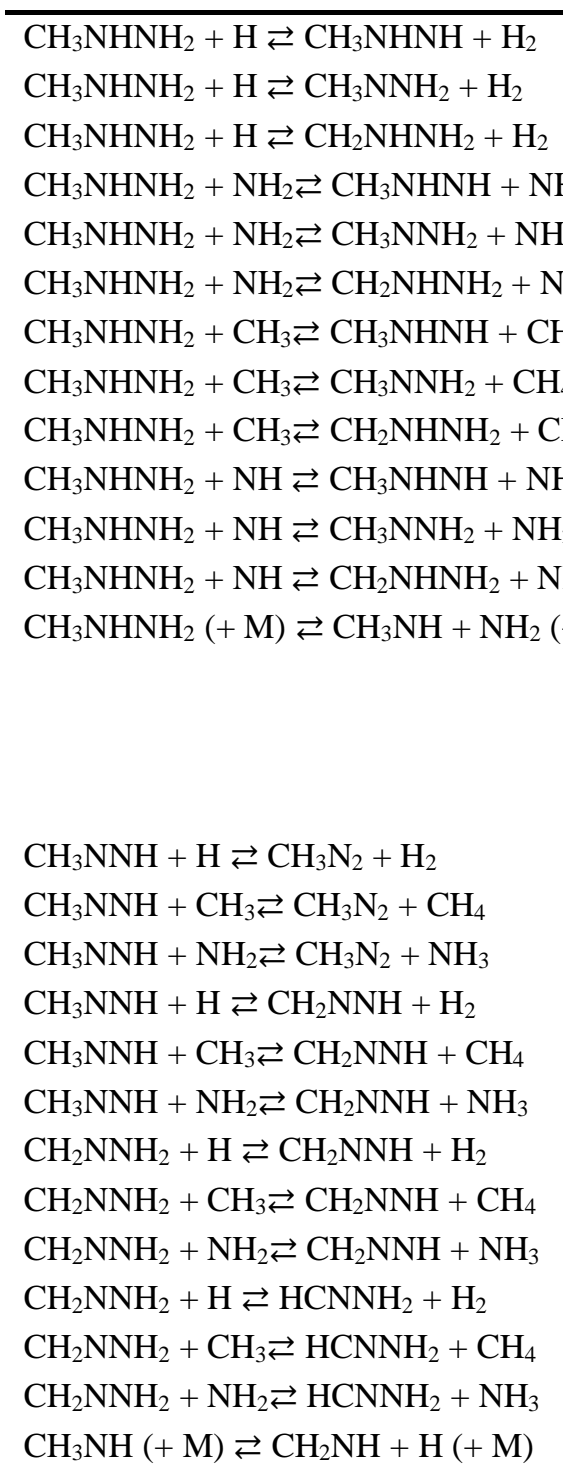

$\mathrm{CH}_{2} \mathrm{NH}_{2}(+\mathrm{M}) \rightleftarrows \mathrm{CH}_{2} \mathrm{NH}+\mathrm{H}(+\mathrm{M})$

$\mathrm{CH}_{3} \mathrm{NH} \rightleftarrows \mathrm{CH}_{2} \mathrm{NH}_{2}$

$\mathrm{CH}_{2} \mathrm{NH}+\mathrm{H} \rightleftarrows \mathrm{CH}_{2} \mathrm{~N}+\mathrm{H}$

$$
\begin{aligned}
& k=1.08010^{6} T^{2.310} \exp (-594.8 / T) \\
& k=7.27010^{6} T^{2.030} \exp (-431.8 / T) \\
& k=1.17010^{4} T^{3.080} \exp (-807.7 / T) \\
& k=1.40210^{3} T^{2.741} \exp (-518.3 / T) \\
& k=3.09210^{2} T^{2.884} \exp (-82.7 / T) \\
& k=2.80510^{-2} T^{4.083} \exp (-867.8 / T) \\
& k=1.18010^{1} T^{3.550} \exp (-1782.4 / T) \\
& k=9.480 T^{3.390} \exp (-1061.3 / T) \\
& k=4.30010^{-2} T^{4.320} \exp (-2925.7 / T) \\
& k=9.55610^{1} T^{3.278} \exp (-1856.3 / T) \\
& k=4.096 T^{3.630} \exp (-976.7 / T) \\
& k=4.34010^{-1} T^{4.161} \exp (-3312.6 / T) \\
& k_{\infty}=8.41310^{25} T^{-3.151} \exp (-32457.0 / T) \\
& k_{0}=4.71610^{62} T^{-13.164} \exp (-29921.2 / T) \\
& F_{c}=0.625 \exp (-T / 10)+0.375 \exp (-T / 514) \\
& +\exp (-4228 / T) \\
& \mathrm{Ar} / 0.62 / \mathrm{N}_{2} / 1.00 / \mathrm{CH}_{3} \mathrm{NHNH}_{2} / 3.50 / \\
& k=7.57010^{7} T^{1.815} \exp (-355.9 / T) \\
& k=4.40210^{2} T^{3.139} \exp (+209.3 / T) \\
& k=2.33810^{2} T^{2.945} \exp (+2094.4 / T) \\
& k=5.32010^{3} T^{3.162} \exp (-4942.4 / T) \\
& k=4.73610^{-2} T^{4.243} \exp (-7016.8 / T) \\
& k=1.58110^{-2} T^{4.296} \exp (-4675.7 / T) \\
& k=2.71310^{4} T^{2.751} \exp (-1250.9 / T) \\
& k=1.71510^{-3} T^{4.415} \exp (-1784.6 / T) \\
& k=3.80910^{-1} T^{3.704} \exp (+132.8 / T) \\
& k=8.71210^{2} T^{3.417} \exp (-2668.5 / T) \\
& k=1.492 T^{3.649} \exp (-4161.9 / T) \\
& k=2.68610^{-4} T^{4.531} \exp (-1128.3 / T) \\
& k_{\infty}=1.23610^{4} T^{3.022} \exp (-16001.4 / T) \\
& k_{0}=2.04910^{35} T^{-5.471} \exp (-18786.7 / T) \\
& F_{c}=0.392 \exp (-T / 23)+0.608 \exp (-T / 1093) \\
& +\exp (-6580 / T) \\
& \mathrm{Ar} / 1.00 / \mathrm{N}_{2} / 2.00 / \mathrm{CH}_{3} \mathrm{NHNH}_{2} / 5.00 / \\
& k_{\infty}=7.92010^{4} T^{2.555} \exp (-19476.7 / T) \\
& k_{0}=1.63010^{37} T^{-5.924} \exp (-22216.6 / T) \\
& F_{c}=0.401 \exp (-T / 19)+0.599 \exp (-T / 1200) \\
& +\exp (-6994 / T) \\
& \mathrm{Ar} / 1.00 / \mathrm{N}_{2} / 2.00 / \mathrm{CH}_{3} \mathrm{NHNH}_{2} / 5.00 / \\
& 0.001 \mathrm{~atm} k=4.18910^{23} T^{-5.520} \exp (-20041.4 / T) \\
& 0.010 \mathrm{~atm} k=1.27710^{28} T^{-6.237} \exp (-20032.5 / T) \\
& 0.100 \text { atm } k=8.04210^{31} T^{-6.829} \exp (-20467.3 / T) \\
& 1.000 \mathrm{atmk}=3.45410^{37} T^{-7.987} \exp (-22615.8 / T) \\
& 10.00 \mathrm{~atm} k=2.24910^{34} T^{-6.763} \exp (-22198.9 / T) \\
& 100.0 \mathrm{~atm} k=3.18710^{32} T^{-5.860} \exp (-22778.5 / T) \\
& k=2.40010^{8} T^{2.445} \exp (-771.7 / T)
\end{aligned}
$$




$$
\begin{aligned}
& \mathrm{CH}_{2} \mathrm{NH}+\mathrm{H} \rightleftarrows \mathrm{CHNH}+\mathrm{H} \\
& \mathrm{NH}_{2} \mathrm{NH}(+\mathrm{M}) \rightleftarrows \mathrm{N}_{2} \mathrm{H}_{2}+\mathrm{H}(+\mathrm{M})
\end{aligned}
$$

$\mathrm{NH}_{2} \mathrm{NH}+\mathrm{H} \rightleftarrows \mathrm{N}_{2} \mathrm{H}_{2}+\mathrm{H}_{2}$

$\mathrm{NH}_{2} \mathrm{NH}+\mathrm{H} \rightleftarrows \mathrm{H}_{2} \mathrm{NN}+\mathrm{H}_{2}$

$\mathrm{NH}_{2} \mathrm{NH}+\mathrm{CH}_{3} \rightleftarrows \mathrm{N}_{2} \mathrm{H}_{2}+\mathrm{CH}_{4}$

$\mathrm{NH}_{2} \mathrm{NH}+\mathrm{CH}_{3} \rightleftarrows \mathrm{H}_{2} \mathrm{NN}+\mathrm{CH}_{4}$

$\mathrm{NH}_{2} \mathrm{NH}+\mathrm{NH}_{2} \rightleftarrows \mathrm{N}_{2} \mathrm{H}_{2}+\mathrm{NH}_{3}$

$\mathrm{NH}_{2} \mathrm{NH}+\mathrm{NH}_{2} \rightleftarrows \mathrm{H}_{2} \mathrm{NN}+\mathrm{NH}_{3}$

$\mathrm{N}_{2} \mathrm{H}_{2}+\mathrm{H} \rightleftarrows \mathrm{HNN}+\mathrm{H}_{2}$

$\mathrm{N}_{2} \mathrm{H}_{2}+\mathrm{CH}_{3} \rightleftarrows \mathrm{HNN}+\mathrm{CH}_{4}$

$\mathrm{N}_{2} \mathrm{H}_{2}+\mathrm{NH}_{2} \rightleftarrows \mathrm{HNN}+\mathrm{NH}_{3}$

$\mathrm{CH}_{4}+\mathrm{NH}_{2} \rightleftarrows \mathrm{CH}_{3}+\mathrm{NH}_{3}$

$\mathrm{C}_{2} \mathrm{H}_{6}+\mathrm{NH}_{2} \rightleftarrows \mathrm{C}_{2} \mathrm{H}_{5}+\mathrm{NH}_{3}$

$$
\begin{gathered}
k=3.67910^{4} T^{2.738} \exp (-1892.2 / T) \\
k_{\infty}=1.27510^{11} T^{0.819} \exp (-24187.3 / T) \\
k_{0}=3.84010^{40} T^{-6.880} \exp (-27406.8 / T) \\
F_{c}=0.168 \exp (-T / 80000)+0.842 \exp (-T / 28) \\
+\exp (-7298 / T)
\end{gathered}
$$

$\mathrm{Ar} / 1.00 / \mathrm{N}_{2} / 2.00 / \mathrm{CH}_{3} \mathrm{NHNH}_{2} / 5.00 /$

$$
\begin{gathered}
k=7.47610^{3} T^{2.796} \exp (-2357.3 / T) \\
k=6.24310^{6} T^{1.890} \exp (-124.1 / T) \\
k=1.39510^{1} T^{3.290} \exp (-254.5 / T) \\
k=4.06510^{1} T^{3.045} \exp (-935.5 / T) \\
k=6.07510^{-1} T^{3.574} \exp (-600.8 / T) \\
k=1.11110^{1} T^{3.080} \exp (-106.2 / T) \\
k=3.88610^{8} T^{1.732} \exp (-371.5 / T) \\
k=1.85510^{3} T^{3.045} \exp (-455.3 / T) \\
k=2.71110^{5} T^{2.226} \exp (+520.4 / T) \\
k=1.402 T^{3.793} \exp (-4006.4 / T) \\
k=1.40510^{1} T^{3.619} \exp (-2926.7 / T)
\end{gathered}
$$



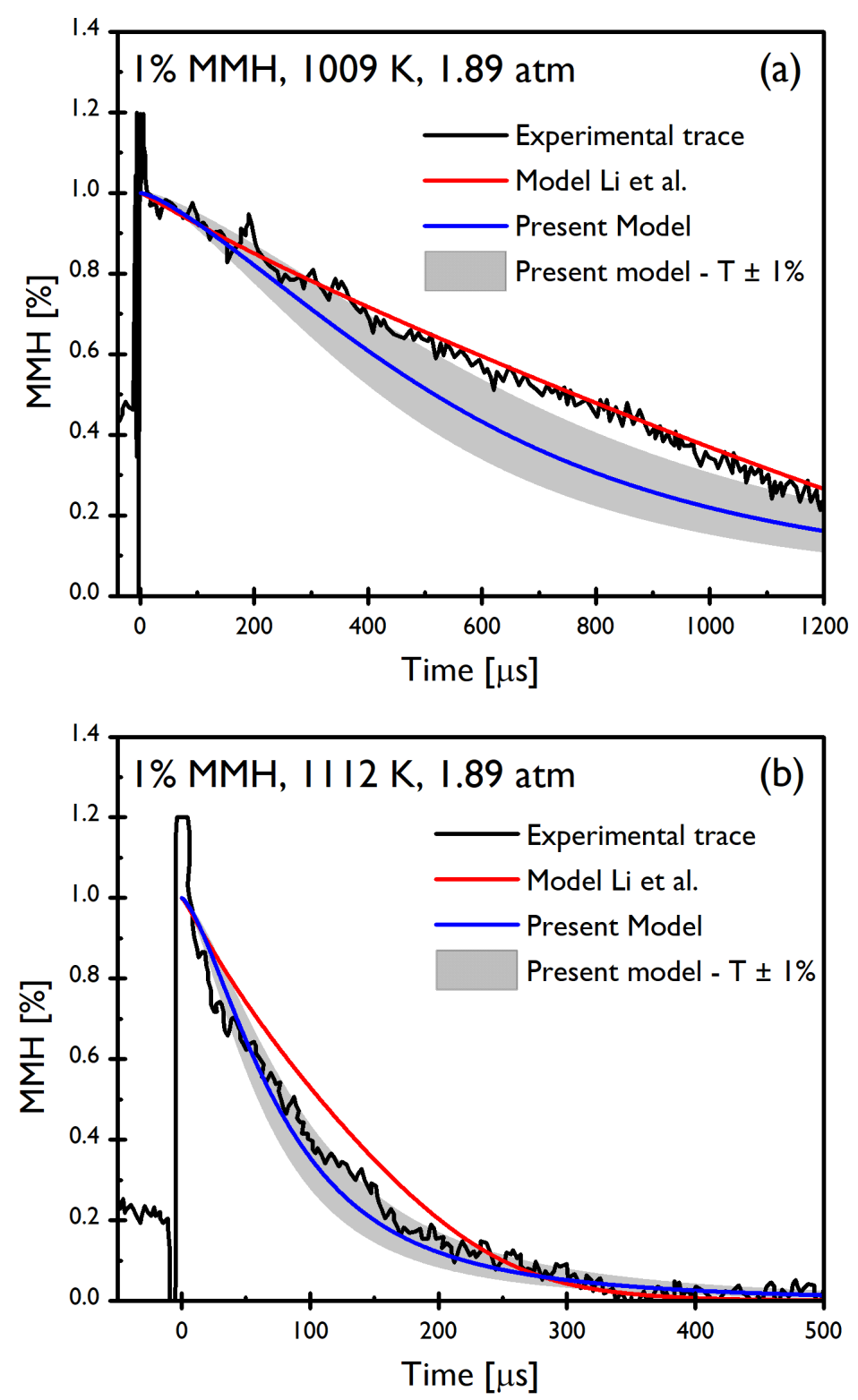

Figure 18: Comparison of measured $\mathrm{MMH}$ time profiles ${ }^{4}$ against simulated profiles with the present model and the model of Li et $\mathrm{al}^{5}$. The shadowed area displays the effect of a $1 \%$ change in temperature on the simulated profiles.

The distribution amid all possible consumption paths of MMH according to the present model is shown in Figure 19 at the two temperatures of Figure 18. At early stages $(t=1 \mu \mathrm{s})$, MMH mostly reacts through thermal decomposition to generate $\mathrm{NH}_{2}$ and $\mathrm{CH}_{3} \mathrm{NH}$, regardless of the temperature. After a few microseconds, $\mathrm{H}$ abstraction reactions become and then remain the main $\mathrm{MMH}$ depleting reaction channels, with $\mathrm{H}$ atom being the main scavenger (up to $60 \%$ of $\mathrm{MMH}$ consumption), illustrating the need to provide the community with accurate rate coefficients for these reactions. As MMH 
concentration decreases, thermal decomposition once again becomes a significant contributor to $\mathrm{MMH}$ decomposition, most likely as the result of the competition between the initial fuel and the pyrolysis products $\left(\mathrm{CH}_{3} \mathrm{NNH}, \mathrm{CH}_{2} \mathrm{NNH}_{2}\right)$ for the chain carriers. A similar analysis with the model of $\mathrm{Li}$ et al. reveals the similar trends, i.e. thermal decomposition followed by metathesis as the dominant reaction paths, with the exception that $\mathrm{NH}_{2}$ is here the main scavenger, contributing up to $40 \%$ to $\mathrm{MMH}$ consumption, while $\mathrm{H}$ atom accounts for at most $18 \%$.

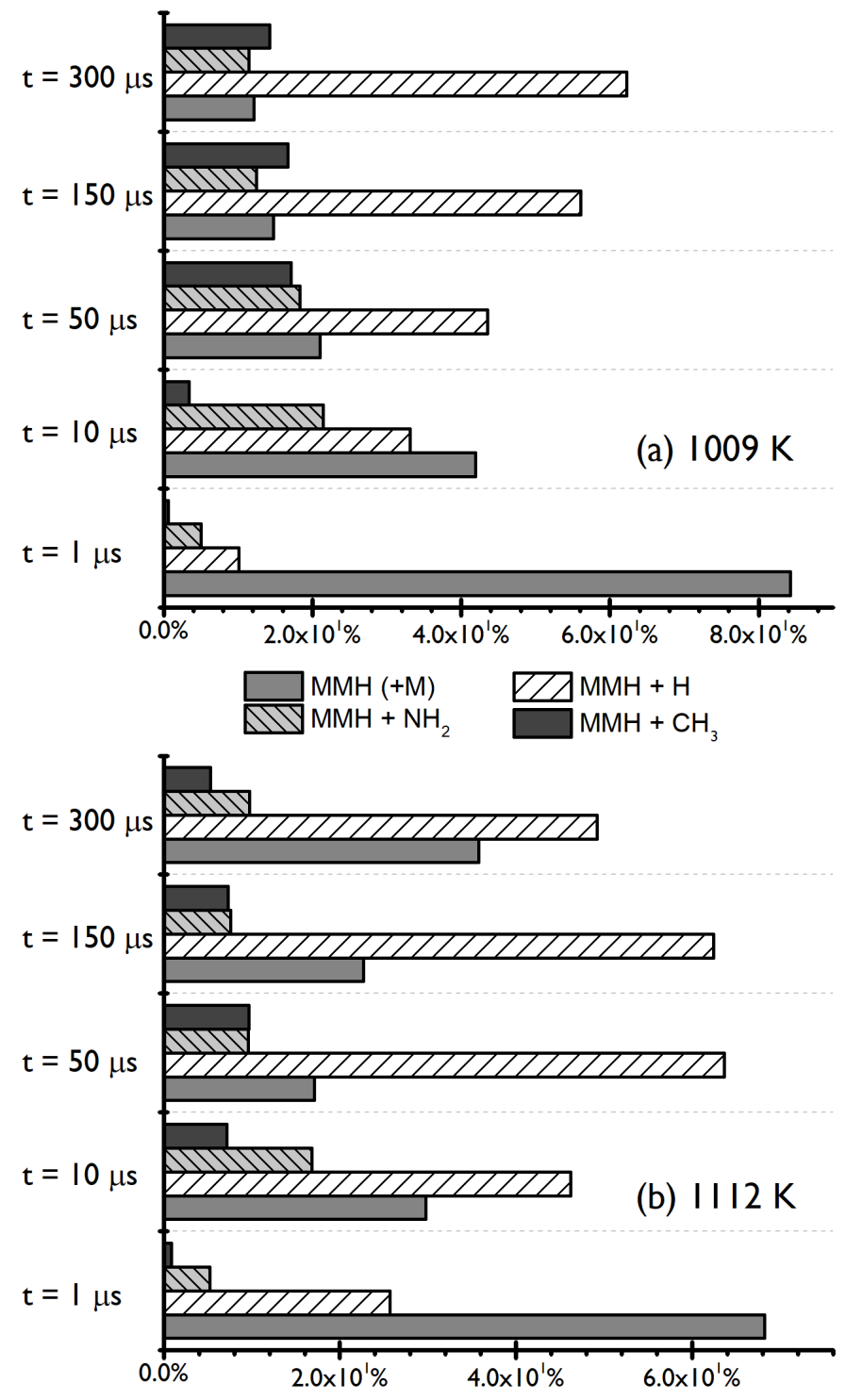

Figure 19: MMH path flux analysis with the present model for MMH/Ar mixtures of Figure 18 


\subsection{2. $\mathrm{NH}_{2}$ speciation profiles}

The amidogen radical $\mathrm{NH}_{2}$ is a direct thermal decomposition product through $\mathrm{CH}_{3} \mathrm{NHNH}_{2} \rightleftarrows$ $\mathrm{CH}_{3} \mathrm{NH}+\mathrm{NH}_{2}$, which is the main unimolecular decomposition reaction of MMH. As such, Li et al. and Cook et al. ${ }^{4}$ monitored the time evolution of this labile species concentration after a shock wave in $\mathrm{MMH} / \mathrm{Ar}$ mixtures. Whereas Cook et al. employed 1\% MMH mixtures around $2.5 \mathrm{~atm}$, Li et al. further diluted MMH (150 to $400 \mathrm{ppm}$ ) and scanned a larger set of temperatures and pressures. Although these time profiles were mainly dedicated to infer rate coefficients for MMH thermal decomposition, they allow testing detailed kinetic models.
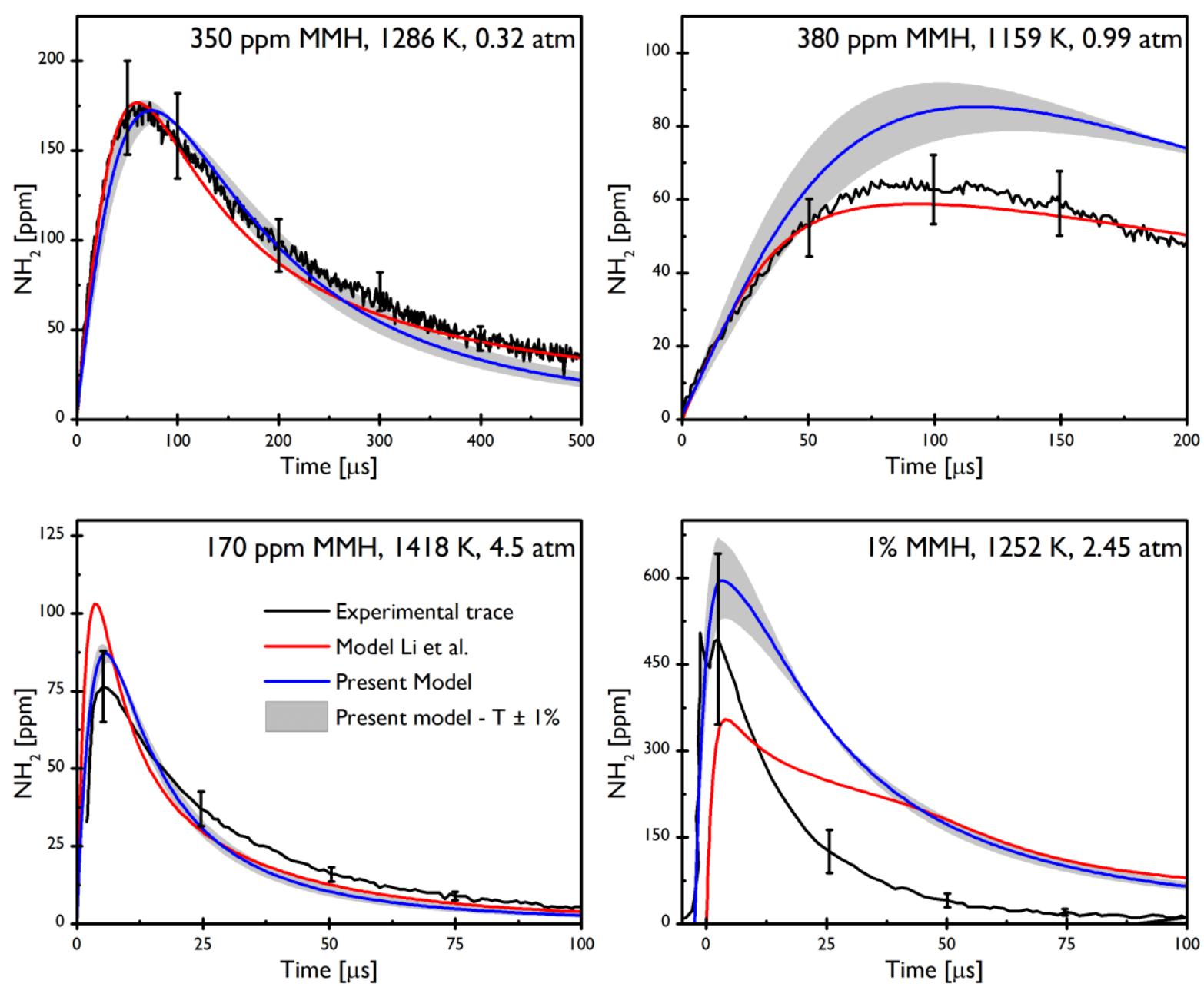

Figure 20: Comparison of experimental ${ }^{4,5}$ and computed $\mathrm{NH}_{2}$ time profiles at different pressures, temperatures and dilution ratios. The shadowed area displays the effect of a $1 \%$ change in temperature on the simulated profiles. The vertical bars denote the reported experimental uncertainties on the measurements. 
Computed $\mathrm{NH}_{2}$ time profiles with the present model and the model of $\mathrm{Li}$ et al. are compared to experimental traces in Figure 20. The present model portrays the main features of the experimental $\mathrm{NH}_{2}$ time profiles: an early build-up of the radical concentration at short reaction times followed then by a decay. Production and consumption rates increase with the temperature and pressure, resulting in higher concentration peak but an almost total consumption of $\mathrm{NH}_{2}$ after a few hundreds of microseconds. The model exhibits also a quite fair quantitative agreement with the reported measurements at low and high pressures, but larger deviations are surprisingly observed around atmospheric pressure while the model of Li et al. compares well with the experimental data obtained for highly diluted mixtures at all pressures and temperatures. Regarding the 1\% MMH mixtures, both models exhibit large deviations with the measured profile. On one hand, the present model constantly overestimates $\mathrm{NH}_{2}$ concentration yet reflects the experimental profile shape. On the other hand, the model of $\mathrm{Li}$ et al. first underestimate the $\mathrm{NH}_{2}$ concentration peak then underrates $\mathrm{NH}_{2}$ consumption.
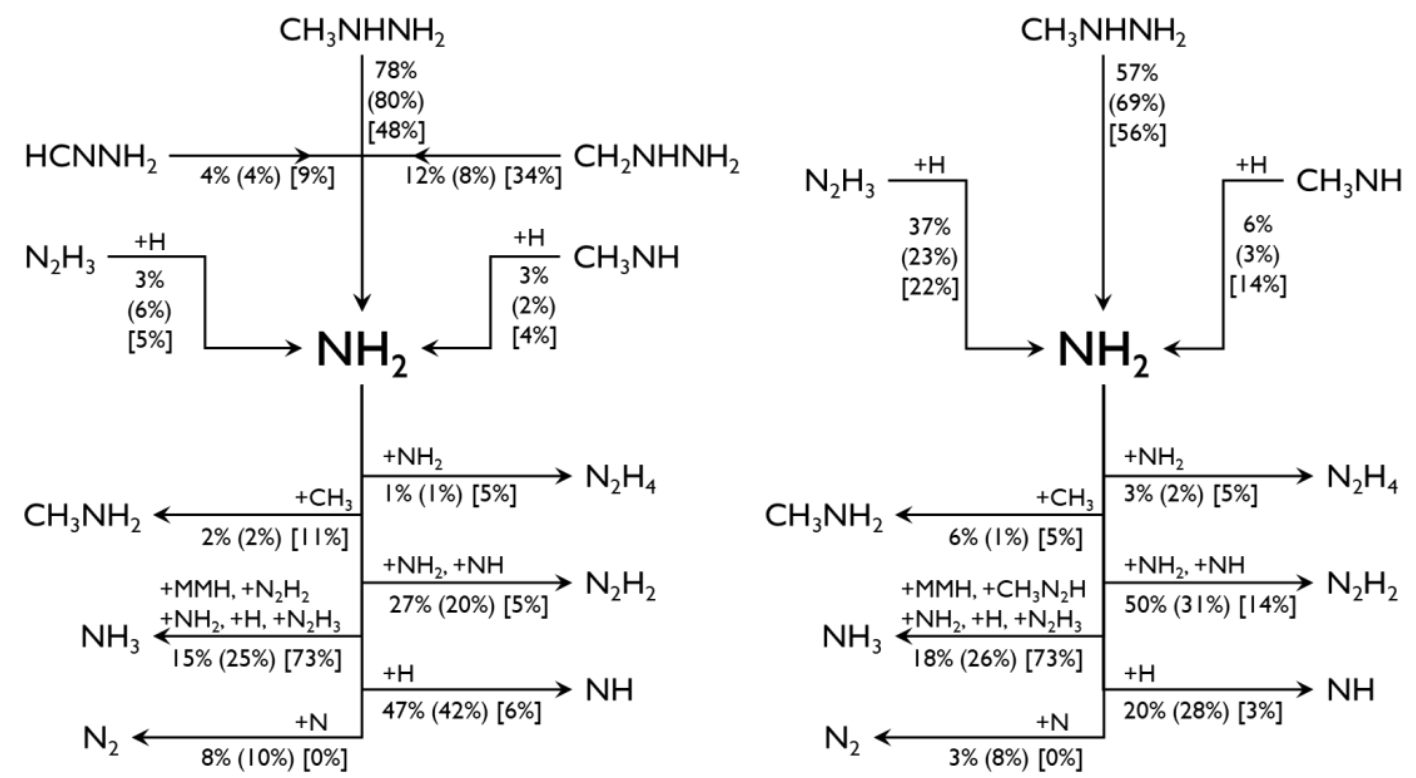

Figure 21: $\mathrm{NH}_{2}$ rate of production with the present model (left) and the model of Li et al. (right). Values without brackets are at $1286 \mathrm{~K}$ and $0.32 \mathrm{~atm}(350 \mathrm{ppm} \mathrm{MMH}$ in $\mathrm{Ar})$, values in brackets are at $1418 \mathrm{~K}$ and $4.50 \mathrm{~atm}$ (170 ppm MMH in Ar), and values in square brackets are at $1252 \mathrm{~K}$ and $2.45 \operatorname{atm}(1 \% \mathrm{MMH}$ in $\mathrm{Ar})$.

Although both models computes nearly similar $\mathrm{NH}_{2}$ time profiles, rate of production analysis have been performed to observe whether it is so for the major production and consumption pathways. 
The overall picture of $\mathrm{NH}_{2}$ reaction flows is displayed in Figure 21. For highly diluted mixtures (hundreds of ppm), $\mathrm{NH}_{2}$ is, according to the present model, mostly produced from the thermal decomposition of MMH (80\%) and to a much smaller extent ( 10\%) from the $\beta$-scission decomposition of the $\mathrm{CH}_{2} \mathrm{NHNH}_{2}$ radical. Regarding the model of $\mathrm{Li}$ et al., although the $\mathrm{MMH}$ decomposition remains the main source of $\mathrm{NH}_{2}$, the $\mathrm{H}$ atom activated decomposition of $\mathrm{N}_{2} \mathrm{H}_{3}$ radicals $\left(\mathrm{N}_{2} \mathrm{H}_{3}+\mathrm{H} \rightleftarrows 2 \mathrm{NH}_{2}\right)$ accounts for 20 to $40 \%$ of the overall $\mathrm{NH}_{2}$ production. Major identified consumption paths are, for both models, self-recombination into diazene, reaction with $\mathrm{H}$ atoms to produce imidogen $\mathrm{NH}$, and finally formation of ammonia through reaction with the fuel and main intermediates. However, while about $45 \%$ of the total $\mathrm{NH}_{2}$ ends up into $\mathrm{NH}$ and only about $25 \%$ in $\mathrm{N}_{2} \mathrm{H}_{2}$ according to the present model, the relative importance of these two paths is reverted in the model of $\mathrm{Li}$ et al.

In $1 \%$ diluted mixtures, the $\mathrm{CH}_{2} \mathrm{NHNH}_{2}$ radical now contributes to nearly $1 / 3$ of the production of $\mathrm{NH}_{2}$ in the present model (another 10\% comes from the decomposition of the $\mathrm{HCNNH}_{2}$ radical), while this path still is negligible in the Li et al. model. This is to be related to the excessively large rate constant recommended by Cook et al. for the $\mathrm{MMH}+\mathrm{NH}_{2} \rightleftarrows \mathrm{NH}_{3}+\mathrm{CH}_{3} \mathrm{NNH}_{2}$ reaction, minimizing the production rate of the two other $\mathrm{MMH}$ radical isomers. On the other hand, the $\mathrm{H}$ atom activated decomposition of $\mathrm{CH}_{3} \mathrm{NH}$ accounts for $14 \%$ of the production. Depletion of the $\mathrm{NH}_{2}$ pool is ensured in the two models, to a large extent $(\sim 75 \%)$, by $\mathrm{H}$ abstraction reactions, thus converting $\mathrm{NH}_{2}$ into $\mathrm{NH}_{3}$, while the secondary consumption paths are the formation of methylamine (11\%) and diazene (14\%) in the present model and the model of Li et al., respectively.

\subsection{3. $\mathrm{NH}_{3}$ Profiles}

Aside from $\mathrm{MMH}$ and $\mathrm{NH}_{2}$ time profiles, Cook et al. ${ }^{4}$ also reported time speciation data for ammonia. Indeed, with $\mathrm{NH}_{2}$ as one of the main chain carrier during $\mathrm{MMH}$ pyrolysis, it is expected to observe significant amount of $\mathrm{NH} 3$ in the product gases. Computed $\mathrm{NH}_{3}$ profiles with the present model and the model of $\mathrm{Li}$ et al. are compared to experimental traces in Figure 22. At the lower temperature $(991 \mathrm{~K})$, the present model underestimates the production of $\mathrm{NH}_{3}$ while the model of $\mathrm{Li}$ et al. matches the measured profile. However, at $1207 \mathrm{~K}$, both models underpredict the final $\mathrm{NH}_{3}$ concentration. Cook 
et al. had noticed the inability of existing $\mathrm{MMH}$ models to produce $\mathrm{NH}_{3}$, and had proposed to increase by a factor 10 the rate constant of the reaction $\mathrm{CH}_{3} \mathrm{NHNH}_{2}+\mathrm{NH}_{2} \rightleftarrows \mathrm{CH}_{3} \mathrm{NNH}_{2}+\mathrm{NH}_{3}$ and by a factor 5 the one of $\mathrm{CH}_{3} \mathrm{NNH}+\mathrm{NH}_{2} \rightleftarrows \mathrm{CH}_{3} \mathrm{~N}_{2}+\mathrm{NH}_{3}$, rate constants adopted in the model of $\mathrm{Li}$ et al., but shown to be strongly overestimated above. As a consequence, $\mathrm{NH}_{3}$ is mainly produced by these two reactions (40\% each) while in the present model $\mathrm{MMH}+\mathrm{NH}_{3}$ and $\mathrm{CH}_{3} \mathrm{NNH} / \mathrm{CH}_{2} \mathrm{NNH}_{2}+\mathrm{NH}_{2}$ reactions account for only $\sim 20 \%$ and $\sim 3.5 \%$ of $\mathrm{NH}_{3}$ production, respectively.

At $\sim 1200 \mathrm{~K}$, the $\mathrm{NH}_{3}$ plateau is presumably reached after a hundred of microseconds, with a conversion yield of about $30 \%$ (i.e. $30 \%$ of the nitrogen of the reactant is recovered as $\mathrm{NH}_{3}$ ), whereas twice more time is required for the two models, but with slightly different yields: $33 \%$ and $23 \%$ with the model of Li et al. and the present model, respectively. This lower yield combined with the lower production of $\mathrm{NH}_{3}$ drove us not to plot the sum of all the stable species containing a $\mathrm{N}-\mathrm{H}$ bond exclusive MMH. This is denoted by the dashed line in Figure 22, and one can see that this summation is a better representation of the experimental profiles, suggesting either that the model underrates the conversion of this species into $\mathrm{NH}_{3}$ or that the experimental measurements did not exclusively sample ammonia.
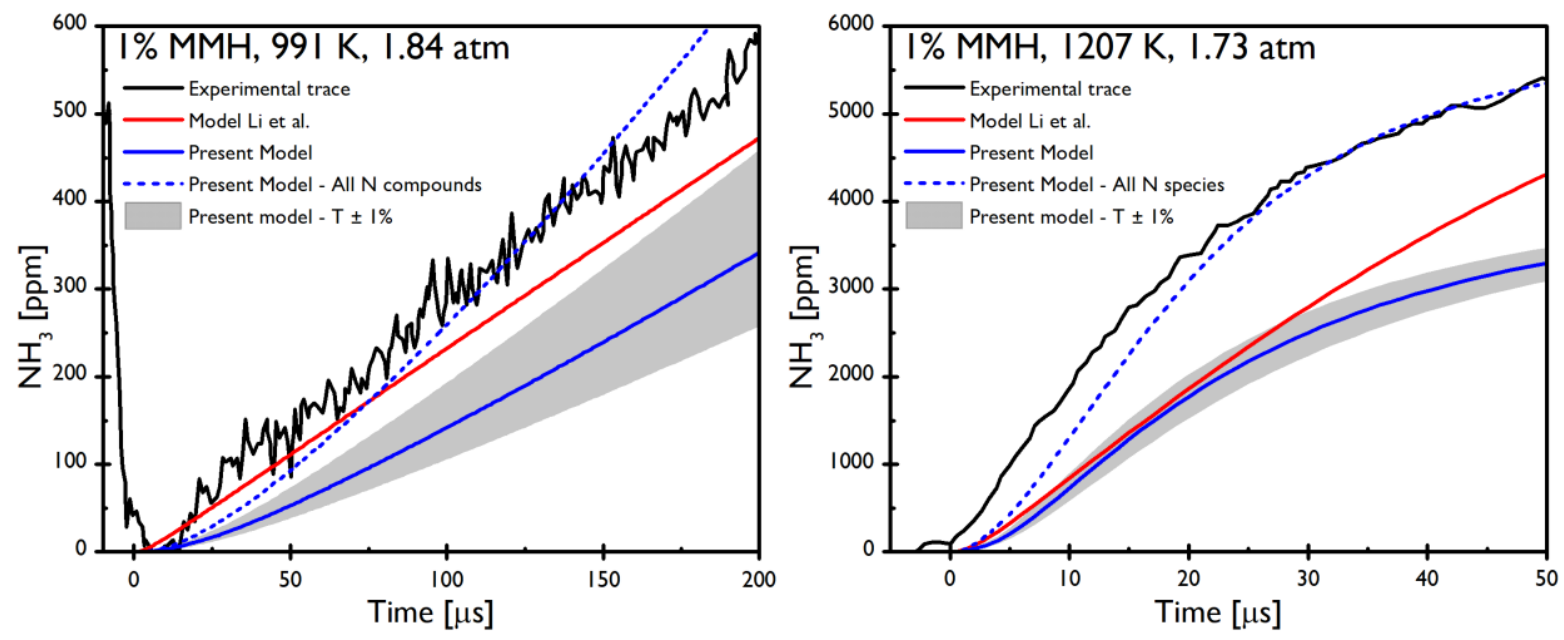

Figure 22: Comparison of $\mathrm{NH}_{3}$ experimental time profiles ${ }^{4}$ with predicted profiles with the present model and the model of $\mathrm{Li}$ et al. The shadowed area displays the effect of a $1 \%$ change in temperature on the simulated profiles. The dashed line denote the total concentration of stable nitrogen products ( $\left.\mathrm{NH}_{2}, \mathrm{CH}_{3} \mathrm{NNH}, \mathrm{CH}_{2} \mathrm{NNH}_{2}, \mathrm{~N}_{2} \mathrm{H}_{4}, \mathrm{~N}_{2} \mathrm{H}_{2}, \mathrm{H}_{2} \mathrm{NN}\right)$. 
Ammonia is indeed not the only nitrogenous compound produced during MMH pyrolysis. A closed balance on the nitrogen distribution among the final products with the present model (model of Li et al.) shows that $\mathrm{N}_{2}$ and $\mathrm{HCN}$ account for $41 \%(43 \%)$ and $26 \%$ (18\%) of the initial nitrogen, while $\mathrm{N}$-aminomethanimine is a minor product with $5 \%$ (less than $0.1 \%$ ).

\subsection{4. $\mathrm{CH}_{4}$ Profiles}

In a side study Cook et al. have reported an experimental trace regarding $\mathrm{CH}_{4}$ production during MMH (1\% in Argon) pyrolysis, and determined the methane yields, i.e. the ratio of the final methane concentration over the initial MMH concentration, at 2.5 atm but different temperatures. These data, as well as the simulated profiles and yields, are displayed in Figure 23. The present model predicts an earlier onset of methane production than the model of $\mathrm{Li}$ et al., but still delayed with regard to the experimental observations. However, our computed final methane yields are in close agreement with the measured ones whereas the model of $\mathrm{Li}$ et al. overestimates them by a factor 2 . This propensity to overproduce methane can be related to the large production (through $\mathrm{CH}_{3} \mathrm{NNH}_{2}$ ) and consumption of methyldiazene in a self-sustaining loop $\left(\mathrm{CH}_{3} \mathrm{NNH}+\mathrm{CH}_{3} \rightleftarrows \mathrm{CH}_{3} \mathrm{~N}_{2}+\mathrm{CH}_{4}\right.$, followed by $\mathrm{CH}_{3} \mathrm{~N}_{2} \rightleftarrows \mathrm{CH}_{3}+$ $\mathrm{N}_{2}$ ), a pathway accounting for $45 \%$ of methane production $\left(\mathrm{MMH}+\mathrm{CH}_{3}\right.$ reactions are the source of $28 \%$ of the overall $\mathrm{CH}_{4}$ produced, and the recombination of $\mathrm{CH}_{3}$ and $\mathrm{H}, 25 \%$ ). On the other hand, methane is mainly produced by $\mathrm{H}$ abstraction reactions from $\mathrm{MMH}(54 \%), \mathrm{N}_{2} \mathrm{H}_{2}(20 \%)$, and $\mathrm{CH}_{3} \mathrm{NNH}$ $(11 \%)$ in the present model.

Like $\mathrm{NH}_{3}, \mathrm{CH}_{4}$ is not the only carbon product in reaction gases. The initial carbon is ultimately shared between methane $(20 \%)$, ethane $(15 \%)$, ethylene $(5 \%), \mathrm{N}$-aminomethanimine $(15 \%)$, and hydrogen cyanide (35\%) according to the present model. The model of Li et al. predictions differs only by the methane yield $(\sim 40 \%)$ and the absence of $\mathrm{N}$-aminomethanimine. 

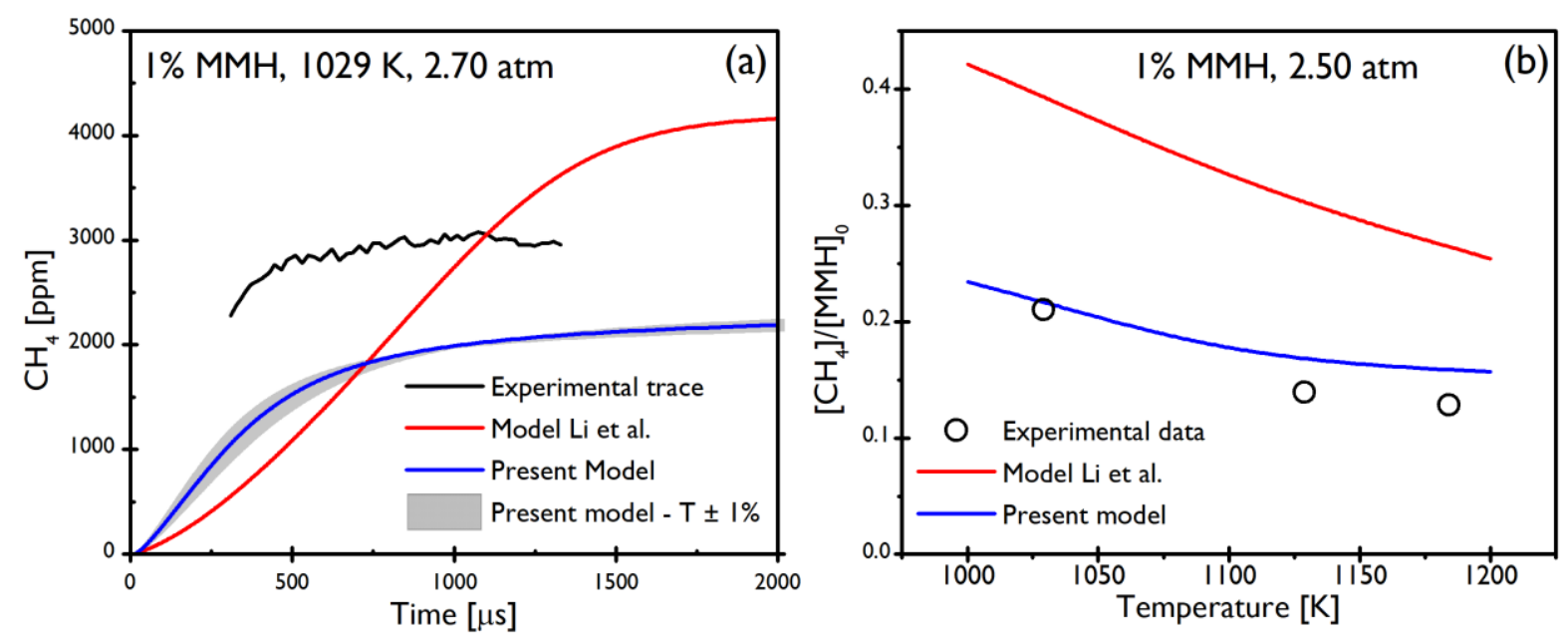

Figure 23: (a) Comparison of $\mathrm{CH}_{4}$ experimental time profiles ${ }^{6}$ with predicted profiles with the present model and the model of $\mathrm{Li}$ et al. (b) Comparison of $\mathrm{CH}_{4}$ plateau yields during $\mathrm{MMH}$ pyrolysis.

\subsubsection{Induction Delays}

The induction delays herein measured for concentrated MMH/Ar mixtures are compared to model predictions in Figure 24. The present model is a significant improvement over the literature models regarding this metric, although the computed delays are still about three times larger than experimentally measured but close to the upper uncertainty bounds. Particularly, the fuel concentration effect on the induction delay is underestimated since the computed delays do not change considerably when increasing from 20 to $30 \%$ the $\mathrm{MMH}$ amount. An extended experimental database along with further modeling efforts would be necessary to improve the present model performance. 


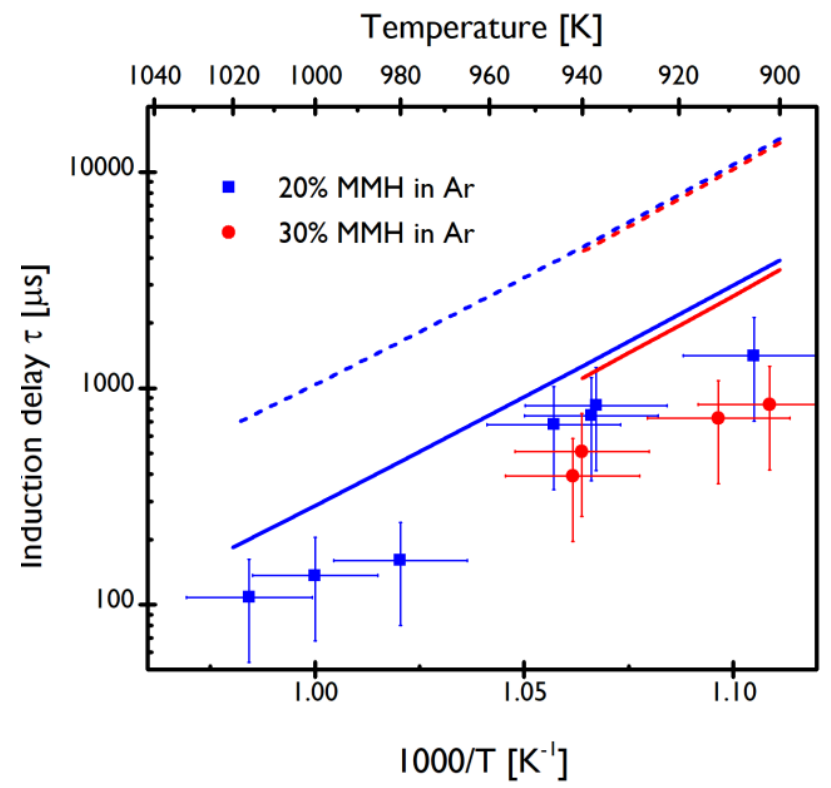

Figure 24: Comparison of MMH experimental induction delays with predicted profiles using the present model (solid lines) and the model of Li et al. (dashed lines).

\subsubsection{Sensitivity analysis}

Experimental data employed to test and validate the present kinetic model span a large range of MMH initial mole fraction. As mentioned in the introduction, sensitive reactions may change with the mixture composition, thus sampling different reaction paths (see Figure 21 for $\mathrm{NH}_{2}$ production and consumption for example). In order to perform a meaningful sensitivity analysis over a large composition domain, the inflection point of the $\mathrm{NH}_{3}$ time profile has been chosen over the temperature or pressure increase. The most sensitive reactions and their coefficient are displayed in Figure 25.

As expected, the fuel thermal decomposition reaction remains one of the most sensitive reaction regardless of the fuel initial concentration. However, the effect of reactions between the fuel and main chain carriers $\left(\mathrm{H}, \mathrm{CH}_{3}\right.$, and $\left.\mathrm{NH}_{2}\right)$ strongly depends on the initial mixture. At $0.05 \%$ and $1 \% \mathrm{MMH}$ loads, the reaction $\mathrm{MMH}+\mathrm{H} \rightleftarrows \mathrm{CH}_{3} \mathrm{NNH}_{2}+\mathrm{H}_{2}$ is not sensitive, but exhibits a strong inhibitive character at the highest load. Likewise, the similar reactions with $\mathrm{CH}_{3}$ and $\mathrm{NH}_{2}$ show the same behavior, worsened with the latter, as the sensitivity coefficient is negative for highly diluted mixtures, which may rationalize the increasing of the rate constant of this reaction by Cook et al. to improve both simulated $\mathrm{NH}_{2}$ and $\mathrm{NH}_{3}$ time profiles. On the other hand, the formation of the $\mathrm{CH}_{3} \mathrm{NHNH}$ radical has a clear 
promoting effect at $20 \% \mathrm{MMH}$ loading, but is mitigated in more diluted condition with sometimes an inhibiting impact ( $+\mathrm{NH}_{2}$ at $\left.1.00 \% \mathrm{MMH}\right)$.

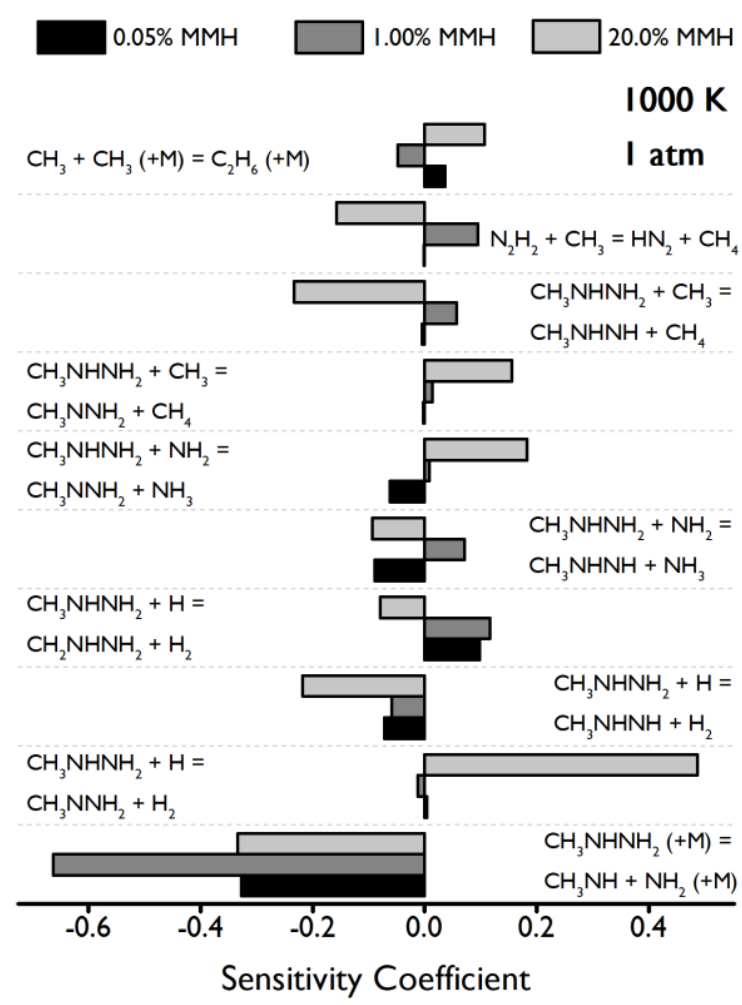

Figure 25: Sensitivity analysis of $\mathrm{NH}_{3}$ time profile inflection point at $1000 \mathrm{~K}$ and $1 \mathrm{~atm}$ for three different MMH initial mole fraction. Negative (positive) sensitivity coefficients indicate that the reaction promote (inhibit) the production of ammonia.

With the increase of the fuel concentration, secondary chemistry demonstrates greater sensitivity, especially reactions involving methyl radicals. Methyl radical self-recombination and the $\mathrm{H}$ atom abstraction by $\mathrm{CH}_{3}$ from diazene are among the most sensitive reactions, with an effect that depends on the initial conditions. For example, whereas the formation of the diazenyl radical slows down the overall reactivity at low $\mathrm{MMH}$ content, it promotes the system reactivity in concentrated mixtures. On the other hand, the termination reaction producing ethane behaves at the exact opposite.

\section{Conclusion}

New induction delays of concentrated (20-30\%) MMH/Argon mixtures measured behind a shock wave have exposed the limitations of available MMH kinetic models, which had been validated exclusively against data collected form highly and diluted mixtures. A new kinetic model, in which the 
rate coefficients of a large set of reactions relevant to $\mathrm{MMH}$ pyrolysis have been revised based on RCCSD(T)/aug-cc-pVœZ//M06-2x-D3/aug-cc-pVTZ theoretical calculations, has been proposed. This model shows satisfying predictions for the whole set of experimental results, from highly diluted to concentrated mixtures, illustrating that experimental data a priori irrelevant for chemical kinetics can help in developping a unique and comprehensive kinetic model, since as displayed in Figure $\mathbf{2 5}$ the set of most sensitive reactions can differ as the fuel concentration increases.

Nevertheless, detailed speciation data from flow reactors or shock tubes with a focus on specific MMH subproducts, such as methyldiazene, $\mathrm{N}$-aminomethanimine or hydrogen cyanide, could help better picturing MMH pyrolysis and therefore refine the present model. Meanwhile, the model has to be extended to oxidative conditions, adopting a similar strategy to the one herein employed.

The conclusion that a unique model is predictive for such a wide concentration range may be extended to all endothermic fuels. For fuel/oxidant/diluent mixtures, it may be also true as preliminary shown with methane-oxygen based mixtures (see text). This remains to be more thoroughly demonstrated.

\section{Supporting Information}

Supporting information include the FTIR spectra of MMH/Ar mixtures, the computed enthalpies along with the isodesmic reactions employed, the Cartesian coordinates of all the computed structures, the rovibrational properties of species listed in Table 4 and 5, and the spherically-averaged interaction potentials of $\mathrm{CH}_{2} \mathrm{NH}_{2}$ and $\mathrm{CH}_{3} \mathrm{NH}$ with helium. 


\section{Reference section}

(1) Eberstein, I. J.; Glassman, I. The Gas-Phase Decomposition of Hydrazine and Its Methyl Derivatives. Symp. Combust. 1965, 10 (1), 365-374.

(2) Catoire, L.; Bassin, X.; Dupre, G.; Paillard, C. Experimental Study and Kinetic Modeling of the Thermal Decomposition of Gaseous Monomethylhydrazine. Application to Detonation Sensitivity. Shock Waves 1996, 6 (3), 139-146.

(3) Catoire, L.; Ludwig, T.; Dupré, G.; Paillard, C. Kinetic Modelling of the Ignition Delays in Monomethylhydrazine/Hydrogen/Oxygen/Argon Gaseous Mixtures. Proc. Inst. Mech. Eng. Part G J. Aerosp. Eng. 1998, 212 (6), 393-406.

(4) Cook, R. D.; Pyun, S. H.; Cho, J.; Davidson, D. F.; Hanson, R. K. Shock Tube Measurements of Species Time-Histories in Monomethyl Hydrazine Pyrolysis. Combust. Flame 2011, 158 (4), 790-795.

(5) Li, S.; Davidson, D. F.; Hanson, R. K. Shock Tube Study of the Pressure Dependence of Monomethylhydrazine Pyrolysis. Combust. Flame 2014, 161 (1), 16-22.

(6) Cook, R. D.; Pyun, S. H.; Davidson, D. F.; Hanson, R. K. MMH Pyrolysis and Oxidation: Species TimeHistory Measurements behind Reflected Shock Waves. In ICDERS; 2011; pp 1-6.

(7) Sun, H.; Law, C. K. Thermochemical and Kinetic Analysis of the Thermal Decomposition of Monomethylhydrazine: An Elementary Reaction Mechanism. J. Phys. Chem. A 2007, 111 (19), 37483760 .

(8) Sun, H.; Catoire, L.; Law, C. K. Thermal Decomposition of Monomethylhydrazine: Shock Tube Experiments and Kinetic Modeling. Int. J. Chem. Kinet. 2009, 41 (3), 176-186.

(9) Catoire, L.; Swihart, M. T. Thermochemistry of Species Produced from Monomethylhydrazine in Propulsion and Space-Related Applications. J. Propuls. Power 2002, 18 (6), 1242-1253.

(10) Zhang, P.; Klippenstein, S. J.; Sun, H.; Law, C. K. Ab Initio Kinetics for the Decomposition of Monomethylhydrazine $\left(\mathrm{CH}_{3} \mathrm{NHNH}_{2}\right)$. Proc. Combust. Inst. 2011, 33 (1), 425-432.

(11) Sun, H.; Zhang, P.; Law, C. Ab Initio Kinetics for Thermal Decomposition of $\mathrm{CH}_{3} \mathrm{~N}^{\bullet} 2$, Cis- $\mathrm{CH}_{3} \mathrm{NHN}^{\bullet} \mathrm{H}$, Trans- $\mathrm{CH}_{3} \mathrm{NHN}^{*} \mathrm{H}$, and $\mathrm{C}^{*} \mathrm{H}_{2} \mathrm{NNH}_{2}$ Radicals. J. Phys. Chem. A 2012, 116 (33), 8419-8430.

(12) Zhao, Y.; Truhlar, D. G. The M06 Suite of Density Functionals for Main Group Thermochemistry, Thermochemical Kinetics, Noncovalent Interactions, Excited States, and Transition Elements: Two New Functionals and Systematic Testing of Four M06-Class Functionals and 12 Other Functionals. Theor. Chem. Acc. 2008, 120 (1-3), 215-241.

(13) Kesharwani, M. K.; Brauer, B.; Martin, J. M. L. Frequency and Zero-Point Vibrational Energy Scale Factors for Double-Hybrid Density Functionals (and Other Selected Methods): Can Anharmonic Force Fields Be Avoided? J. Phys. Chem. A 2015, 119 (9), 1701-1714.

(14) Frisch, M. J.; Trucks, G. W.; Schlegel, H. B.; Scuseria, G. E.; Robb, M. A.; Cheeseman, J. R.; Scalmani, G.; Barone, V.; Mennucci, B.; Petersson, G. A.; et al. Gaussian 09, Revison D01. Gaussian, Inc., Wallinford CT 2013.

(15) Neese, F. The ORCA Program System. Wiley Interdiscip. Rev. Comput. Mol. Sci. 2012, 2 (1), 73-78.

(16) Neese, F. Software Update: The ORCA Program System, Version 4.0. Wiley Interdiscip. Rev. Comput. Mol. Sci. 2018, 8 (1).

(17) Dunning, T. H. Gaussian Basis Sets for Use in Correlated Molecular Calculations. I. The Atoms Boron through Neon and Hydrogen. J. Chem. Phys. 1989, 90 (2), 1007-1023.

(18) Riplinger, C.; Pinski, P.; Becker, U.; Valeev, E. F.; Neese, F. SparseMaps - A Systematic Infrastructure for Reduced-Scaling Electronic Structure Methods. II. Linear Scaling Domain Based Pair Natural Orbital Coupled Cluster Theory. J. Chem. Phys. 2016, 144 (2), 024109.

Barker, J. R.; Nguyen, T. L.; Stanton, J. F.; Aieta, C.; Ceotto, M.; Gabas, F.; Kumar, T. J. D.; Li, C. G. L.; 
Lohr, L. L.; Maranzana, A.; Ortiz, N. F.; Preses, J. M.; Stimac, P. J. MultiWell-2016 Software Suite. University of Michigan, Ann Arbor, Michigan, USA 2016.

(20) Glowacki, D. R.; Liang, C. H.; Morley, C.; Pilling, M. J.; Robertson, S. H. MESMER: An Open-Source Master Equation Solver for Multi-Energy Well Reactions. J. Phys. Chem. A 2012, 116 (38), 9545-9560.

(21) Reaction Design, Inc., San Diego, 2018. CHEMKIN PRO Release 19.2.

(22) Hanson, R. K.; Davidson, D. F. Recent Advances in Laser Absorption and Shock Tube Methods for Studies of Combustion Chemistry. Prog. Energy Combust. Sci. 2014, 44, 103-114.

(23) Zhou, C. W.; Li, Y.; Burke, U.; Banyon, C.; Somers, K. P.; Ding, S.; Khan, S.; Hargis, J. W.; Sikes, T.; Mathieu, O.; Petersen, E. L.; et al. An Experimental and Chemical Kinetic Modeling Study of 1,3Butadiene Combustion: Ignition Delay Time and Laminar Flame Speed Measurements. Combust. Flame 2018, 197, 423-438.

(24) Otomo, J.; Koshi, M.; Mitsumori, T.; Iwasaki, H.; Yamada, K. Chemical Kinetic Modeling of Ammonia Oxidation with Improved Reaction Mechanism for Ammonia/Air and Ammonia/Hydrogen/Air Combustion. Int. J. Hydrogen Energy 2018, 43 (5), 3004-3014.

(25) Goldsmith, C. F.; Magoon, G. R.; Green, W. H. Database of Small Molecule Thermochemistry for Combustion. J. Phys. Chem. A 2012, 116, 9033-9057.

(26) Burke, S. M.; Simmie, J. M.; Curran, H. J. Critical Evaluation of Thermochemical Properties of C1C4species: Updated Group-Contributions to Estimate Thermochemical Properties. J. Phys. Chem. Ref. Data 2015, 44 (1).

(27) Ruscic, B.; Bross, D. H. Active Thermochemical Tables (ATcT) values based on ver. 1.122g of the Thermochemical Network (2019); available at ATcT.anl.gov.

(28) Lucassen, A.; Zhang, K.; Warkentin, J.; Moshammer, K.; Glarborg, P.; Marshall, P.; Kohse-Höinghaus, K. Fuel-Nitrogen Conversion in the Combustion of Small Amines Using Dimethylamine and Ethylamine as Biomass-Related Model Fuels. Combust. Flame 2012, 159 (7), 2254-2279.

(29) Goos, E.; Burcat, A.; Ruscic, B. Extended Third Millenium Ideal Gas and Condensed phase Thermochemical Database for Combustion with Updates from Active Thermochemical Tables $\mathrm{ftp}: / / \mathrm{ftp}$. technion.ac.il/pub/supported/aetdd/thermodynamics.

(30) Pitzer, K. S.; Gwinn, W. D. Energy Levels and Thermodynamic Functions for Molecules with Internal Rotation: I. Rigid Frame with Attached Tops. J. Chem. Phys. 1942, 10 (7), 428-440.

(31) Yumura, M.; Asaba, T. Rate Constants of Chemical Reactions in the High Temperature Pyrolysis of Ammonia. Symp. Combust. 1981, 18 (1), 863-872.

(32) Davidson, D. F.; Kohse-Höinghaus, K.; Chang, A. Y.; Hanson, R. K. A Pyrolysis Mechanism for Ammonia. Int. J. Chem. Kinet. 1990, 22 (5), 513-535.

(33) Röhrig, M.; Wagner, H. G. The Reactions of $\mathrm{NH}\left(\mathrm{X}^{3} \Sigma^{-}\right)$with the Water Gas Components $\mathrm{CO}_{2}, \mathrm{H}_{2} \mathrm{O}$, and $\mathrm{H}_{2}$. Symp. Combust. 1994, 25 (1), 975-981.

(34) Dove, J. E.; Nip, W. S. A Shock-Tube Study of Ammonia Pyrolysis. Can. J. Chem. 1979, 57 (6), 689701.

(35) Vaghjiani, G. L. UV Absorption Cross Sections, Laser Photodissociation Product Quantum Yields, and Reactions of H Atoms with Methylhydrazines at 298 K. J. Phys. Chem. A 1997, 101 (23), 4167-4171.

(36) Wang, L.; Zhao, Y.; Wen, J.; Zhang, J. Mechanisms and Kinetics of Hydrogen Abstraction of Methylhydrazine and Deuterated Methylhydrazine with H/D Atoms. Theor. Chem. Acc. 2013, 132 (2), 114.

(37) Gray, P.; Herod, A. A.; Jones, A.; Thynne, J. C. J. Kinetics of Hydrogen and Deuterium Atom Abstraction by Methyl Radicals from Hydrazines and Substituted Hydrazines. Trans. Faraday Soc. 1966, 62, 27742784.

(38) Kerr, J. A.; Sekhar, R. C.; Trotman-Dickenson, A. F. The Pyrolyses of Hydrazines and Benzylamines. CC and N-N Bond Dissociation Energies. J. Chem. Soc. 1963, No. 0, 3308-3320.

(39) Golden, D. M.; Solly, R. K.; Gac, N. A.; Benson, S. W. Very Low-pressure Pyrolysis. VII. The Decomposition of Methylhydrazine, 1,1-dimethylhydrazine, 1,2-dimethylhydrazine, and 
Tetramethylhydrazine. Concerted Deamination and Dehydrogenation of Methylhydrazine. Int. J. Chem. Kinet. 1972, 4 (4), 433-448.

(40) Jasper, A. W.; Miller, J. A. Theoretical Unimolecular Kinetics for $\mathrm{CH}_{4}+\mathrm{M} \rightleftarrows \mathrm{CH}_{3}+\mathrm{H}+\mathrm{M}$ in Eight Baths, $\mathrm{M}=\mathrm{He}, \mathrm{Ne}, \mathrm{Ar}, \mathrm{Kr}, \mathrm{H}_{2}, \mathrm{~N}_{2}, \mathrm{CO}$, and CH4. J. Phys. Chem. A 2011, 115 (24), 6438-6455.

(41) Balucani, N.; Bergeat, A.; Cartechini, L.; Volpi, G. G.; Casavecchia, P.; Skouteris, D.; Rosi, M. Combined Crossed Molecular Beam and Theoretical Studies of the $\mathrm{N}\left({ }^{2} \mathrm{D}\right)+\mathrm{CH}_{4}$ Reaction and Implications for Atmospheric Models of Titan. J. Phys. Chem. A 2009, 113 (42), 11138-11152.

(42) Dean, A. M.; Bozzelli, J. W. Combustion Chemistry of Nitrogen. In Gas-Phase Combustion Chemistry; Springer New York, 2000; pp 125-341.

(43) Jasper, A. W.; Miller, J. A. Lennard-Jones Parameters for Combustion and Chemical Kinetics Modeling from Full-Dimensional Intermolecular Potentials. Combust. Flame 2014, 161 (1), 101-110.

(44) Vidyarthi, S. K.; Willis, C.; Back, R. A. Thermal and Photochemical Decomposition of Methyldiimide in the Gas Phase. J. Phys. Chem. 1976, 80 (6), 559-564.

(45) Klippenstein, S. J.; Harding, L. B.; Ruscic, B.; Sivaramakrishnan, R.; Srinivasan, N. K.; Su, M. C.; Michael, J. V. Thermal Decomposition of $\mathrm{NH}_{2} \mathrm{OH}$ and Subsequent Reactions: Ab Initio Transition State Theory and Reflected Shock Tube Experiments. J. Phys. Chem. A 2009, 113 (38), 10241-10259.

(46) Linder, D. P.; Duan, X.; Page, M. Thermal Rate Constants for $\mathrm{R}+\mathrm{N}_{2} \mathrm{H}_{2} \rightarrow \mathrm{RH}+\mathrm{N}_{2} \mathrm{H}(\mathrm{R}=\mathrm{H}, \mathrm{OH}, \mathrm{NH})$ Determined from Multireference Configuration Interaction and Variational Transition State Theory Calculations. J. Chem. Phys. 1996, 104 (16), 6298-6307.

(47) Lesclaux, R.; Demissy, M. The Kinetics of the Gas Phase Reactions of $\mathrm{NH}_{2}$ Radicals with Alkane and Alkyl Radicals. J. Photochem. 1978, 9 (2), 110-112.

(48) Demissy, M.; Lesclaux, R. Kinetics of Hydrogen Abstraction by NH2 Radicals from Alkanes in the Gas Phase. A Flash Photolysis-Laser Resonance Absorption Study. J. Am. Chem. Soc. 1980, 102 (9), 28972902.

(49) Hack, W.; Kurzke, H.; Rouveirolles, P.; Wagner, H. G. Direct Measurements of the Reaction $\mathrm{NH}_{2}+\mathrm{CH}_{4} \rightarrow \mathrm{NH}_{3}+\mathrm{CH}_{3}$ in Temperature Range $743 \leq \mathrm{T} / \mathrm{K} \leq 1023$. Symp. Combust. 1988, 21 (1), $905-911$.

(50) Ehbrecht, J.; Hack, W.; Rouveirolles, P.; Wagner, H. G. Hydrogen Abstraction Reactions by $\mathrm{NH}_{2}\left(\mathrm{X}^{2} \mathrm{~B}_{1}\right)$ Radicals from Hydrocarbons in the Gas Phase. Berichte der Bunsengesellschaft/Physical Chem. Chem. Phys. 1987, 91 (7), 700-708.

(51) Grotheer, H.; Riekert, G.; Walter, D.; Just, T. Non-Arrhenius Behavior of the Reaction of Hydroxymethyl Radicals with Molecular Oxygen. J. Phys. Chem. 1988, 92 (13), 4028-4030.

(52) Song, S.; Golden, D. M.; Hanson, R. K.; Bowman, C. T.; Senosiain, J. P.; Musgrave, C. B.; Friedrichs, G. A Shock Tube Study of the Reaction $\mathrm{NH}_{2}+\mathrm{CH}_{4} \rightarrow \mathrm{NH}_{3}+\mathrm{CH}_{3}$ and Comparison with Transition State Theory. Int. J. Chem. Kinet. 2003, 35 (7), 304-309.

(53) Mebel, A. M. Prediction of Absolute Rate Constants for the Reactions of $\mathrm{NH}_{2}$ with Alkanes from Ab Initio G2M/TST Calculations. J. Phys. Chem. A 1999, 103 (13), 2088-2096.

(54) Siddique, K.; Altarawneh, M.; Gore, J.; Westmoreland, P. R.; Dlugogorski, B. Z. Hydrogen Abstraction from Hydrocarbons by $\mathrm{NH}_{2}$. J. Phys. Chem. A 2017, 121 (11), 2221-2231.

(55) Hennig, G.; Wagner, H. G. G. A Kinetic Study About the Reactions of $\mathrm{NH}_{2}\left(\overline{\mathrm{X}}^{2} \mathrm{~B}_{1}\right)$ Radicals with Saturated Hydrocarbons in the Gas Phase. Berichte der Bunsengesellschaft für Phys. Chemie 1995, 99 (6), 863-869. 
Table of Content (TOC) graphic:
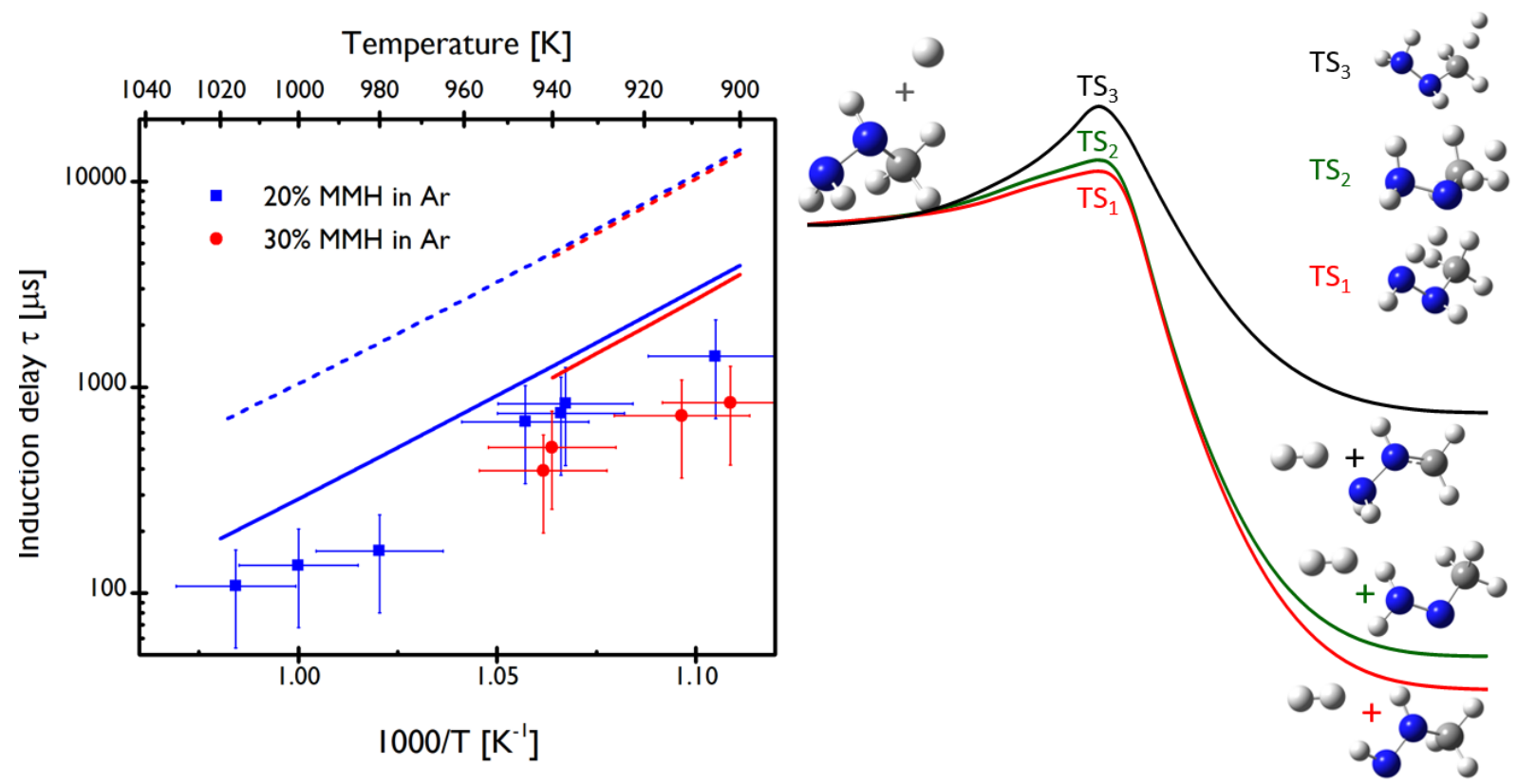